\title{
Supervisee Experiences of Impression Management, the Supervisory Working Alliance, and Counseling Self-Efficacy
}

Jennifer M. Haist

West Virginia University

Follow this and additional works at: https://researchrepository.wvu.edu/etd

\section{Recommended Citation}

Haist, Jennifer M., "Supervisee Experiences of Impression Management, the Supervisory Working Alliance, and Counseling Self-Efficacy" (2014). Graduate Theses, Dissertations, and Problem Reports. 220.

https://researchrepository.wvu.edu/etd/220

This Dissertation is protected by copyright and/or related rights. It has been brought to you by the The Research Repository @ WVU with permission from the rights-holder(s). You are free to use this Dissertation in any way that is permitted by the copyright and related rights legislation that applies to your use. For other uses you must obtain permission from the rights-holder(s) directly, unless additional rights are indicated by a Creative Commons license in the record and/ or on the work itself. This Dissertation has been accepted for inclusion in WVU Graduate Theses, Dissertations, and Problem Reports collection by an authorized administrator of The Research Repository @ WVU.

For more information, please contact researchrepository@mail.wvu.edu. 
Supervisee Experiences of Impression Management, the Supervisory Working Alliance, and Counseling Self-Efficacy

Jennifer M. Haist

\author{
Dissertation submitted \\ to the College of Education and Human Resources \\ at West Virginia University \\ in partial fulfillment of the requirements for the degree of \\ Doctor of Philosophy in \\ Counseling Psychology
}

Jeffrey Daniels, Ph.D., Chair James Bartee, Ph.D.

Christine Schimmel, Ed.D.

Deborah Hendricks, Ed.D.

James Nolan, Ph.D.

Department of Counseling, Rehabilitation Counseling, and Counseling Psychology

\author{
Morgantown, West Virginia \\ 2014
}

Keywords: Impression Management; Counseling Self-Efficacy; Supervisory Working Alliance

Copyright 2014 Jennifer M. Haist 


\section{ABSTRACT \\ Supervisee Experiences of Impression Management, the Supervisory Working Alliance, and Counseling Self-Efficacy}

\section{Jennifer M. Haist}

Supervision plays a vital role in fostering competent, ethical and effective counseling psychologists. However, studies have shown that supervisees act in ways that counteract the benefits of supervision. Trainees manage supervisor impressions to the detriment of their professional growth; they withhold information that would help supervisors promote learning, clarify misunderstandings, gain insight into supervisee weaknesses and strengths, and provide feedback that would enhance supervisee competence. Supervisee nondisclosure is a particularly prevalent impression management behavior documented in the supervision literature (Hill, Thompson, \& Corbett, 1992; Ladany et al., 1996). It and other forms of impression management may be particularly related to counseling self-efficacy and the supervisory working alliance. Recent evidence does suggest that impression management is related to counseling self-efficacy, but its role in the supervisory working alliance has not yet been examined. Given research findings that doctoral level supervisees in counseling and clinical psychology programs withhold information from their supervisors and are concerned with their supervisors' impressions of them impression management at this level of training needs to be understood. This study examined the nature of the relationships among supervisee counseling self-efficacy, supervisory working alliance, and impression management. With more insight into impression management behaviors as it relates to the experiences of supervisees, the findings of this study provided evidence of how further research into impression management is important to preparing effective counseling psychologists. 



\section{TABLE OF CONTENTS}

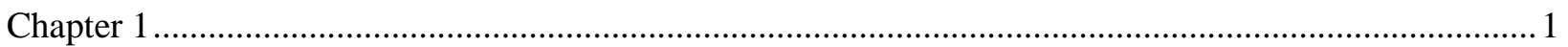

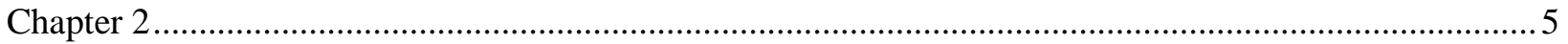

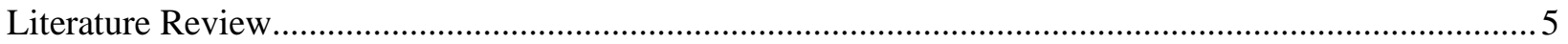

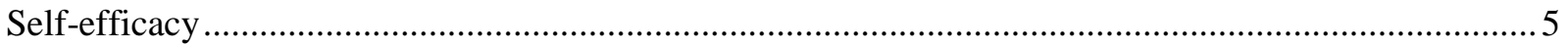

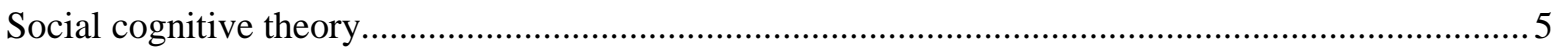

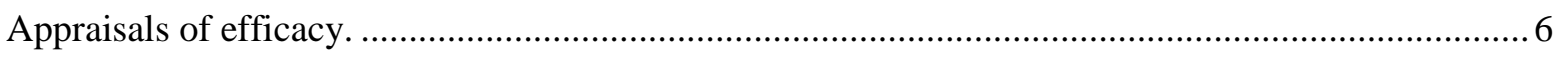

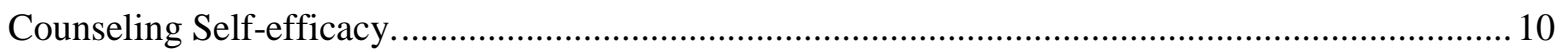

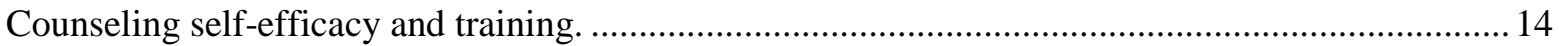

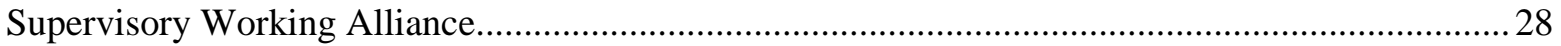

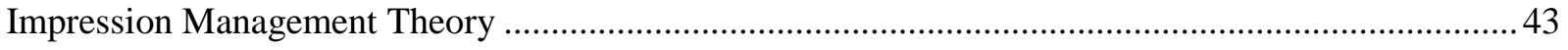

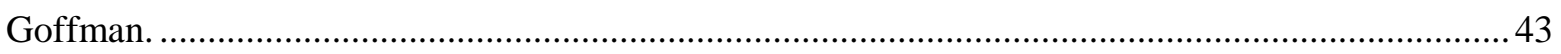

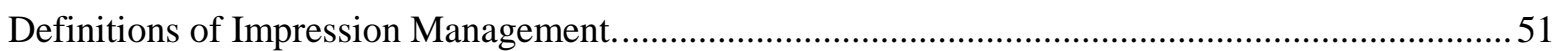

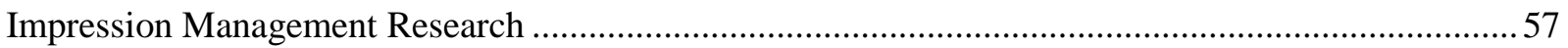

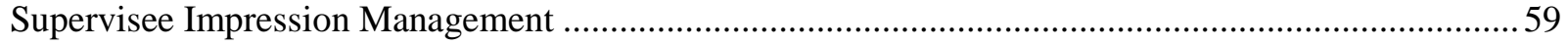

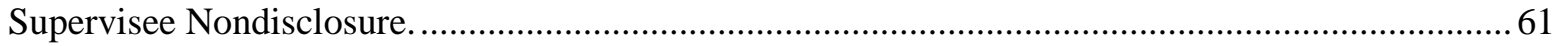

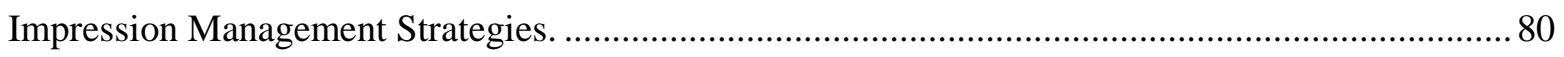

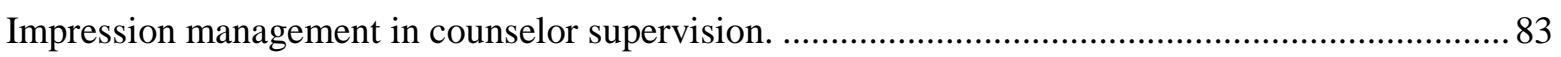

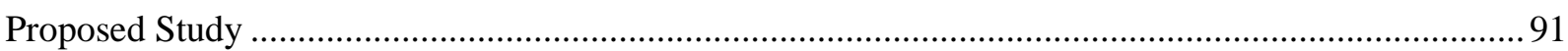

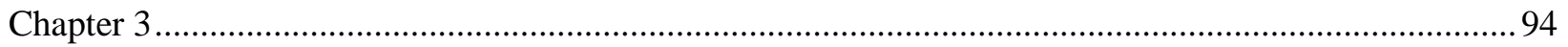

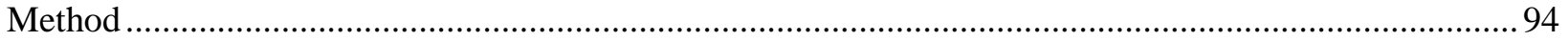

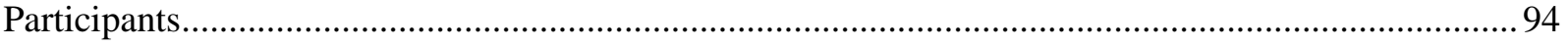

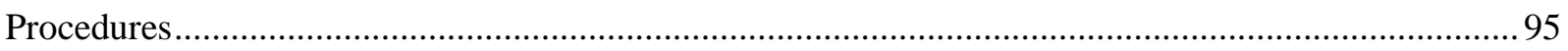

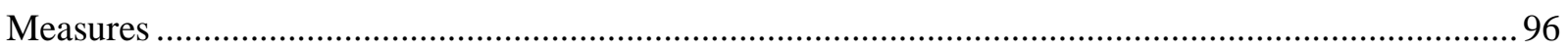

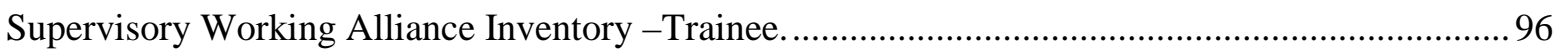

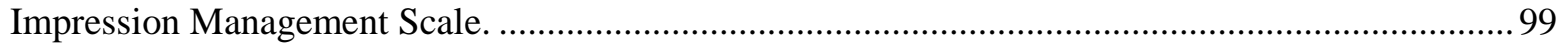

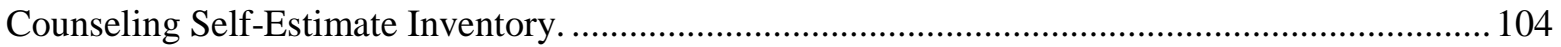

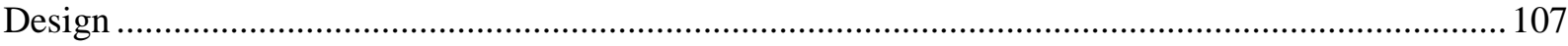

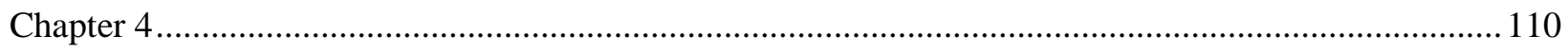

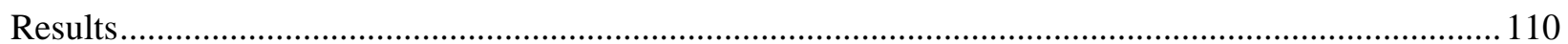

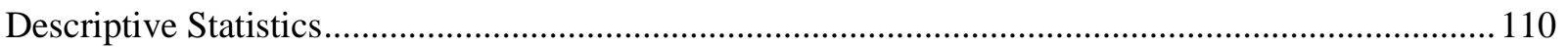

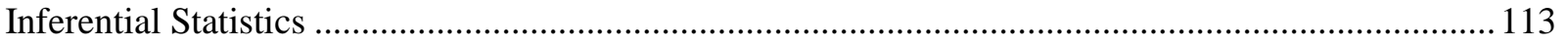

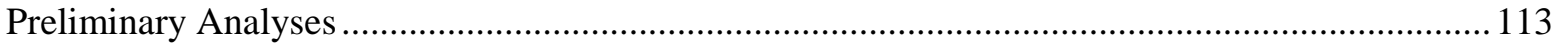

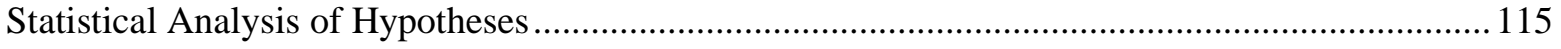




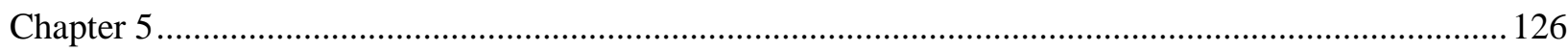

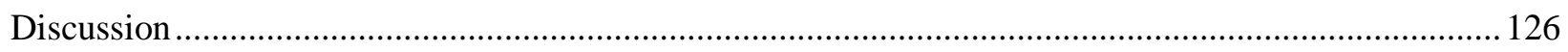

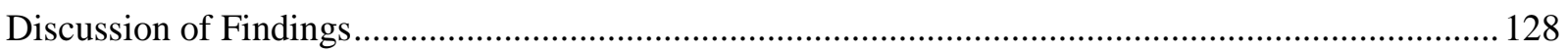

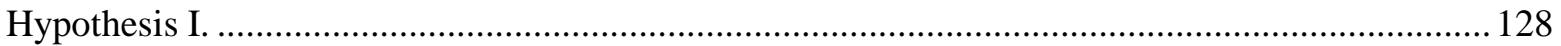

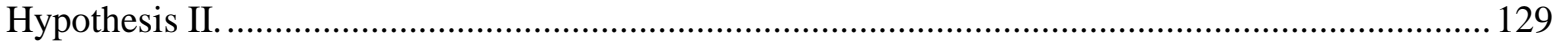

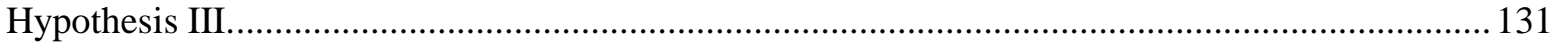

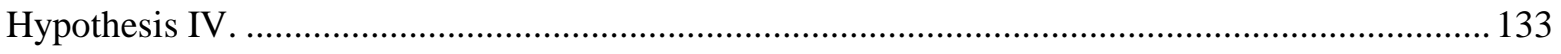

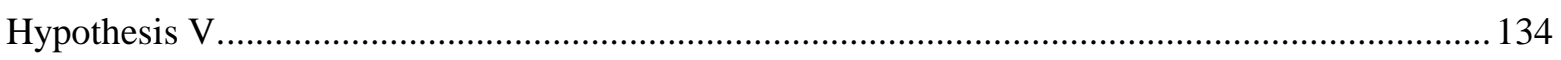

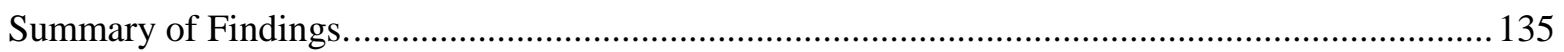

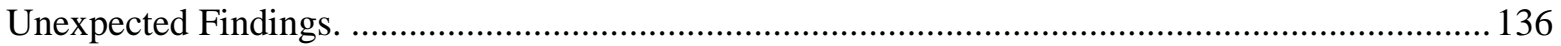

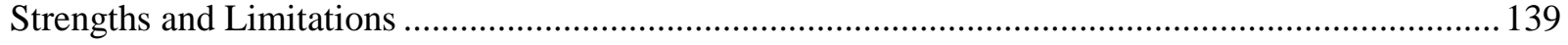

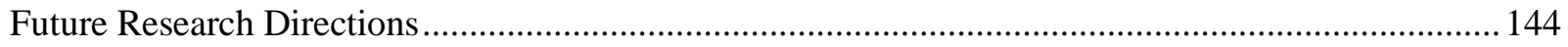

Implications for Counseling and Clinical Psychologists ............................................................. 146

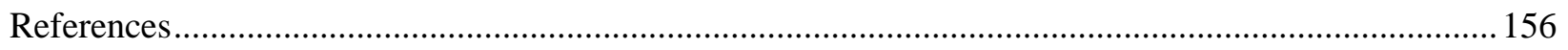




\section{Chapter 1}

Although supervision is just one aspect of psychological training, it plays a vital role in fostering counseling psychologists who are competent, ethical and effective (Behnke, 2005; Bernard \& Goodyear, 1998; Bernard \& Goodyear, 2009; Holloway, 1987; Smothers, 2010). Often referred to as the link between theory and practice, supervision helps counseling psychologist trainees apply learned concepts in the clinical setting. Supervisees learn to monitor and more accurately review the quality of their performances and the progress of their clients. Supervision serves, furthermore, both as a protective mechanism and as a gate-keeping function. As a protective mechanism, supervisors ensure that trainees provide ethical and culturally sensitive treatment to their clients. As a gate-keeping function, it ensures that trainees who fail to demonstrate professional competence are barred from entering the profession (Bernard \& Goodyear, 2009).

Consistent monitoring and feedback are important to successful supervision. They promote the effective application of knowledge, skills, theoretical conceptualizations, clinical judgments, and techniques. As Bernard and Goodyear (2009) pointed out, supervision "provides a means to impart necessary skills, to socialize novices into the particular profession's values and ethics, to protect clients, and finally, to monitor supervisees' readiness to be admitted to the profession" (p. 3). Given the importance of supervision to the profession, a careful examination of those elements that may promote or deter the professional growth of trainees is warranted. One of those elements is impression management, which is the specific focus of this study.

A great deal of literature concerns the influence of supervisors (e.g., intervention, style, feedback) on trainees (Bernard \& Goodyear, 2009); however, given the dyadic nature of supervision, there is also reason to suggest that supervisees similarly influence the process. A 
review of supervision literature revealed that supervisees attempt to manage supervisor impressions (Ward, Friedlander, Schoen, \& Klein, 1985; Webb \& Wheeler, 1998). The literature, however, does not always associate these attempts with impression management. For instance, studies have demonstrated that supervisees often withhold information from supervisors but only some of them refer to supervisee non-disclosure as an impression management strategy (Callis, 1997; Ladany, Hill, Corbett, \& Nutt, 1996; Schwartz, 2008; Yourman \& Farber, 1996). The extant research on impression management nevertheless suggests that supervisees are especially likely to manage impressions due to the hierarchical and evaluative nature of supervision (Jones, Gergen, \& Jones, 1963).

Given the hierarchical and evaluative structures supervision operates in, the question arises as to how cognizant supervisors need to be of impression management. For counseling psychologists to qualify as supervisors, they must demonstrate a certain level of expertise, a level that trainees have not yet reached. Furthermore, supervisors conduct regular evaluations on supervisees to provide them feedback and to monitor their progress. In terms of hierarchy, however, supervisees are lower-status professionals, and Jones et al. (1963) demonstrated, however, that lower-status individuals (supervisees) are especially likely to use impression management. It is also the case that supervisees often depend on positive recommendations from their supervisors for entry into internship programs or for employment purposes. Therefore, supervisees are aware of the importance of proving themselves to be valuable and competent trainees, which can mean, among other things, managing the impressions supervisors have of them.

Empirical findings have demonstrated that these conditions, the increased awareness of one's lower status (expertise) and dependency on current and future evaluations, are linked to an 
increase in impression management (Jones et al., 1963; Tyler, 2009). These conditions give shape to the primary components of the supervisory relationship, hierarchy and evaluation, which are inevitable and even necessary to promote professional growth. However, another component of supervision, the supervisory working alliance (Bordin, 1983; Efstation, Patton, \& Kardash, 1990), has been shown to alleviate some of the tension associated with these components of supervision (Callis, 1997; Gnilka, Chang, \& Dew, 2012). Agreement on goals and tasks and the development of an emotional bond between supervisors and supervisees, in particular, can counteract the potential consequences of a hierarchical and evaluative relationship, such as supervisee anxiety (Mehr, Ladany, \& Caskie. 2010; Smothers, 2010) and reduce the need to manage supervisor impressions (Mehr et al.).

Evidence suggests, moreover, that a strong inverse relationship exists between the strength of the supervisory relationship and supervisee nondisclosures (Callis, 1997). That is, the stronger the alliance between supervisor and supervisee, the fewer the nondisclosures. This suggests that the supervisory working alliance can also mediate the need supervisees feel to use impression management strategies.

Studies need to be conducted to examine the nature of this relationship. The extant research does reveal mixed findings regarding the relationship between supervisory working alliances and supervisee self-efficacy, that is, a supervisee's belief in his or her ability to effectively counsel. Some researchers have demonstrated that supervisee self-efficacy levels tend to increase with stronger working alliances (Efstation et al., 1990; Humeidan, 2002; March, 2005; Smothers, 2010; Strauss, 1994) while others have failed to find a significant relationship (Ladany, 1992; Ladany, Ellis, \& Friedlander, 1999; Mirgon, 2007). 
Given that motivation to convey favorable impressions is heightened when individuals lack confidence in their abilities to perform tasks, and given that supervisee counseling abilities are the primary focus in supervision, it is important to consider whether supervisee self-efficacy relates positively or negatively to the use of impression management. Likewise, an understanding of the nature of the relationships among all three variables (supervisee selfefficacy, supervisory working alliance, and impression management) should offer more insight into those factors that promote or hinder the goal of supervision to promote competent and effective counseling psychologists. To understand the nature of these relationships, this literature review seeks first to review the theoretical groundings of these concepts and secondly to examine the empirical findings regarding their relation to supervision. 


\section{Chapter 2}

\section{Literature Review}

\section{Self-efficacy}

Social cognitive theory. Albert Bandura (1977a) hypothesized that human behavior is best understood in terms of the reciprocal relationship between behavior, environmental influences, and cognitions. This hypothesis serves as the foundation for Social Cognitive Theory (SCT). This theory suggests that learning and outcomes result from cognitive interpretations of the environment, the behavioral reactions to it, and interactions among behaviors, cognition and environmental influences. Self-efficacy, an essential component in this reciprocal relationship, is defined as "people's judgments of their capabilities to organize and execute courses of actions required to attain designated types of performances" (Bandura, 1986, p. 391). In short, selfefficacy is the degree to which individuals believe themselves to be capable of performing a desired behavior. Beliefs one holds about one's ability to perform behaviors influence the likelihood that one will attempt a particular activity, how the activity is approached, and how well it is performed (Bandura, 1977a, 1977b, 1986). Expressed another way, self-efficacy impacts the decision to attempt an activity, the amount of effort put forth, and the degree of perseverance sustained throughout the activity (Bandura, 1986).

As a cognitive mechanism, self-efficacy influences the quality of social, cognitive and affective functioning (Bandura, 1977b, 1982, 1986, 1991). More specifically, it mediates the impact of skill proficiency and ability level on performances. "Different people with similar skills, or the same person on different occasions, may perform poorly, adequately, or extraordinarily" (Bandura, 1986, p. 391). Bandura accounted for these variations by explaining that positive efficacy beliefs lead to an increase in willingness to attempt tasks, to persevere, and 
to put forth effort on tasks. Conversely, low efficacy expectations are associated with increased avoidance of tasks and decreased perseverance and effort. On account of avoidance behaviors, individuals who engage them are not exposed to the "enriching environments and activities" that serve as the foundation for potential growth (Bandura, 1986, p. 393). Without the opportunity to demonstrate capability to the self, one's efficacy expectations remain unchallenged and one's perceptions of incompetence persist. The chance of successfully performing a task increases when individuals put forth more effort and persevere during difficulty (Bandura). The self-doubt inherent in low self-efficacy leads to longer preparation times but also prevents successful completion of performances. "By restricting choice behavior and undermining effort, selfdisbeliefs can create their own validation" (Bandura, p. 401). Put another way, low efficacy levels can lead to a kind of self-fulfilling prophecy, by avoiding tasks and giving up when faced with obstacles. When that happens, individuals do not live up to their potential and in a sense, prove their efficacy beliefs to themselves.

Appraisals of efficacy. According to Bandura (1986) there are four major sources of information that contribute to the development of personal efficacy expectations: mastery (performance accomplishments), modeling (vicarious experiences), social persuasion, and physiological arousal. Performance accomplishment, also referred to as mastery, is successful performance of behaviors required to complete a task. In general, mastery experiences raise selfefficacy and repeated failures lower it (Bandura, 1977b, 1986). The determination of success or failure of performances, however, is subject to individual perception. Whether behaviors are considered to be mastery experiences rests on cognitive appraisals of performances. When cognitive appraisals result in perceptions of success, the information gained from these experiences is highly likely to be integrated into efficacy beliefs. Out of all the social learning 
experiences, self-efficacy is most strongly influenced by mastery experiences (Bandura, 1977b, 1982, 1986).

Bandura (1986) explained that mastery experiences involve repeated exposures to previous threats, reductions in emotional arousal, refinements in coping skills, and reinforcements of efficacy expectations. Thus, repeated experiences of mastery strengthen selfefficacy beliefs and reduce the negative impact of failures. Individuals who develop strong, favorable efficacy beliefs from mastery are more likely to attribute failures to external factors, such as the use of inadequate strategies. On the other hand, low efficacy beliefs are associated with internalized failures; failed performances in those cases are likely to be attributed to personal characteristics, such as personal ability, rather than external factors or insufficient effort (Bandura). This cognitive interpretation of failures decreases the likelihood of future success. Bandura (1986) suggested that sustained effort is key to raising low efficacy levels. Persistence in the face of obstacles and successful executions of previously failed tasks are what reinforce efficacy expectations. The enhanced self-efficacy generalizes to other, similar areas previously considered to be beyond personal capability. Taken together, Bandura hypothesized that efficacy beliefs developed from mastery experiences are the most reliable and last for the longest periods of time.

Modeling, or vicarious experience, refers to the observation of others executing successful performances (Bandura, 1982, 1986). Bandura considered this informational source to be the second strongest influence on self-efficacy levels. Modeling has a direct influence on whether individuals pursue personal accomplishments to obtain additional efficacy information. "A given mode of influence can thus set in motion processes that augment its effects or diminish the effects of otherwise powerful influences" (Bandura, 1986, p. 400). Bandura hypothesized 
that efficacy levels raised from modeling leads to greater persistence on difficult tasks, which increases the likelihood of mastery experiences. A caveat, however, is that for modeling to have an effect, the models must be similar to the observer. If models are comparable in skill level and perform well then individuals conclude that they too can perform well on similar tasks. Therefore, social comparisons of self capabilities to similar models are associated with changes in self-efficacy (Bandura, 1982).

A lack of knowledge about the modeled behavior and the absence of performance criteria make it difficult to gauge the quality of the performance. Without this, information from modeling is useless because there is no way for observers to know whether performances are successes or failures or what models correctly or incorrectly model. When this information is available, however, vicarious experiences can positively influence low efficacy beliefs in the sense that individuals learn additional strategies and adaptive ways to approach future performances. Unlike mastery experiences, however, self-efficacy levels influenced by modeling are more vulnerable to change, do not last as long as those developed from mastery, and are less reliable predictors of self-efficacy (Bandura, 1977b).

Social persuasion is the state of being convinced that one possesses the capabilities to successfully perform a desired behavior (Bandura, 1977b, 1982, 1986). It is the third strongest influence on self-efficacy and is most beneficial to those whose actual capabilities reflect a rise in self-efficacy. If individuals are persuaded that they are capable and then fail, then their selfefficacy will fall to a lower level than before. Just as individuals can be persuaded that they possess skills, they can also be persuaded that they are incapable. Bandura (1986) hypothesized that it is probably more likely that social persuasion will create lasting effects by lowering 
efficacy levels rather than enhancing them. Efficacy beliefs based on social persuasion are unstable and as a result liable to change after a short period of time.

Physiological arousal has the least influence on self-efficacy and, similarly, changes in efficacy resulting from physiological arousal tend to have the shortest time span. It is typically induced by situations that have the potential to positively or negatively influence personal performance (Bandura, 1982). Bandura (1977b) maintained that self-efficacy is enhanced with minimal levels of arousal. High levels of physiological arousal are associated with low selfefficacy, and vice versa. When arousal is attributed to personal ineptitude individuals pay more attention to their symptoms, which further heightens their physiology. Similarly, symptoms of autonomic (e.g., anxiety) and somatic arousal (e.g., fatigue) associated with the assumption that something is awry produce negative interpretations of the performance (e.g., incompetence). "Fear reactions generate further fear through anticipatory self-arousal. By conjuring up fearprovoking thoughts about their ineptitude, people can rouse themselves to elevated levels of distress that produce the very dysfunctions they fear" (Bandura, 1986, p. 401). Therefore, cognitive appraisals of arousal impact motivations to persevere and behavioral responses (ability to perform and outcome) which ultimately influence efficacy levels.

Cognitive appraisals determine whether information gained from social learning experiences will influence efficacy expectations (Bandura, 1977b, 1986). Bandura (1977b) contended that contextual factors (i.e., situational, temporal, social) impact the degree to which successes are generalized to personal efficacy. When efficacy judgments are strong, credible information is likely to be discounted or, if efficacy expectations do change, it will be minimal. The reasons ascribed to successes and failures are a key component of cognitive appraisals. For instance, people with low self-efficacy typically ascribe failures to personal ability rather than to 
situational factors (e.g., external aids) and ascribe successes to external factors (e.g., easy task). Stronger low self-efficacy is related to greater fears of erroneous judgments because of the potential risks of future failures. "Those who question their coping efficacy are more likely to distrust their positive experiences than to risk encounters with threats they judge they cannot adequately control" (Bandura, 1986, p. 401). Individuals with high self-efficacy, on the other hand, are likely to attribute failures to circumstances (e.g., low effort) and successes to skill and ability level. In sum, individuals use mastery experiences, modeling, social persuasion and physiological arousal to determine personal levels of competency but it is their cognitive appraisals of efficacy information that ultimately determines whether self-efficacy levels are affected.

Counseling Self-efficacy. The Social Cognitive Model of Counselor Training (SCMCT), one theory that developed out of Bandura's Social Cognitive Theory (SCT), has proved to be a valuable tool for understanding counseling psychologist trainees (Larson, 1998). Larson translated SCT to the field of Counseling Psychology to explain how supervision could foster competency in counseling psychologist trainees. In particular, Bandura's concept of selfefficacy provided the basis for Counseling Self-Efficacy (CSE) which is defined as "one's beliefs or judgments about her or his capabilities to effectively counsel a client in the near future" (Larson \& Daniels, 1998, p. 180). Larson et al. (1992) demonstrated that trainees base their efficacy beliefs on five counseling related areas, which are counseling microskills, therapeutic process, difficult client behaviors, cultural competence and awareness of values. Consistent with SCMCT, efficacy beliefs concerning these skills influence the emotional, motivational and cognitive processes of trainees. In turn, delivery of therapeutic services (performance) is affected because of the resultant impact of the processes on trainee decisions to 
"engage in a counseling task, to put forth effort, and to persevere under failure" (Larson, 1998, p.231).

In supervision trainees are exposed to two of the four social learning experiences outlined in SCT, modeling and social persuasion. According to Larson (1998), modeling experiences, social persuasion and feedback are the three salient functions of the supervisor. In regards to modeling experiences, supervisees observe successful therapeutic performances of themselves (e.g., behavioral rehearsal), their supervisors, or other counselors (e.g., taped sessions). Through social persuasion, supervisors act to persuade trainees of their capability and to provide them with support and learning opportunities. In line with this model, social persuasion is defined as "the extent to which the supervisor provides realistic, supportive encouragement and structured learning situations that increase the chance of counseling success for the counselor" (Larson, p. 240). Lastly, supervisor feedback impacts how supervisees cognitively process their performance. That is to say, trainees learn to attend to specific aspects of their performance and to accurately judge the quality of their work (i.e., whether performance can be classified as a mastery experience). Taken together, the role of the supervisor is to provide social learning experiences to trainees and in turn, each experience offers supervisees additional opportunities to advance their competency level and to refine their efficacy beliefs.

The absence of a supportive supervisory relationship, however, renders the accomplishments of modeling, social persuasion and feedback ineffective (Larson, 1998). Supervisory relationships characterized as safe, positive, and supportive generate conditions that are conducive to learning. Not only are supervisees more likely to take advantage of learning opportunities but they are also more receptive to supervisor messages and feedback. Thus, when supervisors bring up sensitive content, such as trainee competency level on a particular skill, 
supervisees are more likely to interpret the feedback as it was intended. The relationship, then, plays an essential part in fostering efficacious counseling psychologists; it provides a safe context for supervisees to discuss their weaknesses and the support that they need to improve their counseling skills.

Supervisee willingness to examine and work on counseling skills is a function of the perceived environment, which, according to the SCMCT comprises one half of the supervisory environment (Larson, 1998). The other half, referred to as the objective environment, reflects the actual events that occur in supervision sessions. In other words, the perceived and objective parts of the environment provide an anchor for the subjective and objective accounts of supervision.

Of these two parts, the perceived environment is theorized to have the greatest impact on CSE. Research findings suggested that supervisee perceptions, in particular, influence CSE (Larson, 1998; Efstastion et al., 1990). It could be argued, then, that trainee perceptions of supervisor communications and trainee receptiveness to those messages (i.e., changes in their efficacy beliefs) reflect the perceived quality of the supervisory relationship. Put another way, supervisee self-efficacy levels may be a function of their perceptions of the supervisory relationship.

A major component of SCMCT rests on the premise that a reciprocal influence occurs among the environment (e.g., supervision), personal agency variables (i.e., CSE and cognitive, affective, and motivational processes), and actions of the supervisee and supervisor. In addition, this interaction can be influenced by other contextual variables, such as trainee characteristics (personal context) and social, cultural and environmental variables (larger context) (Larson, 1998). Therefore, according to the SCMCT, both the supervisory relationship and trainee 
counseling self-efficacy should influence and be influenced by each other. In line with this reasoning, it should also be the case that supervisee motivation to manage impressions, CSE (personal agency variables) and the supervisory relationship (environment, context) also influence one another.

Up to this point, researchers have explored many of the hypotheses outlined in SCMCT. With respect to CSE, multiple studies have offered support for the proposed relationships (e.g., Daniels \& Larson, 2001; Kocarek, 2002; Kozina, Grabovari, Stefano, \& Drapeau, 2010; Larson \& Daniels, 1998). In lieu of these findings, a positive correlation appears to exist between CSE and stable trainee characteristics (e.g., personality); self-reflective variables (e.g., feeling like an imposter); outcome expectancy (i.e., beliefs that one's actions will produce the desired outcomes); evaluation of completed performances; and actual performance level as measured by trained raters and supervisors (for full review, see Larson \& Daniels). Importantly, CSE appears to have a negative relationship to emotional arousal (Larson \& Daniels). Therefore, theory and research have shown CSE to be a construct of merit and one that significantly impacts counseling psychologist trainees.

Research that pertains to the relationships of CSE and supervisee training level, the quality of supervisory relationship, and impression management has important implications for this study. Supervisees are, by definition, trainees and according to the research, the amount of training that they receive will influence CSE. Given that the training level will be a controlled variable, that is, all trainees will be at the doctoral level, it is important to take into consideration those findings that pertain to doctoral trainees. The nature of the relationship of CSE to training level and to the supervisory relationship is less clear. Research pertaining to training levels suggests that either a linear, positive relationship or a curvilinear relationship exists for training 
level. With respect to the proposed relation between CSE and supervisee perceptions of the supervisory relationship, some researchers found support for this hypothesis (Efstation, et. al., 1990; Smothers, 2010), while others failed to demonstrate that a significant, positive relationship exists (Humeidan, 2002; Ladany, 1992; Ladany et al., 1999; March, 2005; Mirgon, 2007). Likewise, little to no research exists concerning the potentially reciprocal influence of CSE and impression management. Therefore, it is essential to review and examine the relevant research on each of these relationships before arriving at a hypothesis concerning the dynamics of impression management.

Counseling self-efficacy and training. In line with Bandura's Self-Efficacy theory, additional experience and training should raise confidence in one's ability, which in turn, should promote competency. For the most part this hypothesis has held true for CSE: training and experience (counseling and supervision) have been associated with CSE and, likewise, CSE has been related to trainee performance (as measured by client outcome). However, a review of the extant research on the relationship between CSE and training level yields mixed findings. On the one hand, there is evidence to suggest that a positive, linear relationship exists (e.g., Johnson, Baker, Kopala, Kiselica, \& Thompson, 1989; Tang et al., 2004) while other results suggest that a curvilinear relationship is more accurate (Sipps, Sugden, \& Favier, 1988). Similarly, there are multiple variations on how researchers operationalize the professional level of trainees. For instance, several studies examine this relationship in terms of supervision experience (e.g., Leach \& Stoltenberg, 1997), counseling experience (e.g., Johnson et al., 1989; Melchert et al., 1996), professional developmental level and/or level of training (e.g., Larson et al., 1992; Sipps et al.). Likewise, these variables are all related in some way. For example, training in master's and doctoral programs typically offer practicums and internships where students concomitantly 
receive supervision and gain counseling experience. In addition, measures of developmental levels have been found to be significantly related to training level and experience (e.g., Leach \& Stoltenberg, 1997). What follows is a review of the findings regarding the relationship between supervisee training and CSE.

One of the first studies to explore the training level of supervisees in relation to CSE demonstrated an inverse relationship. Sipps et al. (1988) conducted a study on the relationship between graduate training level and counseling self-efficacy. The authors hypothesized that increases in outcome expectations would correspond with increases in basic counseling skills usage whereas efficacy expectations would demonstrate a curvilinear relationship with these skills over the course of graduate training. Participants included 78 graduate counseling students who were grouped according to their level of graduate training: $1^{\text {st }}$ year, $2^{\text {nd }}$ year, $3^{\text {rd }}$ year, and $4^{\text {th }}$ year.

The participants were instructed to watch a videotape of a fictitious client who made 19 statements. After each statement, the participants recorded how they would respond and the desired outcome of their responses. These responses were followed by a self-efficacy questionnaire in which students rated their outcome expectations and efficacy expectations for each response.

The findings of the statistical analyses (MANCOVA) demonstrated a significant relationship between graduate training level and efficacy expectations and between response type and efficacy expectations. In other words, Sipps et al. (1988) found support for their hypothesis that efficacy expectations for basic counseling skills usage and graduate training level have a curvilinear relationship. First year students reported significantly higher efficacy expectations than second year students whereas the third and fourth year students demonstrated the highest 
efficacy expectations. The authors proposed that the first year trainees' high levels of efficacy were likely due to underestimations of the complexity of therapy and due as well to a mistaken belief that common sense is a sufficient method in therapy. Sipps et al. (1988) attributed second year students' low efficacy levels to failed attempts to apply methods of common sense. They contended that third and fourth year students' high efficacy levels were due to the greater amount of mastery experiences. The findings also suggested that outcome expectations were higher for fourth year students than for first or second year students. Therefore, the students with the highest level of training also reported the most confidence that their counseling skills would produce the desired outcome, which was client change.

Overall, Sipps et al. (1988) demonstrated that CSE and graduate training level have a curvilinear relationship. The results of this study suggested that supervisees who are at the beginning and final stages of their training will have high CSE. The cognitive processes of the two groups however, are entirely different. Unlike more advanced trainees, the study implies that beginning trainees have a false sense of efficacy. Supervisees in the middle stages, however, will have low CSE due to the progression of cognitions concerning counseling. Sipps et al's. study was the first to explore how CSE varies with the different levels of training; which to date, has provided the most extensive analysis of the relationship between training level and CSE.

A study that was conducted recently after the Sipps et al. (1988) investigation, however, found that training and CSE had a linear relationship. Johnson et al. (1989) investigated CSE over the course of a master's level pre-practicum counseling class. The authors also examined the relationship of CSE to supervisee personal experience as a client and to overall counseling performance. The authors predicted that self-efficacy levels would consistently increase throughout the eight weeks of training and that changes in post-training efficacy levels would 
correlate with changes in generalized efficacy. The authors measured generalized self-efficacy by asking students to imagine counseling a real client. In addition, Johnson et al. expected that personal counseling experience would increase efficacy levels and that post-training efficacy levels would positively correlate with the quality of counselors' performances.

The participants were grouped according to initial self-efficacy scores and random assignment to counseling services. Data collection methods for students' performances were obtained through the use of the Responding Proficiency Index (initial interview) and the Challenging Skills Rating Form (second interview). To measure self-efficacy levels across training levels, students were first asked to imagine their performances in a role play and then to conduct a role play while being videotaped. The Counseling Self-Efficacy Scale was administered to students prior to training and twice after training. Pre-training efficacy levels were assessed after students imagined a role play whereas post-training efficacy levels were collected both prior to the videotaped role play (to measure perceived capability of basic skills) and after the role play (to measure generalized efficacy).

Results indicated that low and high efficacy levels at pre-training consistently improved with training. The findings from the analysis of variance revealed increases in efficacy from the first to second post-trainings for the low efficacy group and increases in efficacy from pretraining to the first post-training for the high-efficacy group. There was no change in generalized self-efficacy for either group. Correlational analyses indicated that increases in efficacy levels positively correlated with students' expectations of effectiveness when working with clients in the future (generalized efficacy). There were no significant differences in self-efficacy between students who received counseling services. Similarly, efficacy levels measured at post-trainings were unrelated to performance quality. 
The findings of this study demonstrated that self-efficacy levels can change over a relatively short period of time (one semester) and more specifically, that training is directly related to changes in efficacy levels. In addition, it appears that initial efficacy levels may determine how much training impacts future changes. However, what is less clear is the nature of the relationship between self-efficacy and performance. While this study offers support for Bandura's hypothesis that exposure to experiences leads to increases in self-efficacy, it fails to demonstrate that the additional exposure and subsequent increase in efficacy levels enhances performance. What it does suggest, however, is that fostering CSE in trainees may be just as important as enhancing their performance abilities.

In the process of developing the Counseling Self-Estimate Inventory (COSE) Larson et al. (1992) conducted a series of studies, one of which used the inventory to explore the relationship between training level and CSE. More specifically, the authors examined the relationship between CSE and level of training (bachelors, masters, and doctoral degrees), years of experience (none, two to eight, and nine to 39), and the amount of supervision experience in semesters (none, one to three, four to six, and seven to 17). They hypothesized that the master's level counselors and the doctoral level counseling psychologists would have higher CSE levels as measured by the COSE. They expected that individuals with advanced degrees would have more exposure to mastery experiences, modeling, and social persuasion, and less physiological arousal than those with less training.

The results were as the hypotheses predicted. Using the COSE scores as the dependent variable, Larson et al. (1992) conducted an ANOVA for each level (training, counseling experience, supervision experience) and then examined within group differences using post hoc analyses. The findings revealed a significant main effect for the level of training and a post hoc 
pairwise comparison demonstrated that master's level counselors and counseling psychologists had significantly higher CSE than bachelor's level counselors. Similarly, there was a main effect for years of experience and further post hoc analyses indicated that participants with no experience had significantly lower CSE than those with two to eight years or nine to 39 years of experience. A main effect for semesters of supervision was also found, with post hoc comparisons yielding a significant difference between those with no supervision and those who received supervision on all three of the remaining levels. Taken together, these findings suggest that the level of training, counseling experience and supervision experience should be used to predict whether counseling psychologist trainees will have high or low CSE: the more advanced training and experience should reveal higher efficacy levels.

Since the previous studies only found differences between two groups of professional development (little to no experience versus advanced training), Melchert et al. (1996) examined CSE across the entire range of professional development. To assess CSE, the authors developed a self-efficacy scale which they labeled the Counselor Self-Efficacy Scale (CSES). The participants included first and second year master's students, doctoral students, and professional psychologists. Counseling psychology students constituted the largest portion of the sample. Years of experience ranged from none to more than 15 years.

Melchert et al. (1996) hypothesized that self-efficacy would correlate positively with training and experience. To test this hypothesis the authors conducted a multiple regression using level of training and experience as the independent variables, analyses of variance with CSES scores as the dependent variable, and post hoc analyses. The findings from the multiple regression demonstrated that both level of training and experience significantly predicted selfefficacy. The level of training accounted for slightly more of the variance in self-efficacy scores 
than did the amount of experience. Increases in self-efficacy gained through the additional training provided in doctoral programs were not reflected in participants' scores who had additional years of clinical experience with a master's degree. The results from the ANOVA and post hoc analyses revealed significant differences among professionals who had different levels of training and experience. There were significant, consistent increases in self-efficacy scores as the training levels increased. Likewise, participants who reported five to ten years, ten to 15 years, and 15 or more years of experience had significantly higher counseling self-efficacy scores than those who reported less than five years of experience. The authors pointed out that the mean scores demonstrated a consistent increase in efficacy levels as the years of experience increased. This study contributed new information to the field of counseling psychology. It demonstrated that there are significant increases in self-efficacy levels throughout training and after employment. Furthermore, the finding that level of training accounted for more variance than experience may speak to the importance of assessing training level over experience.

Similar results were obtained during the development of the Career Counseling SelfEfficacy Scale (CCSES). To demonstrate the reliability and validity of the CCSES, O'Brien, Heppner, Flores, and Bikos (1997) compared a sample of counseling psychology graduate students enrolled in career counseling courses to psychologists who were employed at APAapproved internship sites. The authors predicted that the psychologists' self-efficacy levels would be higher than the graduate students and that years of career counseling experience would positively correlate to the scores. The scale was administered to the graduate students and the psychologists six different times in 16 week intervals. Dependent t-tests revealed significant differences between pre- and post-test scores for the graduate students. There were consistent increases in efficacy levels across time. Likewise, there were significant differences between the 
scores of the students and psychologists, with the psychologists scoring highest. The statistical analyses failed to demonstrate a significant relationship between efficacy levels and years of experience in the post-test scores. The authors suggested that this finding could reflect the significant impact that training has on efficacy levels. In sum, O'Brien et al.'s (1997) research further corroborates the hypothesis that training level is related to CSE and that training may be more influential than years of experience on CSE.

Leach and Stoltenberg (1997) examined the relation between CSE and developmental level using Stoltenberg and Delworth's (1987) Integrated Developmental Model (IDM) of supervision as a framework. Using the Counseling Self-Estimate Inventory (COSE) and the Supervisee Levels Questionnaire-Revised (SLSQ-R), the authors assessed master's and doctoral counseling practicum students' self-efficacy levels and developmental levels. Developmental level was assessed through the SLSQ-R, which classifies responses as either low (Level One) or high (Level Two). These levels are based off of the main structures in Stoltenberg and Delworth's model: self and other awareness, motivation, and dependency-autonomy. The selected participants had experience with either reactively depressed or sexually abused clients and were grouped according to the amount of clients they had seen and the number of semesters they had been practicing. Consistent with the main assumptions of IDM, the authors hypothesized that trainees would exhibit greater self-efficacy levels in anticipation of working with clients with whom they had previous experience. Similarly, higher developmental levels were expected to positively correlate with self-efficacy levels.

Correlational analyses revealed a significant relationship between the developmental scores to semesters taken and number of clients seen. Level 2 related to participants with greater numbers of clients and semesters completed and Level 1 related to those with less experience 
and training. As expected, the statistical findings from a Multivariate Analysis of Variance (MANOVA) revealed significant differences between participants classified as Level 1 and Level 2 and among the number of clients seen (1 to 3; 4 to 6; 7 or more). Additional univariate analyses found significantly higher self-efficacy levels for Level 2 participants than Level 1. They reported greater understanding of process issues and greater confidence in their abilities to work with difficult client behaviors. The statistical analyses also demonstrated a significant difference in efficacy levels when trainees reported previous experience with sexually abused clients but not for those who had experience with reactively depressed clients. According to Leach and Stoltenberg (1997), this difference may reflect the novice counselors' assumptions about depressed clients. They suggested that trainees may believe that reactively depressed clients are easier to work with than sexually abused ones and as a result, have more initial confidence in their ability to bring about change. The authors' failure to control for potentially confounding variables limits the generalizability of this study. For instance, this study would have benefited from specifications regarding the nature of the participants' training. If their training was specifically geared towards treatment of depression or sexual abuse (e.g., evidence based treatments) then they may have been more likely to take on clients with those presenting concerns. Without this information, it is impossible to know what factors contributed to the differential efficacy (i.e., assumptions regarding clients, type of training, etc). In sum, the findings of this study offer evidence to support the relationship of professional developmental level to CSE, suggesting a significant, positive relationship, but the relationship between experience and CSE remains unclear.

In her dissertation, Kocarek (2001) examined the relationships among CSE, anxiety, developmental level, training level (coursework), counseling experience and counselor 
performance. Master's level counselor students from different training levels (pre-practicum, counseling practicum, and field practicum) were asked to complete the Counseling Self-Estimate Inventory (COSE), State Trait Anxiety Inventory (STAI), and the Supervisee Levels Questionnaire - Revised (SLQ-R). In addition, the students' supervisors completed the Counselors Evaluation Rating Scale (CERS) to assess students' levels of performance.

Correlational analyses revealed CSE to have a significant relationship with developmental level (SLQ-R scores), anxiety (STAI), and training level, but not with counseling experience. Out of all the variables, the developmental level had the strongest, positive relationship. Anxiety level was found to be the second strongest relationship but was inversely related to CSE. Interestingly, the findings indicated that counseling experience negatively correlated with training level (number of courses). The same pattern of findings occurred for counselor performance level as measured by the CERS: it had a significant relationship with all variables except for experience and was inversely related to anxiety. In addition, the findings from regression analyses demonstrated that CSE, developmental level, amount of coursework, and experience level are all significant predictors of counselor performance.

Consistent with previous research findings, CSE had a significant, positive relationship with trainee developmental level. Contrary to previous findings, CSE reports (COSE), ratings of anxiety (STAI), and developmental levels (SLQ-R) did not predict performance (CERS) above and beyond all other variables. On the other hand, counselor developmental levels were significantly different at each level of training: pre-practicum trainees had the lowest mean efficacy scores and field practicum trainees had the highest mean efficacy scores. Developmental level was not found to function as a moderator variable between amount of training and CSE. 
One potential limitation of this study is that the author measured training in terms of courses, which is a different degree of measurement than used by previous studies. Notable limitations mentioned by the author pertain to issues of multicollinearity, measurement, and its overall design. Even though two of the predictor variables, developmental level and CSE, were highly correlated, it is impossible to know how much either of the variables contributed to the results of the multiple regression analyses. In regards to measurement of performance, the author indicated that the use of CERS may have precluded accurate assessments of overall student performance at the different levels. Kocarek (2001) explained that the supervisors' frames of reference could have been different with trainees of different levels. Also, the design of the study was correlational in nature which precludes causal inferences regarding the nature of the relationship between the explored variables.

In an exploratory study, Tang et al. (2004) examined factors that influence counselor selfefficacy levels. Participants were separated into two groups according to their training backgrounds, which included CACREP and non-CACREP accredited programs. The authors administered a demographic questionnaire and the Self-Efficacy Inventory (SE-I) to all participants. The statistical findings of a MANOVA revealed a significant difference between the two groups in terms of the amount of courses taken and the number of internship hours. Although there was no significant difference in overall self-efficacy levels between the two groups, there were moderate to strong positive correlations between self-efficacy and prior experience and training. More specifically, the authors found that course work, internship hours and clinical hours are positively related to CSE. The findings of this study led Tang et al. to conclude that both trainee experience and ongoing involvement in counseling activities help trainees to develop more confidence in their abilities to be effective. 
More recently, Kozina et al., (2010) examined changes in counseling psychology masters' level students' self-efficacy beliefs across a 16 week period of training. The authors also explored whether changes would occur in each of the five skill development areas as assessed in the COSE: micro skills, process, challenging client behaviors, cultural competency, and self-awareness of values. Training was operationalized as weekly academic instruction and supervision in micro skills and case conceptualization. Kozina et al., administered the COSE to the participants on two separate occasions, with an eight week time lapse. A paired two-tailed ttest indicated a significant difference in scores between the two testing times, although the effect size was small. A MANOVA for repeated measures demonstrated that there was a significant difference among the five skill areas but follow-up univariate tests only revealed a significant increase in micro skills. Based on these findings, the authors concluded that training can boost efficacy beliefs over a short period of time and that perceptions of micro skills in particular are especially susceptible to change. The generalizability of these conclusions, however, are limited by the insufficient sample size $(n=20)$ and homogeneity of the sample with respect to gender (female), ethnicity (Anglo-European), and training level (novice counselors). In hindsight, the authors acknowledged that the use of the COSE may have precluded accurate reflections of efficacy beliefs. They contended that the COSE assesses efficacy beliefs regarding tasks with which counselors are assumed to be familiar. Provided that novice trainees may not be knowledgeable in the assessed areas, the scores may not reflect trainees' perceptions of their capabilities since they have no past experience to use as a basis for their conclusions.

A relatively recent investigation into the singular impact of supervision on CSE was conducted on practicing counselors and doctoral level students (Cashwell \& Dooley, 2001). Cashwell and Dooley hypothesized that counselors receiving supervision would have higher 
levels of CSE than the ones who were not receiving supervision. The majority of the participants were working at a community agency and four were in a counselor education doctoral program. After the authors received permission from the community agency to contact the staff members, they asked the volunteers to fill out and return a packet of questionnaires. Cashwell and Dooley used the COSE to obtain measures of self-efficacy. An independent t-test revealed a significant difference in self-efficacy ratings between supervised counselors and non-supervised counselors. These results are consistent with the research that suggests supervision positively impacts counselors' efficacy levels. From these findings, the authors argued for the necessity of continued supervision upon completion of training. In addition to the corroboration of previous findings, this study provided new information in the sense that clinicians who were not enrolled in graduate programs or receiving additional training demonstrated increases in CSE levels. In other words, supervision alone improved CSE levels. However, the insufficient sample size in this study and the homogeneity of the sample with respect to professional level (graduated clinicians) precludes generalizability of the findings to trainees in supervision. On the other hand, additional research that recruited trainees did replicate the results of this study.

Additional data suggested that the style of the supervisor may impact perceptions of selfefficacy in supervisees. Fernando and Hulse-Kilacky (2005) explored supervisor styles in relation to supervisee satisfaction with supervision and perceived self-efficacy levels. They predicted that a relationship would exist among all three constructs. The participants were master's level counseling students who received weekly supervision and were enrolled in an internship class. Fernando and Hulse-Kilacky (2005) asked the counseling program directors to distribute packets containing the inventories to the supervisors, who then distributed the surveys to their supervisees. The participants completed the Supervisory Styles Inventory (SSI), the 
Supervisory Satisfaction Questionnaire (SSQ) and the COSE. Multiple regression analyses indicated that all three supervisor styles (attractive, interpersonally sensitive and task-oriented) explained over half of the variance (53\%) of supervisee satisfaction levels. More specifically, interpersonally sensitive styles were significant predictors of supervisee satisfaction. With respect to self-efficacy, supervisor styles significantly predicted perceived efficacy levels after controlling for the following variables: supervisee developmental level, supervisee experience, and supervisor type (faculty supervisor or doctoral student supervisor). However, subsequent correlational analyses suggested that only the task-oriented style had a strong, positive correlation to perceived efficacy, with supervisor attractiveness style being the weakest correlation of all. The analyses failed to find a relationship between supervisee satisfaction levels and perceived self-efficacy. Taken together, these findings suggest that a relationship exists between the style of the supervisor and supervisee perceived self-efficacy when the supervisor assumes a task-oriented style. However, this study suffers from several limitations. As indicated by Fernando and Hulse-Kilacky, self-reports of supervisor styles may have been influenced by supervisee biases towards supervisors. Similarly, the failure to control for potential confounding variables, such as past supervision experience, precludes generalizability of the findings.

In summary, the previous studies consistently demonstrated that the training level, amount of experience, and developmental level of trainees are related to CSE, although the nature of that relationship is still in question. Similarly, the findings suggest that supervisees who are at the doctoral level should have relatively high CSE. The majority of the studies reviewed up to this point examined how the amount of training related to CSE with the inclusion of supervision as a level of measurement. However, it is necessary to also explore how the 
quality of supervision impacts supervisee efficacy levels, not just the amount that trainees receive. The supervisory relationship, also referred to as supervisory working alliance, is considered to form the basis of supervision and to serve as a major impetus to trainee development. In line with this reasoning, the quality of supervision can be explored through the supervisory working alliance.

Supervisory Working Alliance. Initially, 'working alliance' was a psychoanalytic term that was used to denote the relationship between a psychoanalyst and a client. However, Bordin (1979) introduced the term 'therapeutic working alliance' which encompassed all therapeutic relationships, not just psychoanalytic ones. In short, client change was proposed to be a function of the strength of the three aspects that constituted the working alliance: mutual agreement, tasks, and bond. A strong working alliance requires agreement on goals (i.e., mutual agreement), mutual understandings about the nature of the therapeutic tasks necessary to fulfill those goals (i.e. task), and shared feelings of trust, care and fondness (i.e., bond). Later, the working alliance was extended to the supervision of counselors to describe the change process of trainees (Bordin, 1983).

Similar to the proposed aspects of the therapeutic alliance, the supervisory working alliance encompasses mutual agreement on goals, common understanding of the tasks at hand, and the presence of an emotional bond. Given the differing objectives of supervision and therapy, however, the nature of the supervisory alliance is inherently more didactic. The aim of supervision, to promote competency and to help trainees reach professional goals, is reflected in each constituent of the alliance. Goals and tasks are geared towards enhancement of skills and knowledge and similarly, the supervisory bond assumes a more professional quality than the therapeutic bond: "the bonds required in the supervisory alliance typically fall somewhere 
between those of a teacher to class members and therapist to patient" (Bordin, 1983, p. 38).

Bordin indicated that several obstacles impede the development of bonds in supervision, including the evaluative component of supervision, the supervisor's gatekeeping role, and the tension associated with the status difference between supervisees and supervisors. To transform these obstacles into learning opportunities, Bordin maintained that it is necessary to address all three components of the alliance. Furthermore, these obstacles speak to the importance of fostering a strong working alliance: "all of this makes the trust necessary for confronting one's innermost experiences and its impact on a therapy" (Bordin, p. 38). Taken together, Bordin $(1979,1983)$ was the first to offer a working definition of the supervisory alliance and to highlight the impact that these relationships can have on trainee professional development. While more precise and practical than past references to working alliances, this conceptualization is incomplete without the support of empirical research. As if in response to this concern, Efstation et al., (1990) developed a measure of the working alliance, which resulted in a revised definition.

The more recent conceptualization takes into account the social influence process that occurs in supervision. Efstation et al., (1990) defined supervisory working alliance as "that sector of the overall relationship between the participants in which supervisors act purposefully to influence trainees through their use of technical knowledge and skill and in which trainees act willingly to display their acquisition of knowledge and skill” (p. 323). The studies conducted during the construction of the Supervisory Working Alliance Inventory (SWAI) demonstrated support for this definition. The authors found that perceptions of the supervisor and supervisee characterize the working alliance. Their findings indicated that the working alliance can be measured from both supervisor and supervisee perspectives, although the two are not identical. 
Factor analyses demonstrated that supervisors tend to emphasize three components of the alliance (client focus, rapport, and identification) whereas supervisees consider the relationship to be composed of two aspects (rapport and client focus). In brief, client focus refers to the promotion of trainee understanding of clients; rapport reflects supervisor efforts to build a bond through support and encouragement; and identification pertains to supervisor perceptions of trainee identification with them. Efstation et al., (1990) attributed the additional dimension (identification) from the perspective of supervisors to their greater knowledge and experience with the profession. In addition to the provision of an empirically-based conceptualization of the supervisory working alliance, the authors demonstrated that the alliance is a significant predictor of trainee self-efficacy levels. This was also one of the first studies to examine how the supervisory working alliance relates to variables associated with trainee development.

Research on the supervision process as it relates to CSE has demonstrated a relationship with performance feedback, supervisor style (e.g., Holloway \& Wolleat, 1981; Fernando \& Hulse-Killacky, 2005; Friedlander \& Ward, 1984), supervisor self-efficacy, and supervisor behavior (Heppner \& Roehlke, 1984). Even though evidence suggests the supervisory working alliance plays a significant role in fostering supervisee competence and, similarly, that CSE is a significant predictor of supervisee performance, there has been little empirical research on the relationship between CSE and the supervisory working alliance.

Efstation et al.'s (1990) research included investigations into the relationship between supervisory working alliance and counseling self-efficacy. The authors asked training directors from internship programs and graduate programs in counseling and clinical psychology to solicit participation from supervisor-supervisee dyads. Their resultant sample consisted of doctoral level psychologists (supervisors) and students enrolled in professional psychology internship 
programs, counseling psychology programs, and clinical psychology programs. The trainees were all at advanced levels in their training with an average of 5.7 years of experience. All participants completed the Supervisory Styles Inventory (SSI), the Self-Efficacy Inventory (SEI) and the SWAI. Comparisons of supervisor style and self-efficacy to the supervisory working alliance demonstrated positive correlations of the alliance to supervisor styles and to self-efficacy scores. More specifically, hierarchical regression analyses revealed the rapport and client focus of the SWAI to be significant predictors of supervisee self-efficacy. Thus, from these findings it appears that the supervisory working alliance is positively related to efficacy levels of advanced level trainees. Subsequent research, however, failed to replicate this finding.

In his dissertation research, Ladany (1992) examined Bordin's (1983) hypothesis that supervisee perceptions of the supervisory working alliance are predictive of changes in selfefficacy levels and satisfaction with supervision. He predicted that the supervisory working alliance would have a positive correlation with perceived self-efficacy and satisfaction with supervision both before and after controlling for counseling experience. He conducted his investigation on students from counseling psychology programs (58.9\%) and clinical psychology programs $(36.4 \%)$ who were at the doctoral $(71 \%)$ or master's $(29.0 \%)$ level. The training level of the students varied as they were either classified as beginning practicum (29.9\%), advanced practicum (19.6\%), or internship/post-doctorate. None of the participants received individual supervision from their supervisors prior to the study. Ladany asked participants to complete the Working Alliance Inventory - Trainee Version (WAI-T), the Self-Efficacy Inventory and the Trainee Personal Reaction Scale (perceived satisfaction) on two separate occasions. He collected the scores once after three to five weeks of supervision and again after eleven to sixteen weeks of supervision. To determine whether changes in the working alliance subscale scores 
(Goals, Tasks, and Bond) from the first and second test times were predictive of changes in selfefficacy and satisfaction scores, he conducted a multivariate multiple regression analysis. The results indicated that the supervisory working alliance was a significant predictor of the combined scores of perceived self-efficacy and satisfaction levels. More specifically, the findings of univariate multiple regression analyses demonstrated a significant, positive relationship between the bond subscale of the supervisory working alliance and supervisee satisfaction levels.

With respect to self-efficacy levels, the results failed to demonstrate that a significant relationship existed between supervisory working alliance and self-efficacy. Instead, Ladany (1992) found that self-efficacy levels significantly increased over time, which replicated previous research findings that demonstrated a positive relationship between self-efficacy levels and experience. Taken together, Ladany's findings suggest that there is not a significant relationship between CSE and supervisory working alliance.

Another possible explanation, however, may be that the findings of this study are indicative of the limitations of this study rather than the actual relationship between these variables. To begin, Ladany (1992) relied on retrospective ratings of the supervisory relationship. This data collection method in conjunction with the time lapse between ratings increases the chances that other potential moderating variables influenced the scores. For instance, although self-efficacy ratings significantly increased, the author could only conjecture about the variables that may have been related to the change. Also, none of the participants had previous experience with supervision. This severely restricts the generalizability of the results to trainees with any supervision experience. Considering these points, further research was needed to investigate the relationship between trainee self-efficacy and the working alliance in order to 
address the limitations of this study and explain the contradictory findings of previous research (Efstation et al., 1990).

To do this, Ladany et al., (1999) conducted a related study which also explored whether supervisee perceptions of the supervisory working alliance is predictive of self-efficacy levels and supervisee satisfaction with supervision. To control for factors found to account for changes in self-efficacy levels, the authors measured experience levels and observed whether selfefficacy expectations varied with changes in the working alliance at different time intervals. Presupervision self-efficacy expectations were assessed to ensure an accurate estimate of changes resulting from supervision. The participants were enrolled in doctoral and master's Counseling and Clinical Psychology programs whose training levels were beginning practicum, advanced practicum, and internship/post doctorate. Each participant completed a pack of questionnaires once between the third and fifth week of their supervision and once again between the eleventh and sixteenth week of supervision. The completed measures included the Working Alliance Inventory - Trainee Version, the Self-Efficacy Inventory, and the Trainee Personal Reaction Scale. Overall, the ratings from these measures were consistent with Ladany's (1992) earlier research.

More specifically, supervisory working alliance had a significant, positive correlation with trainee satisfaction levels whereas no such relationship emerged with trainee self-efficacy. In other words, when the emotional bond between the supervisor and supervisee strengthened, the trainees' perceptions of their supervisory experience and themselves improved: "[W]hen the emotional bond was viewed as becoming stronger over time, trainees also perceived their supervisors' personal qualities and performance more positively, they judged their own behavior in supervision more positively, and they were relatively more comfortable in supervision" 
(Ladany et al., 1999, p. 452). Although the participants' self-efficacy levels changed significantly over time, the findings indicated that trainee experience level was not the reason for this change. In other words, experience level and self-efficacy levels were not significantly related. Taken together, these results contradict Efstation et al.'s (1990) findings that a positive, significant relationship exists and instead suggest that there is no such relationship. However, it is important to note that Ladany et al.'s attempt to control for potential moderating variables was unsuccessful: the experience level of trainees did not explain the increase in efficacy levels. Because of that, interpretations of the results are inappropriate since other unknown variables may have influenced the results.

Prior to Ladany et al's (1999) study, Strauss (1994) conducted dissertation research to investigate the relationship between supervisory factors and CSE factors. In particular, Strauss studied the five common supervisory factors found in Bordin (1983), Efstation et al. (1990), and Friedlander and Ward's (1984) supervision theories: task-oriented, interpersonally sensitive, attractive, client focus, and rapport. He explored the relationship among these factors to the five self-efficacy factors that are assessed in the COSE: microskills, attending to process, handling difficult client behaviors, cultural competence, and awareness of values. Strauss recruited participants from a master's level counseling program. All students were enrolled in their first practicum class and received weekly group supervision. Individual supervision was provided two times over the course of one semester by the same supervisor who provided group supervision.

To obtain measures of self-efficacy and supervisory factors, Strauss (1994) administered the COSE, the Supervisory Styles Inventory (SSI), and the Supervisory Working Alliance (SWAI) to the participants nine weeks after the semester began. Strauss reasoned that this time 
frame allowed the students time to be exposed to at least two clients and one individual supervision session. A total of 69 students completed the study. Participants' ratings of these factors produced significant findings.

Specifically, Strauss (1994) found that four self-efficacy factors had a significant, positive relationship to two of the supervisor factors. The trainees' perceived competence levels with respect to using microskills, attending to process, dealing with difficult client behavior, and cultural competency were positively related to supervisor emphasis on understanding of clients (client focus) and on content (task-oriented). Although none of the relationship factors (attractive, interpersonal sensitivity, and rapport) were significantly related to self-efficacy factors, the author pointed out that these factors were moderately skewed. That is, all supervisors were perceived as supportive and trustworthy.

To that end, it could be that relationship factors would have demonstrated a stronger correlation if this element of the relationship was not as common. This corresponds with an underlying premise of SCMCT, that the context of the relationship (e.g., support) influences the extent to which trainees are open to social learning experiences, such as feedback concerning client conceptualization or content related material (Larson, 1992). Strauss, however, came to a different conclusion regarding this finding. He maintained that a focus on client and content in supervision was more highly valued because this provided more opportunities for trainees to experience mastery. Similarly, Strauss referred to Bandura's $(1982,1986)$ assertion that "supportive and persuasive comments offered by supervisors would not enhance self-efficacy unless the individual actually experienced performance accomplishments" (p. 128). However, none of the participants of this study had more than one individual supervision session with their supervisors, which is an insufficient amount of time to develop a supervisory bond. Taken 
together, the lack of adequate exposure to supervisory relationships makes it inappropriate to rely on supervisee insight of the importance of an emotional bond with supervisors. Furthermore, the generalizability of these findings are limited by homogeneity of the sample with respect to ethnicity (Caucasian), gender (female) experience (0 to 2 clients), supervision experience (half a semester) and graduate level (masters). Although these limitations make it difficult to draw any valid inferences, the similarities of these findings to previous research (Efstation et al., 1990) necessitated further investigations into the relationship between the working alliance and CSE.

Dissertation research conducted by March (2005) provided mixed findings with respect to the relationship between self-efficacy and the supervisory working alliance. The primary purpose of the study was to investigate the relationships among supervisee self-efficacy, the supervisory working alliance and supervisee self-disclosure in counselor education students. The participants had all completed at least one semester of supervised practicum or internship and their counseling experiences ranged from 100 to 1000 internship or practicum hours. Measures of self-efficacy and the supervisory working alliance were the COSE and the WAI-T, respectively. A measure of self-disclosure was developed specifically for use in this study, the Intern Self-Disclosure Questionnaire (ISDQ). However, the use of this questionnaire produced slight complications.

Due to the frequency of 'Not Applicable' (NA) responses to half of the items on the selfdisclosure questionnaire, March (2005) deleted items with the most NA responses and obtained a new Cronbach's coefficient. The researcher found that 32 out of the 71 participants responded to 17 items without selecting NA. This finding led March to use two separate forms of the ISDQ, a 34-item ISDQ and a 17-item ISDQ. Identical analyses were conducted on both samples, which consisted of the original 71 participants (34-item ISDQ) and the 32 participants (17-item ISDQ). 
It was on account of these two separate samples that March's (2005) study produced opposite findings. Linear regression analyses on the original sample indicated that the combination of self-disclosure and supervisory working alliance explained a significant amount of variance of supervisee self-efficacy. The two variables were positively correlated to selfefficacy levels. When the same analyses were performed on the revised sample $(n=32)$, the results failed to demonstrate a significant relationship among the three variables. On the other hand, similar to findings from the original sample, self-disclosure and working alliance were positively correlated with self-efficacy. With respect to self-disclosure and self-efficacy, the results of linear regression analyses failed to demonstrate a significant relationship for both samples although further analyses revealed a negative correlation for both data sets.

To determine how much influence the supervisory working alliance had on selfdisclosure and self-efficacy, March (2005) conducted partial and correlation analyses. The results from both the original and revised sample demonstrated a significant, negative relationship between self-disclosure and self-efficacy. That is to say, greater levels of selfefficacy led to significantly less self-disclosure by trainees. To explain this finding, March posited that increases in supervisee confidence levels may also lead to a false sense of competence which, in turn, would cause supervisees to perceive disclosures or discussions of counseling related issues as less important or even unnecessary. With respect to supervisory working alliance and self-efficacy, a significant, positive correlation emerged from the original sample whereas the revised sample's findings revealed an insignificant, positive relationship. To account for previous research findings and the deletion of items that frequently elicited the "not applicable' response, March (2005) concluded that the results from the revised sample may be a more accurate depiction of the nature of the relationship. 
Such conclusions are inappropriate, however, given the limitations of March's (2005) study. March failed to provide evidence for the validity of the self-disclosure questionnaire. Although he indicated that face validity was determined, there were no reports to substantiate this claim. Furthermore, although item responses demonstrated strong internal reliability, with Cronbach's coefficient alphas of .88 and .91 , these estimates were based on the participants' responses in the current study, and no reliability estimates existed beforehand. The self-report measures of supervisees may have further weakened the validity of the results since participant responses could have portrayed themselves in a positive light to the researcher. In addition, March's (2005) sample consisted solely of counselor education students, thus restricting generalizability of these results to supervisees enrolled in different but similar programs.

Lastly, March's (2005) conclusion that the revised version of the ISDQ questionnaire was "a more accurate reflection of reality" is unfounded (p.70). Without information regarding the validity of the measure, it is inappropriate to make conclusions about the relationship between supervisee self-disclosures and self-efficacy or supervisory working alliance. There is no way to determine which of the two datasets best represents supervisee experience. With that said, the contradictory findings regarding the relationship between self-efficacy and the supervisory working alliance warrants further investigation. Provided that supervisee non-disclosure is considered to be a form of impression management, the unexpected negative relationship between self-disclosure and self-efficacy offers some insight into how impression management strategies might correlate with CSE.

Humeidan (2002) sought to clarify the relationship between counseling self-efficacy and the supervisory working alliance by including another variable, social influence, in his investigation. He hypothesized that supervisory working alliance and perceptions of supervisor 
social influence would be significant predictors of CSE. For the most part, participants were enrolled in counseling psychology programs (92\%) and were either master's level students $(47 \%)$ or doctoral level students $(51 \%)$. The duration of supervisory relationships at the time of the study ranged from one to 24 months and counseling experience ranged from one to four years. Humeidan asked participants to complete the Supervisor Rating Form - Short Form (SRF-S), the COSE, the SWAI-T, and a supervisory descriptor form developed specifically for use in this study.

Humeidan's (2002) dissertation research findings demonstrated support for his hypothesis. Correlational analyses revealed a positive relationship of CSE to the supervisory working alliance and to experience level and, likewise, a positive correlation emerged between supervisory working alliance and social influence. In other words, supervisees who reported higher levels of CSE also reported a strong working alliance. Similarly, supervisees who indicated that they had strong working alliances with their supervisors also perceived their supervisors as having a significant, positive influence on them. Neither counseling self-efficacy nor experience level demonstrated a relationship to social influence and no relationship was found between supervisory working alliance and trainee experience level. Hierarchical regression analyses indicated that supervisory working alliance, perceptions of social influence, and experience level were each significant predictors of counseling self-efficacy. Likewise, the combined effect of all three variables emerged as a significant predictor of CSE, with the working alliance as the strongest predictor. The results of this study suggest that supervisory working alliance and self-efficacy are related and therefore, should be taken into consideration when investigating supervisee confidence in their counseling-related abilities. 
However, an exploratory study that examined the relationship of supervisory working alliance and CSE to supervisee development did not produce similar results (Mirgon, 2007). The secondary purposes of this dissertation research were to investigate the relationship between the supervisory relationship and CSE and to study the convergent and predictive validity of the Supervisory Working Alliance Inventory-Trainee Version (SWAI) and Supervisee Levels Questionnaire-Revised (SLQ-R). Mirgon administered the COSE, the SLQ-R, and the SWAI to current students and graduates of master's counseling programs. The participants were practicum students, internship students, post-internship counselors or licensed counselors. Based on the results of the discriminant function analysis, the author concluded that there were three trends within the data: counselor skills and confidence, supervisor helpfulness, and rapport with supervisor. Correlational analyses demonstrated moderate to strong, positive relationships among the subscales of the SLQ-R and the COSE, thereby indicating a correlation between developmental level and CSE and demonstrating excellent concurrent validity between the two measures. On the other hand, the findings failed to reveal a significant relationship between supervisory working alliance to developmental level or to self-efficacy. It is likely that Mirgon's findings were influenced by the restricted sample; all participants were enrolled in the same master's program from a medium sized university located in the southwest. Therefore, the findings cannot be generalized to students enrolled in programs that are part of larger or smaller universities; in a different location; or are of the doctoral level.

Smothers (2010) attempted to reconcile the discrepant findings by exploring whether the supervisory working alliance would be related to CSE when supervisee attachment styles were taken into account. Put another way, the author investigated how supervisee attachment style influences the supervisory working alliance and, in turn, how the alliance then impacts CSE. 
Using the Experience in Close Relationship Scale (ECRS), the WAI-T, and the COSE, Smothers assessed the attachment style, working alliance, and self-efficacy levels of master's and doctoral level students. The majority of the students were enrolled in APA-accredited counseling psychology programs (54\%) from universities across the country. The length of supervision relationships were either less than one semester (38\%) or two to five or more semesters $(62 \%)$. Smothers asked the training directors of the universities via email to forward an invitation to participate to the current students. The participants completed the measures through an online website.

Overall, Smothers's (2010) study corroborated previous research that implied a relationship existed among the proposed variables. The author hypothesized that years of graduate training would be significantly related to CSE and, as predicted, a significant difference emerged between CSE and training. Fourth year doctoral students reported the highest efficacy levels followed by fifth, third, second, first and pre-doctoral level students, in that order. Similarly, greater levels of experience reflected greater CSE. The results of the structural equation model indicated that attachment styles (avoidant and anxious) influence counseling self-efficacy levels through the supervisory relationship. Put another way, the bond and task components of the supervisory alliance mediates the relationship between attachment styles and CSE.

With respect to the relationship between supervisory alliance and CSE (separate from attachment styles) only the supervisory task was found to significantly predict; a positive correlation emerged. In other words, the perceived supervisory task appeared to facilitate higher levels of CSE, which offered partial support for the proposed relationship. This contradicted 
previous findings that the perceived bond between supervisor and supervisee is significantly related to CSE.

Smothers (2010) posited that the relationship is better accounted for by supervisee attachment styles; however, the methodology of this study (data collection at a single point in time) makes causal inferences such as this inappropriate. With that said, it appears that a relationship between CSE and supervisory working alliance exists, but the extent of that relationship still remains unclear. Furthermore, the use of self-report measures and homogeneity of the sample with respect to gender (female) and ethnicity (Caucasian) in this study limit the generalizability of findings. Therefore, it is unclear as to whether other supervisees would rate their experiences similarly to the participants of this study.

In summary, both theoretical and empirical research has highlighted the importance of the supervisory working alliance on supervisee professional development. However, what is less clear is the relationship between the supervisory working alliance and CSE. On one hand, there appears to be a significant, positive relationship and on the other, no relationship at all. Due to the numerous limitations of the studies (e.g., methodology, sample, different measures of CSE), it is impossible to conclude that one finding is a more accurate depiction of the relationship over another. To add to that, the majority of the studies are dated; all but one study was conducted prior to the year 2003. Given that both of these variables have been related to the use of impression management, an understanding of the nature their relationships would provide useful information. However, it is important to first review the theoretical background of impression management. 


\section{Impression Management Theory}

Impression management is a relatively new construct; its conception can be traced back

to only as late as the1950s. Impression management derived from ideas that formed the basis of symbolic interactionism. Symbolic interactionists proposed that behaviors carry symbolic meanings that influence how others respond to individuals (Cooley, 1902; Mead, 1934). Erving Goffman (1959) was the first to propose that individuals strategically manipulate behaviors to convey specific meanings to others and, likewise, interpret others' behaviors as a reflection of the self and of the perception others form of them. Using theatrical performance as a metaphor for social interactions, Goffman (1959) applied the principles of these theories to analyze interpersonal relationships. His theory on the nature of self-presentation became the theoretical foundation for research on impression management thereafter. Subsequent research demonstrated support for impression management theory which, in turn, produced more studies that led to additional, in-depth explanations of impression management. Script theory and attributional theory, for example, have contributed to knowledge regarding how and why individuals engage in impression management (Schlenker, 1980).

Goffman. Through a dramaturgical analysis of interpersonal relations and interactions, Goffman (1959) demonstrated that behaviors within social settings reveal how individuals wish to be perceived and treated. Using qualitative methods, he devised classifications for the various elements of social encounters and framed these elements in terms of a theatrical performance. He labeled individuals in social encounters according to the analogous parts they would play if they were at a play. That is, individuals who manage impressions would be the actors, or performers, whereas the individuals to whom the impressions are targeted would be the audience. 
Goffman (1959) suggested that all individuals use impression management to convey the meaning of their actions and to express their identity to others. He claimed that the transmittance and acceptance of impressions is essential for social interactions to flow smoothly. Individuals are hypothesized to act out a line, which is "a pattern of verbal and nonverbal acts by which [they express their] view[s] of the situation and through [their] evaluation[s] of the participants, especially [themselves]" (Goffman, 1967, p. 5). To Goffman, the question of whether individuals intend to act out a line is irrelevant. He asserted that a performer's involvement in a social interaction implies that a stance has been taken. "The other participants will assume that he has more or less willfully taken a stand... if he is to deal with their response to him he must take into consideration the impression they have possibly formed of him" (Goffman, 1967, p. 5). Thus, others ascribe particular images to persons based on the impressions that are emitted, and performers in turn lay claim to the positive values associated with the respective roles. Goffman also suggested that individuals associate themselves with these images by putting on a face, or mask. He used the term "face" to refer to the espousal of images portrayed in social interactions: "Face is an image of self delineated in terms of approved social attributes - albeit an image that others may share" (Goffman, p. 5). All participants in social interactions seek to maintain face and to act out their respective lines because not to do so would break the natural progression of social interactions.

Goffman's (1959, 1961a, 1961b, 1967; 1971, 1974) view of impression management rests on several fundamental suppositions (Branaman, 1997). First, he maintained that the self is formed through social interactions. In other words, the self is a product of public performances that are accepted and validated by others. Through performances individuals make public claims about the self and, in turn, public validation of the respective claims leads individuals to integrate 
these claims as a valid conception of the self. Individual performances are hypothesized to be constrained, however, in deference to ones that are consistent with their respective social statuses and roles in society. Failure to be constrained decreases the likelihood of public validation.

In that same vein, impressions are limited by the constraints of reality. That is, personality traits, physical attributes, and personal possessions must be consistent with the portrayed image to be accepted by others. Highly valued images, as accorded by societal standards, are not always attainable. For instance, individuals may value education but not have the access to the necessary resources to obtain an education. In addition to resources, individual claims are restricted to images associated with the respective roles, statuses and relationships. Adherence to the societal expectations of the performer self serves to maintain the ritual order of social life, and in turn individuals are able to 'maintain face.' Acceptance and validation of others' claims further promotes the maintenance of face; this establishes a norm of reciprocity in which individuals work under the understanding that each will support the other's claims. This unspoken agreement, and therefore social order, is strengthened by adherence to social norms. With that said, Goffman (1961b) also emphasized the tendency to act in ways that will bolster self-esteem and noted that if an opportunity arises, then this tendency will take precedence over maintaining the status quo (Branaman, 1997).

Another key element the dramaturgical theory seeks to explain is why individuals engage in impression management. In line with this view, individuals are driven by the desire to act according to moral values and by the desire to manipulate others. According to Goffman (1959), these drives cannot be examined independently because a reciprocal relationship exists between the two. On one hand, Goffman recognizes that humans tend to be concerned with upholding the moral standards of society. When this is the case, concerns arise out of the social self. However, 
individuals are not necessarily concerned with acting in ways to uphold the moral standards; rather, the greater emphasis is placed on giving off an impression of morality (Goffman, 1959). Goffman's (1959) depiction of the nature of social life therefore entailed constant vacillations between morality and manipulation. Like the self, morality is presumed to be a product of social life; customary social exchanges function as an affirmation of the innate right to respect and to ethical treatment. These very social rituals that bolster the moral principles governing society are preserved through face-work, that is, through manipulation of impressions. Even when individuals are driven by internal standards of morality, to fulfill these standards they must give off the impression that they are moral and help others to do the same. Therefore, individuals claim images of morality through self-enhancement and manipulation and can be driven by the desire to benefit the self, others or society as a whole.

Lastly, Goffman (1974) proposed that the meaning of social experience depends on the frame, which is the context of social events. The frame gives significance to events by placing them into context which then gives meaning to the activity, that is, to all of the impression management related activity (Branaman, 1997). It is important to know that how social experiences are framed not only gives meaning to performances but defines the identities of the performers as well. These identities are social, and social structures and social organizations, however, strongly influence the framing of social experiences (Branaman; Goffman). The images associated with socially constructed variables, such as gender and class, are predefined by societal standards, and assumptions about others based on social constructs also frame individual experiences in social interactions. Experiences can contradict these assumptions, however, and influence social structures. Taken together, Goffman theorized that the overall 
context of social experiences guides how those experiences will be interpreted by performers and audiences alike.

Furthermore, he held that individuals use impression management as a means to construct their identities. The assumption is that the audience's impressions of the performers become a reality for the audience, and therefore, a reality for the performer. Individuals enact multiple roles with their audiences through the masks, or faces, they wear when in the company of different audiences and in different contexts. Successful portrayals of favorable images are integrated and failed ones are discarded. Likewise, unfavorable images can also become integrated, such as when individuals consistently fail at eliciting a favorable impression. For the most part, however, individuals work to maintain a consistent mask across similar types of encounters (Goffman, 1959).

There are two certain conditions that make impression management possible. The first condition applies to the individual level: the motivation and impetus that drives individuals to impression manage. The second condition applies to the dynamics between persons, which is also the condition that makes it possible for individuals to maintain face in social interactions.

In Goffman's (1959) view, all participants in a social interaction seek to maintain equilibrium and operate under the assumption that others share the same intention. In line with this view, all interactions are governed by an implicit agreement that each will help the other to maintain the desired face. Individuals rely on others to cooperate with them and enter social situations prepared to support each other's performances. On account of this approach to interactions with others, individuals are thought to be generally successful in their endeavors. Goffman indicated that individual awareness is oriented towards others and towards the self, which he labeled as defensive and protective orientations, respectively. An individual assumes 
"a defensive orientation toward saving his own face and a protective orientation toward saving the other's face" (Goffman, 1959, p. 216). In sum, individuals not only manage impressions but are also respectful and accepting of the impressions that others wish to elicit in them.

In line with the dramaturgical perspective, two components drive the dynamics of relationships. First, by force of circumstance, relationships are upheld through individuals establishing a reciprocal dependence. Individuals maintain relationships with one another by supporting their roles in performances and by engaging in complementary roles. In other words, performers are able to form and maintain relationships because they are each able to trust that the other will respect their chosen performance (definition of the situation). Second, participants in a relationship cooperate with one another to perform for an audience. Since each recognizes that together they are putting on a performance for others (audience), they also acknowledge that they cannot put on that same performance for one another. Goffman (1959) labeled this component reciprocal familiarity and described it as "a kind of intimacy without warmth... a formal relationship that is automatically extended and received as soon as the individual takes a place on the team" (p. 83). In sum, both components are essential for relationships to survive. Reciprocal dependence allows respect to develop and reciprocal familiarity enables empathy and acceptance to occur.

Just as individual roles can vacillate between performer and audience, individuals can also consider themselves and imaginary others to be their audience. Thus, performer and audience can be one in the same. For example, when individuals come to believe performances they previously questioned, their newly acquired self-beliefs can lead them to act in ways that are consistent with these beliefs in the absence of others. While beliefs regarding the self often guide presentations to the self, Goffman (1959) suggested that the internalization of societal 
values and social norms of propriety also leads to private performances. "When a performer guides his private activity in accordance with incorporated moral standards, he may associate these standards with a reference group of some kind, thus creating a non-present audience for his activity" (Goffman, 1959, p. 81). In this case the audience is referred to as an imagined audience. The idea is that through socialization into the dominant culture's norms, individuals come to understand the rules of conduct, whether they pertain to the law, morality, ethics, or etiquette. Similarly, Goffman (1967) later indicated that "the rules of conduct transform action and inaction into expression and whether the individual abides by the rules or breaks them, something significant is likely to be communicated" (p. 51). Thus, when dealing with others, imaginary or real, there are implicit rules of conduct regarding how individuals should relate with one another. Awareness of who comprises the audience offers insight into the behaviors of performers, but social exchanges are best understood when the context of the interaction is also taken into consideration. According to Goffman, it is impossible to understand the structure of social interactions among characters without taking into account the context of the exchange.

Just as individuals change their ways of relating when they interact with different persons, they also change their goals. Thus, actors' goals and social performances change to fit the situation and the audiences with whom they interact. It is important to note, however, that individuals differ as to whether they adjust their performances according to the audience's reactions. For some, the audience's reactions have a direct impact on subsequent behaviors. These individuals closely monitor the audience's reactions and then incorporate this feedback as a means to determine how they should proceed. Other individuals' performances, however, are based on personal estimations of which behaviors will portray the desired images, regardless of 
others' responses to them. According to Goffman (1959), the goals of performers are best understood when the performers 'definition of the situation' is identified.

Performers elicit favorable impressions by impressing their definition of the situation onto their audiences. When individuals define the situation they succeed in conveying their conceptions of the self, the audience, and the ethos that governs the rules of decorum and politeness. These self-presentations provide information about the self which, in turn, serves as a guide for others. To illustrate, individuals communicate their views of themselves, their evaluations of others, and their personal definitions of the situation to one another. If by these means they control the definition of the situation, individuals succeed in conveying how they expect to be perceived and treated and, similarly, how they intend to treat others:

$[\mathrm{C}]$ ontrol is achieved largely by influencing the definition of the situation which the others come to formulate, and [the performer] can influence this definition by expressing himself in such a way as to give them the kind of impression that will lead them to act voluntarily in accordance with his own plan. (Goffman, 1959, pp. 3 - 4)

In line with this view, a key component of impression management clearly involves controlling the definition of the situation; it influences both the roles of the actors and the impressions made on the audiences. The definition of reality is established through a continuous series of negotiations in which performers accept or reject others' portrayals within a given performance.

In sum, the types of impressions individuals portray depend on a complex interplay between the characteristics of the person, the people or images with whom they interact, and the particular situations in which they perform. In line with Goffman's (1959) theory, impression management is present in all interpersonal dealings and operates through an implicit agreement among the participants in the interaction. Similarly, relationships are maintained through 
reciprocal dependence and reciprocal familiarity, allowing for social interactions to flow smoothly. To elicit a particular impression, individuals associate their personal images with the symbolic meanings attached to the setting. They make their appearance consistent with the desired image, and they act in a manner that will confirm that image. In so doing, individuals strive to impress upon others their definition of the situation. That is, they convey their view of reality and how others should perceive and treat them. To define the situation, according to Goffman's (1959) theory, is to manage impressions.

Definitions of Impression Management. In the literature, the terms "impression management" and "self-presentation" are either used interchangeably (e.g., Jones \& Pittman, 1982) or are referred to as separate but related constructs (e.g., Leary, 1996; Schlenker, 1980). In most cases, references to impression management are drawn from a comprehensive definition that covers all attempts to control others' perceptions. Self-presentation, on the other hand, refers most often to a specific form of impression management; it refers to attempts to control information directly related to the self. Thus, impression management represents all attempts to control impressions, regardless of the content of the information controlled, whereas selfpresentation concerns only the presentation of the self. So for purposes of this literature review, the terms will be treated as separate constructs. The separate definitions are more suitable than a single, generic definition for both concepts because they provide greater clarification and are generally considered to be separate terms within the impression management literature.

A generally accepted definition of impression management is that it is the attempt to control the type of information conveyed about the self, an idea, an object, or an event (Goffman, 1959). However, there is little consensus regarding the nature and scope of impression management. Two perspectives are presented throughout impression management research. 
Depending on which perspective is adopted, the construct is either depicted as a ubiquitous and natural part of the interpersonal process or as a manipulative and deceitful control strategy employed by certain types of individuals. More specifically, there is disagreement in the literature concerning whether the use of impression management is genuine or egoistical, and whether it is ubiquitous.

Impression management has been conceived both as a social behavior that occurs under limited conditions (Buss \& Briggs, 1984; Jones \& Pittman, 1982) and as a permanent underlying feature of social interaction (Goffman, 1959; Leary, 1996; Schlenker, 1980; Schlenker \& Weigold, 1992; Schlenker \& Pontari, 2000; Silver \& Schlenker, 1981; Snyder, 1983). These separate viewpoints are related to factors attributed to increased self-awareness and the motivation to manage impressions (e.g., personality or environmental factors). In line with Schlenker and Weigold's description, these viewpoints are best categorized as restrictive and expansive positions.

Researchers who argue in favor of a more restrictive view of impression management suggest that there are specific situational and personality variables that lead to impression management. To illustrate, Buss and Briggs (1984) suggested that impression management occurs only when the following conditions are present: extrinsic rewards are dependent on individual performance, such as a positive evaluation; the formality of the setting requires decorum; and individuals are the center of attention. These authors also argued that certain personality characteristics (shyness, public self-consciousness, and self-monitoring) increase the likelihood that individuals impression manage under these conditions. Jones and Pittman (1982) expanded on these specifications and listed conditions unlikely to evoke impression management, including the following: intellectual tasks that demand undivided attention; 
preoccupation with emotional arousal; customary social exchanges that are habitual; and intimate relationships. Based on these parameters, impression management can be hypothesized to be elicited only under specific conditions and by individuals who are characterized as self-monitors, self-conscious, and shy.

Those in favor of an expansive view, on the other hand, argue that impression management cannot be conceived of as a behavior that occurs under limited conditions until impression management related behaviors are differentiated from non-related ones. This is a noted limitation of the restrictive position (Schlenker and Weigold, 1992; Schlenker \& Pontari, 2000). As Schlenker and Pontari pointed out, these categories (expansive and restrictive) help to specify factors that are indirectly related to impression management, such as motivation and selfawareness. Thus, impression management cannot be separated from social interactions; it is a ubiquitous feature of interpersonal exchanges.

In contrast to the restrictive view, the amount of attention paid to impression management concerns is hypothesized to determine the nature of the image presented. Attention, according to the expansive view, is directed towards relevant concerns when self-awareness is heightened. Increased awareness is hypothesized to occur for multiple reasons, including evaluative conditions and lessened confidence in one's ability to successfully execute a given task. Consistent with the restrictive view, attentional direction towards impression management reflects a personality trait; when individuals have low levels of self-consciousness, they are unlikely to impression manage because their attentions are not geared towards making specific impressions. The expansive view, however, argues that attention only influences whether impression management behaviors are conscious or unconscious acts (Schlenker, 1980). 
To emphasize this point, researchers who take the expansive perspective have distinguished between conscious and unconscious regulations of impressions. For instance, Schlenker and Weigold (1992) labeled impression regulation as the "goal-directed activity of controlling information about some object or event, including self" and impression management as the actual behaviors employed to regulate the information (Schlenker \& Weigold, p. 138). Impression regulation requires self-awareness, motivation to manage impressions, and conscious effort. The absence of impression regulation implies a lack of conscious awareness, not the absence of impression management. Likewise, Leary and Kowalski (1990) proposed that two separate processes, impression motivation and impression construction, underlie selfpresentational behaviors. Impression motivation is the desire to create a specific impression of the self in others' minds and involves processes that lead to a heightened awareness of others' perceptions and increased motivations to control those perceptions. Impression construction involves the processes used to determine which impressions will be portrayed.

In sum, there are two opposing views on the role of self-awareness and attention in impression management. One viewpoint asserts that attention towards impression management is a function of individual makeup while the other maintains that impression management occurs regardless of whether individuals are self-conscious; awareness only impacts the degree to which individuals are motivated to make impressions and the types of impression that are made.

The expansive and restrictive positions also reflect differences of view regarding the authenticity of impression management. On one hand, impression management is regarded as deceitful (Buss \& Briggs, 1984; Jones \& Pittman, 1982) while on the other hand the genuineness of presentations is recognized as existing on a continuum. Honest and dishonest presentations are likely to take place in social interactions, for example (Baumeister, 1982; Goffman, 1959; 
Schlenker, 1980; Schlenker \& Weigold, 1992). With that said, the expansive view holds that most conscious attempts to impression manage are intended to portray accurate, consistent images of the self (Leary, 1996; Schlenker, 1980). Only on rare occasions will the portrayals be outright deceptive or exaggerations of the truth. Rather, individuals seek to portray themselves according to their self-view, although this changes depending on the types of person in the social exchanges and on the circumstances (Leary; Schlenker, 1980,1992; Silver \& Schlenker, 1981). For example, the desire to manage others' impressions and responses toward them results in different behaviors than those guided by values and beliefs.

Arguments concerning the veracity of impression management are related to hypotheses regarding the motivations associated with it. If impression management is deceptive then it follows that there must also be self-serving, mal-intentions. Advocates of the restrictive view propose that individuals manage impressions only for self-serving reasons, such as to gain power and control over others or to get specific personal wants and needs met (Buss \& Briggs, 1984; Jones \& Pittman, 1982). On the other hand, when impression management is regarded as an inherent part of social life and, in general, as authentic then it is hypothesized to be related to both personal gain and/or the benefit of others (Goffman, 1959; Leary, 1996; Schlenker, 1980; Schlenker \& Britt, 1999; Schlenker \& Pontari, 2000; Schlenker \& Weigold, 1992; Silver \& Schlenker, 1981). The latter view, that of benefitting others, was initially proposed by Goffman in his preliminary discussions regarding impression management. He indicated that individuals help others to 'save face' when others are faced with a threat to their identity or are in the midst of an embarrassing situation. In line with the expansive view, then, concerns about the self and others are both possible explanations for the use of impression management. 
Similarly, the expansive viewpoint holds that the self is not merely a product of social life; rather, the self is thought to play an integral part in determining social behaviors. In particular, self-concepts, categorizations of the self (self-constructs) and beliefs in the self to successfully carry out behaviors (self-efficacy expectations) influence the use of impression management:

The images people have of themselves shape and are shaped by social interactions. If we know what people think about themselves, how they evaluate their attributes, and what they believe they can accomplish given their attributes and the situation, we can make predictions about how they are likely to present themselves to others, we can sometimes make inferences about what they privately think of themselves. (Schlenker, 1980, p. 47) Therefore, social experiences influence the self through reflected appraisals and comparative appraisals. Reflected appraisals are perceptions of others' impressions of the self which, in turn, are integrated into the self-view. Likewise, comparative appraisals are comparisons of the self in relation to others that offer information about the self relative to others. On account of social experiences individuals categorize and evaluate themselves which then influences their selfconcepts. Taken as a whole, the self influences social behaviors, especially those motivated by impression management concerns, and likewise, social experiences influence the self. In sum, theorists and researchers are divided in their views on whether impression management can be regarded as a pervasive part of social life, on whether it is a genuine or deceptive attempt to portray the self, and on whether it is a behavior that reflects purely selfish motives or both selfserving and pro-social motives.

In this paper, impression management is defined according to the expansive view. The reason is that impression management is an inherent part of social interactions involving both 
genuine and inauthentic portrayals of the self and guided by either selfish or altruistic intentions. The restrictive view recognizes only impression management strategies related to inauthentic self-portrayals that are motivated by selfish intentions. Consistent with the expansive view, moreover, the factors hypothesized to influence individual sensitivity to the impressions that others form include factors other than intention, such as increased levels of awareness and attention, as well as motivation to manage impressions. The expansive perspective maintains that the relationships among environmental factors, internal processes, and the actions of the self and others play an important role in the use of impression management. That is, impression management cannot be reduced to a single determining factor, such as personality traits.

For these reasons, the expansive perspective best corresponds with Bandura's (1986) Social Cognitive Theory (SCT), a theory that has proved to be applicable to counseling psychologist trainees (Larson, 1998). Compatible with SCT, the expansive perspective makes it possible to treat supervision as the environmental factors, qualities such as self-efficacy, selfawareness and motivation as internal processes, and the relationship between the supervisor and the supervisee as actions of the self and others. Social Cognitive Theory and the expansive view show the role all these factors can play in use of impression management.

\section{Impression Management Research}

Impression management had negative implications for research until theoretical revisions proved it to be a viable construct that was capable of offering insight into the human condition. Initially regarded as a nuisance variable in research, such as when participants responded in socially desirable ways, researchers took measures to eliminate it. At that time, given its association with Machiavellian power schemes, this concept was of interest only to politicians, advertisers and business persons (Schlenker \& Weigold, 1992). Since the 1980s, however, 
different conceptual analyses provided a new outlook (Schlenker, 2003). The earlier, restrictive view of impression management was evidenced by studies that explored ingratiating behaviors (Jones, 1964) and manipulation tactics (Buss \& Briggs, 1984). These studies were the first to corroborate some of Goffman's assertions. There is no question that Goffman's theoretical propositions were a novel and invaluable source of information; however, his narrative essays were limited to his personal observations and anecdotal accounts. Thus, his theoretical propositions lacked the objectivity and exactness that scientific research demands.

This missing component was first addressed by Jones et al. (1963), whose seminal research on the nature of self-presentations produced the first empirical evidence to support the existence of impression management. These researchers' use of objective measures and controlled studies allowed for replication and therefore, validation of the proposed constructs. Leary (1996) asserted that "Goffman tried to persuade his readers... whereas Jones tried to "confirm and disconfirm particular theoretical ideas through controlled experimentation" (p. 8). Subsequent research uncovered factors that determined different types of self-presentations. Such factors included, but were not limited to, social status, interpersonal goals, personal expectations of future interactions, others' evaluations, and feedback (Leary, 1996). With the expanded ability to connect self-presentations to these and other factors, impression management theory proved to be valuable in understanding social phenomena (Jones \& Pittman, 1982; Leary, 1992; Schlenker \& Pontari, 2000; Schlenker \& Weigold, 1992). Consequently, this area of research began to be investigated by other professional domains, including clinical and counseling psychology (Leary; Leary \& Miller, 1986).

Numerous studies focused on providing evidence that impression management is a legitimate construct and a valid topic for future research. As a result, there are now four general 
areas of research on impression management (Leary, 1996). One area of research establishes a relationship between impression management and social behaviors. A second area focuses on motivations underlying impression management. Studies in this area are based on the assumption that behaviors are related to impression management concerns. A third area concerns factors that influence the types of impressions that individuals aim to elicit. Not to be confused with the second body of research, this area of research does not examine 'why' individuals impression manage, but rather, what causes individuals to choose certain impressions over others. The fourth and final area examines the impact that impression management related concerns have on individuals, both emotionally and behaviorally. In particular, this area addresses the negative impact of impression management concerns on affect and behaviors.

The concerns of this paper are centered on, and intended to add to the second area of research mentioned above, motivations underlying impression management. The review that follows covers studies that fall into this category, in particular studies that offer insight into the relationship between impression management and the supervision of upcoming counseling psychologists. More specifically, consideration will be given to research relating to supervisee use of impression management, CSE, and the supervisory working alliance.

\section{Supervisee Impression Management}

Conditions specific to supervision, evaluation, status hierarchy (power differential), and dependency have a tendency to heighten concerns with self-presentations (Jones et al., 1963; Jones \& Pittman, 1982; Schlenker \& Leary, 1982). Concerning supervision, a supervisor's impressions of a supervisee will, in part, determine the supervisee's passage into the profession. According to impression management theory, when individuals believe that important outcomes 
(including entry into the counseling psychology profession) rest on others' perceptions, they will be more motivated to manage those impressions (Jones \& Pittman; Schlenker \& Leary).

Similarly, impression management motivations also increase when others are perceived to be experts, high in status, or powerful (e.g., supervisors) because their opinions are perceived to have more value (Schlenker \& Leary, 1982). Impression management is especially likely to occur in relationships in which a power differential exists, as in the supervisory relationship. Jones and Pittman (1982) even described impression management as an attempt to boost or uphold one's power within a given relationship:

Formally, we define strategic self-presentation as those features of behavior affected by power augmentation motives designed to elicit or shape others' attributions of the actor's dispositions. Features of course include the most subtle aspects of style and nonverbal expressions, as well as the contents of overt verbal communications...such features typically involve selective disclosures and omissions, matters of emphasis and toning rather than of deceit and simulation (p. 233).

Given that trainees in graduate counseling psychology programs are required to receive supervision and that their future employment partly rests on supervisor evaluations of their clinical performance, it is likely that they would be motivated to impress their supervisors. Impression management theory predicts this by relating evaluation and hierarchy, two necessary and unavoidable aspects of the supervisory relationship, to an increase in the likelihood that persons will manage impressions.

Accounts of supervisee management of supervisor impressions are present in the supervision literature; however, not all of them are labeled impression management. For the most part, discussions concern supervisee resistance and supervisee failure to disclose important 
information (Kadushin, 1968, 1992; Ladany et al., 1996; Yourman, 2003; Yourman \& Farber, 1996). Terms used to describe these behaviors are analogous to dated accounts of impression management that portray it as manipulative and deceitful. As an example, Kadushin (1968, 1992) maintained that supervisee resistance and nondisclosure are manifestations of the games that supervisees play to manipulate the level of demand placed on them; to change the dynamics of the relationship; to reduce the power disparity; and to gain control over the supervisory situation. Similar depictions of supervisee behaviors continue today, as evidenced in Delano and Shahs' (2011) "modern version" of "games played in supervision" (p. 177). Interestingly, some researchers demonstrated that impression management motivates supervisees to withhold information even though nondisclosure was not identified as such (e.g., Ladany et al.). Other researchers, however, have explicitly labeled supervisee nondisclosure as a self-presentational strategy, that is, as impression management (e.g., Schwartz, 2008). Taken together, the multiple accounts of supervisee nondisclosure have significant implications for this study. First, they suggest that supervisees do manage supervisor impressions and, second, that the nature of this phenomena in the context of counseling psychology supervision remains unclear.

Supervisee Nondisclosure. Supervisee nondisclosure is a particularly prevalent and problematic behavior documented in the supervision literature (Hill, Thompson, \& Corbett, 1992; Ladany et al., 1996). Supervisees withhold information that has important implications for their training. To name a few examples, reports of nondisclosures include situations or conditions that negatively impact supervisee learning (Hsu, 2007); incidences that elicit shame (Hahn, 2001; Yourman \& Farber, 1996); perceived changes in the style of the supervisor or supervisory relationship (Hsu); and relationship difficulties with the supervisor (Ladany et al.). 
This vital information would help supervisors promote trainee learning, clarify misunderstandings, gain insight into supervisee weaknesses and strengths, and provide feedback to enhance supervisee competence. Ladany et al. (1996) suggested that the effectiveness of supervision "rest[s] on the willingness of supervisees to share their concerns with their supervisors" since "supervisors cannot help supervisees with concerns they do not know about" (p. 10). Put more succinctly, "the unexamined is hard to fix" (Schwartz, 2008). With that said, it is essential to review the nature of supervisee nondisclosures according to the extant research. To date, there are only six empirical studies on intentional nondisclosures by supervisees (Callis, 1997; Gulla, 2008; Hess, 2008; Ladany et al.; Webb \& Wheeler, 1998; Yourman \& Farber, 1996).

One of the first large-scale investigations into supervisee nondisclosure explored the nature, extent and importance of what supervisees chose to withhold from their supervisors (Ladany et al., 1996). Ladany et al.'s sample consisted of 108 trainees, the majority of whom were from counseling psychology programs (63\%) and at the doctoral level (65\%). All participants were receiving individual supervision. The authors reported a mean of 15.73 supervision sessions. Ladany et al. (1996) asked the supervisees to give up to four examples of nondisclosures for five areas of possible nondisclosure; to indicate their reasons for the nondisclosures; to rate the importance of the non-disclosed material; and to disclose whether they discussed their nondisclosures with anyone. In addition, the researchers administered the Supervisory Styles Inventory (SSI) and the Supervisory Satisfaction Questionnaire (SSQ).

The results indicated that the majority of supervisees (97\%) withheld information from their supervisors. With respect to the content of nondisclosures, supervisees did not disclose negative reactions to their supervisors (90\%), personal issues (60\%), clinical mistakes (44\%), 
evaluation concerns (44\%), general client observations (43\%), negative reactions to clients $(36 \%)$, countertransference issues (22\%), positive reactions to supervisors $(18 \%)$, and to a lesser degree, supervisee-supervisor attraction (9\%), client-counselor attraction (4\%), and positive reactions to clients (5\%). Typical supervisee reasons for nondisclosures included "perceived unimportance, the personal nature of the nondisclosure, negative feelings about the nondisclosure, a poor alliance with the supervisor, deference to the supervisor, and impression management" (Ladany et al., 1996, p. 18). The authors found that many supervisees believed that disclosing information would not be helpful and that supervisors lacked the competence to help them. In addition, negative feelings (e.g., shame, embarrassment) and a weak supervisory alliance significantly influenced supervisee decisions to withhold information. In particular, supervisees reported fears of being hurt by supervisors and a general lack of trust. Concealment of the withholding of information was achieved primarily through passive attempts (i.e., avoidance of topic) (83\%). Diversionary approaches, such as discussing other topics to divert the supervisors' attentions, were less common (10\%) and active approaches (informing supervisors that they do not want to discuss something) were rare (4\%).

The findings also revealed a significant negative relationship between supervisee nondisclosures and supervisee satisfaction. In general, less satisfied supervisees withheld more information. When satisfaction levels were low, supervisee reasons for nondisclosures included a poor supervisory alliance, supervisor incompetence, and political suicide (i.e., concern about negative consequences for evaluations and future encounters). In addition, the authors discovered that the nondisclosures were directly related to both the perceived quality of supervision and whether supervision was geared towards their developmental needs. 
Although all nondisclosures were significantly related to the reasons mentioned earlier, further analyses specifically revealed impression management as underlying several types of nondisclosures. To begin with, impression management reasons were associated with uncertainty or uneasiness about supervisor assessment of supervisees (evaluation) that led to nondisclosures. As indicated in an example provided by the authors, a typical concern listed by supervisees dealt with their reliance on supervisors for future letters of recommendation. The study also found that clinical mistakes and negative reactions to supervisors were not disclosed due to impression management reasons. Put another way, supervisees withheld information regarding evaluation concerns, clinical mistakes and negative reactions in order to manage their supervisors' impressions of them. In fact, based on these findings, Ladany et al. (1996) concluded that "supervisees may, at times, need to limit the extent to which they disclose issues that put them in a critical light. To this end, supervisees may use impression management strategies" (p.18).

In addition, the content of the nondisclosures related to impression management appear to have similarities with the variables relevant to this study: self-efficacy and the supervisory working alliance. To illustrate, clinical mistakes were defined as "thoughts related to perceived errors or inadequacy as a counselor" (Ladany et al., 1996, p. 14). This definition resembles Banduras' (1986) conception of efficacy beliefs: “people's judgments of their capabilities to organize and execute courses of action required to attain designated types of performances" (p. 391). The authors also found that supervisee nondisclosures were related to the involuntary, evaluative, and hierarchical aspects of supervision. Reports of poor supervisory alliances and negative reactions to supervisors underscored the centrality of the supervisory relationship in reducing behaviors associated with impression management concerns. 
Although the findings appear to suggest a relationship between impression management behaviors, specifically between a poor supervisory working alliance and low efficacy beliefs, the authors' use of a different terminology precludes a conclusion of this kind. To add to that, Ladany et al.'s (1996) research appears to have limited value. The correlational nature of this study and the failure to control for potential moderating variables, such as the supervision setting, makes it inappropriate to make causal inferences.

A related study on supervisee nondisclosures was conducted in the same year that Ladany et al.'s (1996) findings were published. Yourman and Farber (1996) explored common types of conscious distortions by supervisees. In particular, the authors sought to determine the frequency of nondisclosures and the extent to which certain factors were predictive of conscious omissions. They presented the Supervisory Questionnaire (SQ), a self-report questionnaire developed for the study, to 93 doctoral students enrolled in clinical psychology programs in the New York metropolitan area. On average, the students had received 11.2 months of supervision and 3.3 years of training.

Using a 7-point Likert scale, students rated how often and how likely they were to disclose information, to intentionally withhold or distort information, and to feel comfortable discussing material that pertained to a range of issues. The authors found that although supervisees typically communicate an honest account of their experiences, they reported frequent use of conscious nondisclosures to distort information. Students indicated that they withheld perceived clinical errors at a moderate to high frequency $(39.8 \%)$ and that they told their supervisors what they wanted to hear at a moderate to high frequency (47.3\%). Similarly, students chose 'never' or 'infrequently' when asked whether they informed their supervisors when they thought they (supervisors) were wrong (30.1\%) and when asked whether they felt 
comfortable disclosing negative feelings toward their supervisors $(59.1 \%)$. In total, 30 to $40 \%$ of the sample reported that they withheld information at a moderate to high frequency and approximately half of the sample reported that they tell their supervisors what they think they (their supervisors) wanted to hear.

In addition to replicating Ladany et al.’s (1996) findings, Yourman and Farber (1996) also demonstrated that supervisee nondisclosures are significantly related to supervisee satisfaction level and discussions of countertransference in supervision. The more satisfied supervisees were with supervision, the less likely they were to withhold important information. Likewise, greater incidences of countertransference discussions were related to lower reports of conscious nondisclosures by supervisees. Given that other research findings have demonstrated a significant, positive relationship between satisfaction levels and the supervisory working alliance (Ladany, 1992; Ladany et al., 1999; Sterner, 2009; Ting, 2009), it could be argued that the working alliance may also be related to the use of an impression management tactic, such as supervisee nondisclosure. Similarly, frequent discussions of countertransference could be indicative of the level of communication that takes place between supervisor and supervisee, which is essential to a strong working alliance. To add to that, Yourman and Farber's findings indicated that most nondisclosures pertained to events in supervision and the supervisory relationship. In consideration of all these factors, an open line of communication and a strong working alliance may play an important role in how often or how infrequently supervisees employ this tactic.

A critical review of this study does suggest the following limitations. The homogeneity of the sample with respect to training level (third and fourth year students) and region (New York metropolitan area) restricts the generalizability of these findings to other doctoral students 
with different characteristics. The authors' failure to demonstrate that the self-report questionnaire was a valid measure creates additional problems. Without established measures of validity, it is not possible to know whether the instrument actually measures what the authors intended. In addition, the authors did not measure other factors that may have been related to supervisee nondisclosure, such as the supervisory working alliance. Yourman and Farber's (1996) success in replicating Ladany et al.'s (1996) findings does suggest that open communication and the strength of the working alliance may be factors that are relevant to impression management.

Given that a direct relationship between supervisee satisfaction and the supervisory working alliance has been demonstrated in previous findings (e.g., Ladany, 1992), it could be argued that the working alliance may have served in particular as a mediating factor between satisfaction levels and supervisee nondisclosure. As if to address this limitation, dissertation research conducted by Callis (1997) explored relationships among the quality of the supervisory relationship, supervisee nondisclosures, and trainee reactance.

Using impression management theory as one of the principal explanations for supervisee nondisclosure, Callis (1997) investigated whether supervisee nondisclosures could be predicted through differential levels of reactance to curtailment in freedom and through the perceived quality of supervisory relationship. Callis recruited 76 pre-doctoral psychology interns who were enrolled in clinical and counseling psychology programs by contacting training directors of predoctoral internship sites that were members of the Association of Psychology and Postdoctoral Internship Centers (APPIC). On average, trainees had 4.8 years of experience and 20 supervision sessions with their current supervisor. Callis asked participants to complete the 
Withholding Scale, Relationship Quality Scale, Therapeutic Reactance Scale, and a demographic questionnaire.

Overall, the findings revealed that nearly all of the supervisees $(97 \%)$ withheld some information from their supervisors and that the quality of supervisory relationship had a significant negative relationship to supervisee nondisclosure. In other words, when perceptions of the supervisory relationship were stronger, supervisees were less likely to withhold information from their supervisors. Conversely, supervisees who reported a weak relationship indicated that they withheld more information. This finding led the author to conclude that individuals who are evaluated "will be less likely to engage in impression management strategies when ... [they] are in a satisfying relationship with their supervisor" (Callis, 1997, pp. $44-45$ ). The quality and strength of the supervisory relationship was determined to be a better predictor of supervisee nondisclosure than supervisee reactance level. A significant negative relationship also emerged between the responses of supervisees who indicated that they were conforming (low-reactant), and nondisclosures. The less reactant (i.e., more conforming) they were, the more they withheld information. Thus, "low reactant supervisees tend to be more concerned with conforming and making a good impression to avoid being harshly criticized or judged by the supervisor" (Callis, 1997, p. 45).

Although these findings suggest that the supervisory relationship is significantly related to impression management strategies, the correlational nature of this study precludes causal inferences. One cannot conclude that the quality of the supervisory relationship will cause supervisees to disclose or withhold more information. To add to that, the author did not provide information on the validity or reliability of the scale used to assess the supervisory relationship. 
In addition, the small sample size and homogeneity of the sample with respect to training level (predoctoral psychology interns) limits the generalizability of these findings.

Overall, however, Callis' (1997) dissertation research demonstrated the value of using impression management theory as a framework for understanding supervisee nondisclosure. “Trainees will engage in self-enhancing behaviors when they want to gain approval, respect or admiration from another. This tendency increases when a person is being evaluated or when ... people are trying to gain a professional image" (Callis, p. 44).

In a related study, Webb and Wheeler (1998) examined the relationship between supervisee self-disclosure and the supervisory working alliance. Unlike Callis (1997), however, the authors did not conceptualize supervisee nondisclosure in terms of impression management. Instead, the authors explored a range of factors that may influence supervisee nondisclosure, including the number of supervision participants, the type of training, the location of supervisors relative to supervisee, and the sensitive nature of the issues withheld. A total of 96 counselors, 44 of whom were in training, completed the Supervisory Working Alliance Inventory (Efstation et al., 1990) and a scale was designed to measure participants' sensitivity to disclosing certain issues in supervision and the strength of identified barriers. The sensitivity scale was designed specifically for use in this investigation.

Overall, Webb and Wheeler's (1998) findings corroborated previous research regarding supervisee nondisclosure and its relationship to the supervisory working alliance. On all accounts, trainees were significantly likely to withhold sensitive information about the therapeutic and supervisory relationship due to perceived risks to the self and anticipated difficulties with supervisors. Some conditions, however, were related to these nondisclosures. For instance, supervisees were more likely to withhold sensitive issues in group supervision than 
in individual supervision. Additionally, the quality of rapport between supervisees and supervisors played an important role in whether trainees withheld or disclosed information. In general, rapport was positively correlated to disclosures pertaining to the therapeutic and supervisory relationship. A negative correlation emerged when supervisees expected to 'clash' with supervisors and a risk to the self was anticipated.

The findings also suggested that counselors who were "in-training" and required to participate in supervision were significantly less likely to disclose sensitive issues surrounding their clients and supervisors than counselors who were not "in-training." This was also the case for trainees who were receiving supervision in their work setting. When supervision was provided in counseling settings, trainees were significantly less likely to disclose perceived difficulties (i.e., with clients and supervisors) than trainees who received supervision in separate locations. The authors found that trainees who were supervised at the counseling settings and who withheld information from their supervisors also reported fears of clashing with their supervisors. Conversely, supervisees who were able to choose who supervised them were more likely to disclose sensitive issues.

This study's findings regarding the nature of supervisee nondisclosures have potentially relevant implications for supervisee impression management. It could be argued that the conditions found to be related to the frequency of nondisclosures are ones that would increase supervisee motivations to manage supervisor impressions. The significant relationship between rapport and supervisee nondisclosure suggests that the emotional bond of the supervisory working alliance will be particularly relevant when examining supervisee uses of impression management strategies. Although Webb and Wheeler (1998) did not conceptualize supervisee 
nondisclosures as impression management, the authors' conclusions regarding supervisee reasons for withholding information are analogous to impression management motivations:

Consideration of perceived inhibitors of disclosure reveal fears about being thought badly of by the supervisor and of abilities being assessed negatively...The extent to which supervisees report being inhibited by such fears may indicate ...the need to alter certain conditions of supervision which contribute to the extent of the perceived threat. (Webb \& Wheeler, p. 520)

Taken together, the supervisees in Webb and Wheeler's study were motivated to withhold sensitive information for impression management reasons and, in addition, their motivation levels appeared to be related to perceptions of rapport within the supervisory relationship.

The limitations of this study call into question the generalizability of the findings. The sample consisted of participants with homogeneous characteristics, such as theoretical orientation (psychodynamic) and training level (masters level), and training location (United Kingdom). Therefore, the findings of this study may not generalize to supervisees with different orientations, training levels, or to those whose training took place elsewhere than in Britain.

Nonetheless, a subsequent study similarly demonstrated that supervisee willingness to disclose mistakes to their supervisors is related to a mutual relationship existing between supervisee and supervisor. Walsh, Gillespie, Greer and Eanes (2002) presented 75 pastoral counseling students from two separate master's level counseling programs with four instruments: Factors Affecting Supervisee Disclosure to Supervisors, the Self-Disclosure of Clinical Mistakes Form, the Mutual Psychological Development Questionnaire, and the Relational Health Indices. The first two measures were developed specifically for this study. The authors explored factors 
related to supervisee willingness to self-disclose, the type of persons to whom supervisees do disclose clinical mistakes, and the relationship between supervisory relationships and supervisee disclosures.

Walsh et al. (2002) discovered that supervisees rated factors related to the supervisory relationship as most important. That is, a positive relationship emerged between disclosure of clinical mistakes to supervisor style, investment in the supervisee success, willingness to share personal experiences, and willingness to disclose clinical mistakes. Likewise, the level of mutuality in supervisory relationships was positively related to supervisee disclosures. Almost all participants reported that they disclosed clinical mistakes to their on-site supervisors or in other supervisory relationships and trainees who disclosed clinical mistakes to their supervisors reported mutual relationships with supervisors.

Due to the small sample size and specific subset of counseling students (pastoral focus) the generalizability of these findings is restricted to similar populations. Given that the authors failed to provide information on the validity of either the Mutual Psychological Development Questionnaire or the Relational Health Indices instruments, the inferences drawn from these findings are problematic. Therefore, while the findings of this study suggest that supervisees are likely to disclose clinical mistakes in a supervisory relationship where feelings of mutuality are present, further research needs to be conducted to corroborate these results.

So far, only one of the above studies on nondisclosure explored the phenomenon from the perspective of supervisees enrolled in their internship year. For this reason, Hess (2008) sought to determine whether this phenomenon was an experience that was prevalent among pre-doctoral interns through a mixed methods study. Additional purposes included explorations of the content of nondisclosures, the underlying reasons for nondisclosures, the perceived impact of 
nondisclosures, and the factors that may facilitate or mitigate the tendency to withhold important information, such as supervisor style and supervisee satisfaction with supervision. Hess recruited 14 pre-doctoral interns, the majority of whom were enrolled in counseling psychology Ph.D. programs (13). Data were collected from phone interviews (audiotaped), the Supervisory Styles Inventory (SSI; Friedlander \& Ward, 1984), and the Supervisory Satisfaction Questionnaire (SSQ). The phone interviews, which took place during the last two months of the pre-doctoral internship year, elicited information about nondisclosures. This included details regarding specific incidences of nondisclosure; underlying reasons for withheld information; factors that may have facilitated disclosures; and the personal and professional effects of nondisclosures.

Using the Consensual Qualitative Research (CQR) methodology to analyze the data, Hess (2008) identified two groups, which were identified as good and problematic supervisory relationships. Eight of the participants were in good supervisory relationships and six were in problematic ones. Supervisees exposed to good relationships were significantly more satisfied with supervision and their ratings of supervisor attractiveness and interpersonal sensitivity were significantly higher.

Qualitative analyses revealed six categories of core ideas that occurred for more than half of the supervisees involved in both good and problematic supervisory relationships. The six categories were: (a) context of nondisclosures, (b) supervisory relationships, (c) content of nondisclosures, (d) reasons for nondisclosures, (e) factors that would have facilitated disclosure, and (f) perceived effects of nondisclosures.

The first category, context, refers to characteristics of supervision and supervisors that contributed to supervisee experiences: supervisor style, supervisory relationship quality, and 
supervisee awareness of the supervisor's power to give negative evaluations, for example.

Supervisees in the problematic group reported many incidents of nondisclosure whereas those in the good group generally described one incident, which was associated with "one difficult moment within the context of an overall satisfying and positive supervision experience" (Hess, 2008, p. 406). Problematic relationships also resulted in low ratings of safety, satisfaction, supervisor attractiveness, and supervisor interpersonal sensitivity while good relationships resulted in reports of feeling safe and satisfied, which was associated with greater disclosures.

Although context encompasses quality of the supervisory alliance, Hess (2008) found that the supervisory relationship warranted a separate category. Similar to characteristics of the context, good supervisory relationships were associated with feelings of safety, comfort disclosing personal and professional issues, valued supervisory styles, and perceptions of supervisors as supportive, present, collaborative and challenging. Problematic supervisory relationships were associated with feelings of discomfort and a general lack of safety with disclosing information, perceptions of the relationships as critical and evaluative, and perceptions of supervisors as incompetent and not invested in the relationship.

The third category, content of nondisclosures, revealed differences in the type of information that supervisees withheld. Interns in the good group withheld information about clinical issues, such as countertransference and perceived mistakes. Interns in the problematic group withheld information related to problems in the supervisory relationship, such as supervisor expectations and mixed messages. The reasons for these disclosures, the fourth category, revealed that interns in both groups feared disclosures would risk negative evaluations and even cause supervisors to form negative impressions of them. Reports of negative feelings, 
such as self-doubt and feeling insecure, and of decreases in self-efficacy appeared to contribute to intern nondisclosures and to have a negative impact on the supervisory relationships.

The next category, factors that would have facilitated disclosure, differed between the two groups. Supervisees in the good relationships might have disclosed information if their supervisors specifically asked about the incident or disclosed personal information about a similar event. Supervisees in the problematic group reported that nothing would have helped or that they did not know of any facilitative factors.

The final category perceived effects of nondisclosure. With respect to the supervisory relationship, interns in the good group reported neutral effects. Nondisclosures neither weakened nor strengthened the relationship. On the other hand, supervisees with problematic relationships reported negative effects only. In particular, they experienced frustration and disappointment, they felt unsafe in the relationship, and they disclosed even less or became less invested in supervision. As for the personal impact of nondisclosures, all supervisees reported negative feelings, such as a loss of confidence and a decreased sense of competence. Supervisees from both groups also indicated that nondisclosures had negative effects on their clinical work.

Taken together, the findings of this study demonstrated the nature as well as the prevalence of pre-doctoral intern nondisclosures in supervision. The qualitative analyses of the interviews, in particular, supported the proposed influence of the supervisory relationship on supervisee nondisclosure, with significantly fewer reports of nondisclosures by interns who were in good supervisory relationships. In fact, supervisees in the good group indicated that they felt more comfortable disclosing personal and professional issues and that it was 'safe' to disclose such information whereas those in the problematic group viewed disclosure as a risk to their future. 
Many of the distinguishing characteristics of supervisees' relationships with their supervisors bear a close resemblance to components of the supervisory working alliance. Interns in good supervisory relationships indicated that their supervisors offered support and encouragement, fostered equal and collaborative alliances, promoted understanding of clients, and communicated their expectations clearly. All of these elements align closely with previous descriptions of components underlying the supervisory working alliance, such as the bond, task, and mutual agreement elements proposed by Bordin (1983) and Efstation et al.'s (1990) empirically supported factors of rapport and client focus. Relationships marked by these components appeared to reduce supervisee desire to manage impressions by alleviating tensions related to the hierarchical and evaluative nature of supervision. When supervisory relationships lacked such components, however, these characteristics (power differential, hierarchy, evaluation) appeared to be in the forefront of supervisee minds. Similarly, interns in problematic supervisory relationships attributed the majority of nondisclosures to problems in supervisory relationships, negative feelings (low sense of competence) and to concerns over negative impressions that could result in poor evaluations.

The findings also suggested that supervisee attempts to manage supervisor impressions through nondisclosures had an impact on their clinical work, self-perceptions, emotional experience, and the supervisory relationships. Interns with problematic relationships found that their relationships with clients and supervisors alike suffered, that they experienced negative feelings such as shame, and that they lost confidence in themselves and felt less competent (i.e., decreased self-efficacy). From this finding, Hess (2008) concluded that supervision at the internship level may create more anxiety "because the internship takes place in a heightened evaluative setting in which the interns' perceptions may be that exemplary performance is the 
norm" and that "distress about [supervisee] status and competence may then increase their feelings of doubt and shame, thus decreasing their self-efficacy and possibly inhibiting disclosure" (p. 409). Therefore, the results of this study indicate that advanced level students, such as doctoral candidates at the internship level, may be even more likely to use impression management strategies given the high stakes environment. To add to that, the use of impression management strategies appears to be located in the supervisory relationship and related to selfefficacy levels.

The qualitative approach taken in this study allowed for a more in-depth analysis of supervisee experiences; however, the small sample size that accompanied this methodology means that other supervisees may have different experiences. The reliance on retrospective data further complicates matters given that the interns' memories of supervisory relationships and events may have been faulty. In addition, given the homogenous sample, the results can only be generalized to doctoral level supervisees who are working at counseling center internship sites.

The previous investigations on nondisclosures sought to explore the phenomenon while supervisees were still enrolled in training programs and were mandated to supervision. As demonstrated by this research (e.g., Hess, 2008) the evaluative nature of supervision and the power differential can lead supervisees to perceive disclosures as a risky action, if supervisors were to form a negative impression, that could potentially jeopardize their ability to obtain future employment. On account of this expressed concern, Gulla (2008) sought to remove potential barriers to complete and honest disclosure about the experiences of supervisees, such as the fear of reprisal for participation in such a study. As such, Gulla conducted his dissertation research on older (45 to 60 years), clinically experienced psychologists who completed internships and were no longer part of evaluative supervisory relationships. 
Using a grounded theory methodology, Gulla (2008) explored interviewees' reflections of nondisclosures upon completion of internships, the reasons for withholding information, conceptualization of decisions to withhold following internship completion, and the influence of age on nondisclosures and the supervisory relationship. More specifically, the author explored “the what's, why's, how's, and so what's of supervisee disclosure and nondisclosure" (Gulla, p. 2). Gulla interviewed a total of 11 graduates, three of whom were used for the pilot study. Experience levels prior to internship entry ranged from five to 15 years. Participants completed their internships either two to four, three to six, seven to 10, or 25 years prior to the study.

The data collected from the interviews revealed central themes that involved supervisor and supervisee attributes, desire to learn, safety in the supervisory relationship, the need to survive, and willingness to allow vulnerability. Out of the 18 supervisory relationships that were discussed, ten were viewed as positive and the remaining eight were negative. Likewise, ten participants indicated that they had positive learning experiences whereas eight did not. Reports of nondisclosures occurred in ten relationships. In general, the content of nondisclosures pertained to either clinical case material or to personal information, such as thoughts, feelings and concerns supervisees viewed as pertinent to clinical work.

When asked how perceptions of supervisors and supervisory relationships influenced decisions to withhold information, participants' responses indicated that nondisclosures were directly related to the supervisory relationships, supervisor attributes, and to self-descriptions. Personality traits, interpersonal skills, degrees of investment in supervisee and supervision, and competence levels were supervisor attributes that were commonly attributed to decisions to disclose or withhold information. Supervisors' commitment to the relationship and supervision was related to the extent and content of disclosures and to the perceived quality of the 
supervisory relationships. When the perceived commitment of supervisors was greater, supervisees indicated that they had more positive relationships and disclosed more information. Commitment to the supervisory process was also associated with memories of being encouraged and supported. According to Gulla's (2008) analyses, all of these factors appeared to form a common theme, a sense of safety in supervisory relationships, which was found to play a major role in whether information would be shared with supervisors.

A subjective sense of safety appeared to ameliorate supervisee experiences of fear, shame and vulnerability, which were emotions found to work against their desires to learn. Participants reported fears of identified risks that were associated with supervisors, supervisory relationships, and their abilities to perform clinical roles (i.e., counseling self-efficacy). Relationships labeled unsafe were perceived as unmanageable or as having high risk levels. To establish a sense of safety, supervisees indicated that they withheld or controlled information. "Most participants ultimately associated their perceptions of relationship safety with their decisions to disclose or withhold information" (Gulla, 2008, p. 81).

Feelings of fear and shame were associated with the need to protect oneself and to survive, respectively. Thus, to establish a sense of safety supervisees alleviated fears through protection against risks associated with supervisors, supervisory relationships, and exposure to vulnerability. The need to survive, however, arose out of "challenges to one's sense of competency" (Gulla, 2008, p. 138). Thus, shame was related to negative self-perceptions of supervisee abilities. Experiences of shame also influenced the type of information withheld or disclosed and, in turn, prevented supervisees from acting in ways that would fulfill their desire to learn. "That sense of not knowing, of not feeling competent, and the struggle of exposing the shame in order to begin the learning process" (Gulla, p. 97). Overall, participants acknowledged 
that allowing vulnerability in the relationship was necessary to learn; however, self-protection and survival needs superseded this when supervisory relationships were perceived as untrusting and unsafe.

In sum, supervisee conceptualizations of their supervisors, supervisory relationships, and supervisor attributes were positively associated with their sense of safety in the relationships. Similarly, participants' conceptualizations of themselves as supervisees were positively related to their subjective sense of safety, perceptions of the supervisory relationships, and willingness to risk being vulnerable. When supervisory relationships were perceived as unsafe and untrusting, supervisees' experiences of fear and shame were heightened, which in turn increased the perceived risks associated with vulnerability. Greater perceptions of risks led supervisees to act in ways they felt would help them to survive or to protect themselves even though these actions went against their desires to learn. Every participant who felt the need to survive or protect themselves used nondisclosure, among other strategies, to establish a sense of safety.

This study did suffer from limitations. The small sample size and homogeneity of the participants with respect to programs (APA accredited) and location (Northeastern) limit the generalizability of these findings to other supervisees. Also, all participants were over the age of 30, which means that these findings could have been unique to supervisees from this particular generation. Second, the use of retrospective data makes inferences regarding the accuracy of the findings inappropriate. For instance, it is possible that participants' recall of the events changed over time. As with all qualitative research, there is also the risk that the researcher's bias may have impacted the findings.

Impression Management Strategies. Selective attempts to withhold or disclose information in supervision are but one form of impression management. Nondisclosures 
typically reflect supervisee desires to be viewed in the best possible light by their supervisors. However, individuals employ multiple other strategies to elicit particular impressions which vary according to what they value and the outcomes they hope to attain. For instance, supervisees may place greater value on being viewed as competent rather than likeable. Perceptions of outcomes (e.g., favorable) depend on individual motives and can involve immediate or delayed gratification (Jones \& Pittman, 1982). Given the complex nature of impression management, Jones and Pittman compiled all impression management strategies which in turn, led to the development of one of the most complex taxonomies of this phenomenon.

According to Jones and Pittman (1982) the strategies are classified in terms of the kinds of attributions sought by individuals. They maintained that self-presentational strategies can be classified under five general areas: ingratiation, intimidation, self-promotion, exemplification, and supplication. However, the authors cautioned that these strategies are not mutually exclusive since "the same act can serve different functions for different audiences" (Jones \& Pittman, p. 250). With that said, the classifications of these strategies serve to distinguish the goal behind the act.

One class of impression management strategies identified by Jones and Pittman (1982) reflects the desire to be liked by others (i.e., ingratiation). Jones and Pittman indicated that three factors determine the use of ingratiating strategies: incentive value, subjective probability, and perceived legitimacy. Incentive value, the extent to which being liked by others is desired, depends on the nature of the relationship. Greater dependence on others increases incentives to be liked. Likewise, ingratiatory desires are greater when one's influence is less than the other in a relationship. Subjective probability refers to the likelihood that one's attempt to elicit approval and acceptance will be successful and will not backfire. The success of ingratiation strategies are 
subject to the relationship between incentive value and subjective probability, which Jones and Pittman (1982) refer to as the ingratiator's dilemma: “The ingratiator's dilemma is created by the fact that as the actors' dependence on the target goes up, his motivation to ingratiate goes up, whereas the subjective probability of its success goes down" (p. 237). The perceived legitimacy of a given presentation also determines whether individuals decide to act on their desire to be liked. Presentations are viewed as legitimate when they are consistent with prior depictions of the self and they are compatible with the situational context. Common strategies of ingratiation include conformity, other-enhancement, performing favors for others, and self-enhancement (direct or indirect self-descriptions).

Self-promotion differs from ingratiation insofar as the ultimate goal is for others to view oneself as competent. Self-promoters point out personal abilities, accomplishments and achievements; they try to take control of conversations; they avoid discussions that highlight others' capabilities or one's own weaknesses (i.e., nondisclosure); and they either act confident or simply express their self-confidence. According to Jones and Pittman (1982), self-promotion is especially likely to occur when individuals are in a hierarchical context where attention is drawn to the power differentials and when the criteria for competence are slightly ambiguous, such as in supervision. The authors suggested that "competence claims are more likely when competence is shaky than when it is high and securely so," a feature they label as the "selfpromoter's paradox" (Jones \& Pittman, p. 243).

Similar to self-promotion, the underlying goal of exemplification is to be respected and admired. However, instead of achieving this through impressions of competence, individuals seek to elicit perceptions of integrity, morality, and dedication. Exemplifiers do more than what is required of them, but to an extreme degree, and in so doing they sacrifice their needs. 
When individuals use intimidation strategies, they portray themselves as people who are willing to cause emotional or physical harm to others. For example, supervisees could make a scene, such as having an emotional breakdown, becoming ill, or demonstrating to others that they have a low threshold for anger. According to Jones and Pittman (1982), intimidation strategies are more prevalent in relationships that are not voluntary (i.e., supervisory relationships) but are just as likely to be used by persons in low positions of power (i.e., supervisee) and in high positions of power (i.e., supervisors).

In contrast to intimidation, supplication strategies are designed to elicit impressions of dependency, weakness, and neediness. In the context of supervision, then, a supervisee may advertise their helplessness and incompetence. This strategy is designed to elicit a sense of obligation and responsibility from the supervisor given their greater position of power in the relationship (Jones \& Pittman, 1982).

In sum, Jones and Pittman (1982) theorized that individuals use ingratiation, selfpromotion, exemplification, intimidation, and supplication strategies to elicit impressions of likeability, competency, dedication, power, and dependency, in that order. To date, this remains the most thorough classification of self-presentational strategies. Furthermore, subsequent research substantiated Jones and Pittman's taxonomy, which, in turn resulted in an empiricallysupported impression management measure (Bolino \& Turnley, 1999).

Impression management in counselor supervision. To date, there are only two empirical studies that directly tested the nature of impression management in counselor supervision. Ward, Friedlander, Schoen, and Klein (1985) took a different approach than prior research on nondisclosures and examined the impact of the evaluative component of supervision on supervisors. That is, given the impact of supervisory evaluations on supervisees, the authors 
sought to determine how supervisee reactions to this component affected supervisors' impressions.

Given the evidence that supervisors observe and evaluate the work trainees do with clients, that supervisees are typically invested in their success, and that strategic selfpresentations occur under similar conditions, Ward et al. (1985) based their study on an assumption that trainees present themselves strategically to their supervisors. Based on previous research findings that individuals under evaluative conditions attempt to influence others' perceptions of their competence levels, the authors assumed that supervisees use self-promotion tactics with supervisors. Self-promotion strategies are defensive tactics whereby individuals take credit for success and deny responsibility for failure in order to impress others with their abilities. In contrast, Ward et al. also assumed that supervisees offer counter-defensive explanations, denying credit for success and accepting responsibility for failure, when their selfpresentations could be invalidated through supervisor observations of future performances. Ward et al. expected that supervisors would view trainees who offer counter-defensive explanations as more likable and trustworthy but as lacking more confidence than supervisees who offer defensive ones.

A secondary purpose of this study was to investigate the degree to which participants (supervisors) attribute client progress or deterioration to clients, trainees, or supervisors. The authors made no hypotheses regarding responsibility attributions.

Using an audiotape of a fictitious supervisory session, Ward et al. (1985) asked a sample of 80 experienced supervisors to imagine themselves in the role of supervisor as they listened to the tape. They then completed instruments that assessed their impressions of the supervisees. On average, supervisors had 5.85 years of experience and provided 7.4 hours of supervision per 
week. The authors presented four seven-minute stimulus tapes to the participants. Supervisors heard a trainee reporting four previous sessions with her depressed client. The trainee's report of the final session varied for each recording. Reports of significant change in the client's status were associated with conditions of improvement or deterioration and explanations for client change were related to attributional explanation conditions. Participants' perceptions of supervisee competence, social skills and self-confidence levels were assessed through their ratings on Tetlock's (1980) trait scales. Ward et al. (1985) also administered the abbreviated form of the Counselor Rating Form (CRF-S; Corrigan \& Schmidt, 1983) to assess supervisor perceptions of supervisee expertness, attractiveness, and trustworthiness. To determine to whom supervisors attributed responsibility for client improvement or deterioration, participants rated client, trainee and supervisor on a 7-point Likert scale.

Overall, Ward et al. (1985) found that supervisee explanations significantly influenced supervisor impressions of them. The results of the ANOVAs indicated that client progress had a significant effect on supervisors' perceptions of trainee competence, self-confidence, expertness, and attractiveness. The means of the supervisors' scores revealed more favorable ratings on competence, self-confidence, expertness, and attractiveness after reports of client improvement than after client deterioration.

Supervisors' ratings also differed according to trainee explanations. The results indicated that trainees who offered defensive explanations were rated significantly higher on the dimension of self-confidence than those who provided counter-defensive explanations. Ratings of social skills were "marginally significantly higher" for counter-defensive explanations than for defensive ones. With respect to responsibility attributions, univariate ANOVAs demonstrated significant main effects for each person (client, trainee, and supervisor). Further examination, 
however, demonstrated that supervisors attributed significantly more responsibility to clients after improvement than after deterioration. Supervisors and trainees were credited with significantly more responsibility after client deterioration than after client improvement. However, further analyses indicated that supervisors viewed clients as significantly more responsible than trainees and supervisors. The trainee was perceived to be significantly more responsible than the supervisor. Taken together, these findings suggest that supervisor evaluations of trainees are largely based on client progress, or lack thereof. In this study, client deterioration led to lower evaluations of the trainee and clients were credited with the most responsibility after improvement.

Based on these findings, the authors concluded that supervisors perceive trainees to be more socially skilled when they offer counter-defensive explanations for client progress but more confident when defensive explanations are given. Contrary to their hypothesis, perceptions of supervisee competence level and trustworthiness were not influenced by either explanation. Also, regardless of which approach the trainee used, the client's status ultimately determined the type of evaluation given. Client progress resulted in more favorable impressions of trainees and client deterioration led to less favorable ones. On the other hand, clients were viewed as significantly more responsible for their success than trainees. Thus, when the client's status worsened, trainees were viewed as responsible but when they improved, clients were deemed responsible. Likewise, evaluations of trainees were negative when the client symptoms worsened.

In general, supervisors' impressions appear to be positively influenced by supervisee selfpresentational tactics when their clients are improving. In this case, supervisors will give favorable ratings on social skills if counter-defensive explanations are given and favorable 
ratings on self-confidence if defensive explanations are provided. However, if clients' symptoms worsen, then supervisor evaluations of supervisees will be unfavorable.

The design of this study did suffer from limitations. First, the authors did not report information on validity and reliability for the scale used to assess ratings of competence, social skills, and confidence. Second, the authors used a fictitious session in which the supervisor was not involved in the interaction. Given the complex nature of relationships, inferences regarding supervisor evaluations are unfounded. Thus, the generalizability of these findings is limited to third party raters, not to supervisors who are involved in the actual supervisory relationship. Also, Ward et al. (1985) based their study on the assumption that supervisees primarily use counter-defensive and defensive explanations as self-presentational tactics. For these results to be generalized, empirical support for this premise should be provided. For instance, there may be other tactics that are more influential than client status.

This study offered insight into the potential impact of supervisee self-presentational tactics on supervisors. Research has yet to explore factors related to supervisee use of impression management, however. An understanding of supervisee impression management in a naturalistic setting, including both the tactics used and the factors related to it, would be more valuable to supervisors. Awareness of how supervisees manage supervisor impressions and their respective goals would offer supervisors more insight into supervisee behaviors.

Two decades after Ward et al.'s (1985) study, Pitariu (2007) used her dissertation research to determine which factors could be used to predict practicum supervisees' use of impression management. More specifically Pitariu examined the relationship between anxiety, self-efficacy, and impression management among novice trainees. Pitariu expected that anxiety 
and self-efficacy levels would predict supervisee use of self-promotion, ingratiation, exemplification, intimidation and supplication tactics.

Pitariu (2007) recruited a total of 118 master's level students enrolled in their first semester of CACREP accredited counselor education programs. Participants completed the Counseling Self-Estimate Inventory (COSE), the State-Trait Anxiety Inventory (STAI), and the Impression Management Scale (IMS) in class during the midterm week of the semester.

Multiple regression analyses demonstrated that CSE and state anxiety levels significantly predicted different types of impression management tactics. To add to that, the use of tactics also varied according to self-efficacy beliefs about different clinical skills (i.e., microskills, counseling process, difficult clients, cultural competence, and awareness of values). Specifically, supervisee efficacy beliefs pertaining to microskills, counseling process, and difficult clients were significant predictors of self-promotion tactics. That is, supervisees presented themselves in a favorable light (i.e., as competent) and avoided discussing weaknesses when they were confident in their abilities to execute basic counseling skills, to actively engage with the client and simultaneously attend to the therapeutic process, and to deal with difficult client behaviors. Alternatively, efficacy beliefs pertaining to awareness of personal values and of the impact of these values on clients (i.e., value) were negatively related to supervisee attempts to be perceived as powerful and dangerous (i.e., intimidation tactic) and to emphasize their weaknesses to elicit perceptions of being needy (i.e., supplication).

The findings also suggested that supervisee anxiety was related to the use of impression management strategies. State anxiety levels predicted supervisee use of favors or flattery toward supervisors were used to portray an image of likeability (i.e., ingratiation tactics) and the extent to which supervisees went above and beyond the requirements to impress an image of dedication 
onto their supervisors (i.e., exemplification tactic). Further analyses, however, indicated that supervisee ingratiation tactics are better predicted by anxiety levels than by self-sacrificing behaviors (i.e., exemplification). None of the demographic variables (i.e., gender, race, previous counseling experience) were significantly related to the use of impression management tactics.

Supervisees indicated that they had high self-efficacy beliefs relating to microskills, counseling process and difficult clients and yet the majority of the sample had little to no counseling experience. This finding corroborates previous research (Sipps et al., 1988) that demonstrated high self-efficacy levels existed among beginning trainees until the complexities of counseling became more apparent mid-training. These same trainees attempted to portray images of competence to their supervisors through self-promotion tactics. That is, they discussed their strengths and accomplishments and avoided disclosures of weaknesses or failures, which, as Pitariu (2007) pointed out, replicates previous findings that supervisees use nondisclosures as an impression management strategy (Ladany et al., 1996). In this way, supervisees ensured that their supervisors viewed them as competent. Supervisees who had little confidence in their abilities to discuss values, however, took a different approach.

When supervisees reported low awareness levels of personal values and of how their values and biases might impact clients, they either presented themselves as weak and dependent persons in need of acceptance (i.e., supplication) or as powerful persons who are indifferent to whether others like or accept them (i.e., intimidation). That is, they either advertised their weaknesses or their intimidating qualities to portray an impression of being needy or dangerous, respectively. Taken together, it appears that supervisees will use different impression management tactics depending on how confident they feel in their abilities to successfully perform different types of counseling skills. 
Even though the relation between impression management and the supervisory working alliance was not explored in this study, Pitariu (2007) concluded that the supervisory relationship could serve as the vehicle through which supervisee efforts to manage impressions could be moderated. The author suggested that supervisors could reduce supervisee use of impression management through a strong working alliance when the following conditions are met:

Establish mutuality and collaboration to accomplish tasks; use self-disclosure to foster openness, honesty, and willingness to admit mistakes; talk openly about the hierarchy or power and the means available to resolve problems; and include supervisees in setting goals, planning, and the evaluation process. (p. 92)

Pitariu's recommendations emphasize the importance of the supervisory relationship and even highlight specific components of the supervisory working alliance (e.g., mutual agreement, rapport, client focus).

Similarly, the author's recommendations indicate that transitory anxiety, which was found to predict ingratiation and exemplification tactics, could be adequately addressed through agreement on tasks and goals in supervision. Pitariu (2007) indicated that supervisees' use of favors and flattery likely masked or reduced their anxiety but that their anxiety could be better addressed through supervisor efforts to normalize their experiences and through discussions of the roles and expectations of supervisees. Given that the supervisory relationship might have a negative relationship to trainee anxiety (Abernethy \& Cook, 2011; Mehr et al., 2010) the working alliance may offer a better explanation for supervisee use of impression management tactics. Given that the researcher did not control for this potentially moderating variable, however, it is not possible to know the extent of these relationships. 
Pitariu's (2007) conclusions reinforced previous findings that supervisees manage their supervisors' impressions and that this behavior is related to self-efficacy levels. However, the exclusion of the supervisory working alliance in this study raises questions about the inferences that can be drawn from these findings. Impression management is a behavior that cannot be taken out of context of the relationships in which they occur. It is, by definition, a social construct and is embedded in the dynamic nature of relationships. Therefore, it is inappropriate to draw inferences regarding this phenomenon without insight into supervisee perceptions of their relationships. Moreover, the emphasis of this study was specifically on master's level trainees who were enrolled in their first semester and had little or no experience. To add to that, the homogeneity of the sample with respect to gender (female) and race (Caucasian) further restricts the generalizability of these findings. For these reasons Pitariu's research cannot be used to understand the use of impression management among doctoral level supervisees. The current study seeks to address the limitations of Pitariu's study by exploring the relationship between the supervisory relationship, counseling self-efficacy and impression management tactics from the perspective of supervisees enrolled in doctoral level counseling psychology programs.

\section{Proposed Study}

To date, no study has directly examined the relationship between three factors found to be invariably related to the experiences of supervisees in supervision: the supervisory working alliance, supervisee CSE, and the use of impression management. Although there are several studies that explore supervisee nondisclosures, nearly all of them conceptualize this behavior as supervisee resistance or manipulation, which confines one's understanding of supervisee experiences to a very narrow and limited view. The approach taken in this study seeks to gain a 
more comprehensive perspective by exploring what impressions supervisees attempt to portray and the behaviors that they use to elicit the respective images. From previous findings (Pitariu, 2007) it appears that nondisclosure is but one tactic used by supervisees and similarly, that impression management tactics vary depending on which counseling skills supervisees have or lack confidence in. Investigations into supervisee nondisclosures suggested that this behavior is negatively related to the supervisory working alliance. However, none of these studies explored the relationship of impression management, specifically, to the supervisory working alliance. In addition, the exact nature of the relationship between the supervisory working alliance and CSE remains unclear. An understanding of supervisee use of impression management in relation to these two variables also requires insight into how these variables interact with one another.

There are only two studies (Pitariu, 2007; Ward et al., 1985) that specifically examined impression management in counseling supervision and only one addressed the prevalence and nature of this phenomenon among supervisees, who were beginning trainees in master's level counseling programs. Given the previous research findings that doctoral level supervisees who are enrolled in counseling and clinical psychology programs withhold information from their supervisors and are concerned with their supervisors' impressions of them, it is necessary to explore the use of impression management among trainees at this level of training. However, an investigation that simply verifies the prevalence of a behavior is insufficient. Theoretical and empirical research on the supervisory working alliance and Counseling Self-Efficacy suggests that these variables are particularly relevant to the experiences of supervisees and, to add to that, may also be related to impression management. For this reason, this study also seeks to understand how the supervisory relationship and CSE possibly relate to supervisee use of impression management tactics. 
In sum, this study seeks to address the following research questions:

1) Do doctoral level supervisees use impression management tactics in supervision?

2) Is counseling self-efficacy (as measured by the total score on the COSE) predictive of impression management strategies (as measured by the five subscales on the IMS) when taking into account the supervisory working alliance, training level and experience level? 3) Is the supervisory working alliance (as measured by the two subscales on the SWAI-T) predictive of impression management strategies (as measured by the five subscales on the IMS) when taking into account CSE, training level and experience level? 


\section{Chapter 3}

\section{Method}

\section{Participants}

Given the dearth of research on impression management strategies used by supervisees who are at the internship phase of their doctoral training, the current study recruited pre-doctoral trainees enrolled in internship programs that are members of the Association of Psychology Postdoctoral and Internship Centers (APPIC). To address this research gap, participants who met the inclusion criteria for this study were trainees enrolled in American Psychological Association (APA) and APPIC accredited pre-doctoral internship programs within the U.S. who received supervision on a regular basis.

To reduce the risk of incorrectly asserting that a relationship does or does not exist, an a priori power analysis, using the statistical program, GPower (Faul, Erdfelder, Lang \& Buchner, 2007), was conducted to determine how many participants would be needed to form an adequate sample size (Cohen, 1992; Faul, Erdfelder, Buchner, \& Lang, 2009). With respect to power and significance criterion, Cohen (1992) recommended a value of .80 and .05, respectively, in order to reduce the risk of Type I (incorrectly asserting a relationship) and Type II errors (incorrectly denying a relationship). The selected effect size was based on the chosen statistical analysis for this study, which is a standard multiple regression. Thus, based on the recommended power (.80), significance (.05), and effect size (Cohen's d; .15; small) values the analysis indicated that 92 participants would constitute an adequate sample size. In order to recruit this number of participants, APPIC internship site training directors were asked to inform interns at their sites about this study via email. Trainees who chose to participate were asked to complete several forms, one of which was a demographic form that elicited information regarding their gender, 
ethnicity, age, training program (e.g., counseling or clinical psychology), years of counseling experience, and amount of supervision experience.

\section{Procedures}

The proposed study was first submitted to the Institutional Review Board (IRB) at West Virginia University (WVU). In accordance with the IRB protocol, this study must be approved by the WVU IRB prior to data collection. Following IRB approval, the researcher identified training directors of internship programs through the Association of Psychology Postdoctoral and Internship Centers (APPIC) online directory. After obtaining the list, an email was sent to every training director to ask them for assistance in recruiting internship trainees from their programs. Two documents were attached to the email: a cover letter addressed to trainees that requested their participation and described the purpose and procedures of the research and an informed consent form for their records. The body of the email asked training directors to distribute the forms to internship trainees via email and provided a summary of the proposed research project.

Interested participants were directed to the URL link included on the cover letter. The URL link to the study first directed the participants to the informed consent page that instructed them to read the information on the page and check a box to indicate whether they agree to participate. The informed consent form also informed participants to send an email to the investigator, Jenni Haist, if they were interested in receiving the final results. If participants indicated that they agreed to participate, they were directed to a page containing the demographic form. Once participants completed the demographic questionnaire, they were directed to the designated instruments where instructions for the respective measures were provided. Participants completed the following measures: demographic questionnaire, Supervisory Working Alliance Inventory - Trainee (SWAI-T), Impression Management Scale (IMS), and 
Counseling Self-Estimate Inventory (COSE). In order to control for potential order or carry over effects, participants completed the measures in a counterbalanced order. For the responses on the SWAI - T and IMS, participants were instructed to select one supervisor for both scales. Participants were informed that the selected supervisor should be providing supervision to them at the time of the study. Once the participants completed all measures, they were directed to a page that thanked them for their participation.

All responses were collected using Qualtrics, which is a company that enables users to create Web-based surveys. According to Qualtrics's security statement and privacy policy, participants' responses are transmitted over a secure, encrypted connection, only authorized persons (i.e., researcher) have access to the data, and all respondents' email addresses are safeguarded. To protect the confidentiality of participants, the researcher designed the survey to collect responses anonymously. No information collected can be used to lead back and identify a participant.

\section{Measures}

Participants were asked to complete a demographics questionnaire (see Appendix A) that solicited information regarding gender, ethnicity, age, counseling experience, year of training, type of doctoral training program, number of supervision sessions with current supervisor, and prior supervision experience. With respect to levels of ethnicity, because the final sample reflected a small number of participants for the different ethnic groups the participants were categorized as either White or Non-White. The following instruments provided measures of supervisory working alliance, impression management strategies, and counseling self-efficacy.

Supervisory Working Alliance Inventory -Trainee. The Supervisory Working Alliance Inventory - Trainee form is a measure of supervisee perceptions of the counseling 
supervision relationship (Efstation et al., 1990). Supervisory working alliance is defined as "that sector of the overall relationship between the participants in which supervisors act purposefully to influence trainees through their use of technical knowledge and skill and in which trainees act willingly to display their acquisition of knowledge and skill" (Efstation et al., p. 323). The development of this scale was based on a sample of advanced doctoral-level supervisees who were primarily from counseling and clinical psychology programs.

The SWAI - Trainee Version consists of 19 items and is divided into two scales: rapport and client focus. Efstation et al. (1990) defined rapport as supervisor efforts to build rapport with trainees through support and encouragement and defined client focus as supervisor emphasis on promoting trainee understanding of clients. Twelve items measure rapport (e.g., "My supervisor makes the effort to understand me") and seven items measure client focus (e.g., "My supervisor encourages me to take time to understand what the client is saying and doing").

The SWAI-T asks respondents to rate how frequently their supervisors engage in specific behaviors on a 7-point Likert-type scale ranging from one, almost never, to seven, almost always. Scores can range from 19 to 133 and scores on the subscales can range from six to 42 for Client Focus and 13 to 91 for Rapport. The two subscale scores are combined to calculate the overall score for the SWAI-T. Higher scores on the subscales and on the total scale indicate perceptions of strong supervisory working alliances and lower scores denote perceptions of weak supervisory working alliances (Efstation et al., 1990).

The SWAI - Trainee version appears to be an adequately valid and reliable measure. Efstation et al.'s (1990) exploratory factor analysis yielded the two subscales, Client Focus and Rapport. The results of an orthogonal (varimax) rotation demonstrated that the Rapport subscale accounted for approximately $30 \%$ of the variance and that the 12 items loaded highly (> .40) on 
this factor. The Client Focus subscale accounted for approximately $8 \%$ of the variance, with seven items loading highly (> .50) on this factor. Using Cronbach's alpha to estimate the internal consistency reliability, the Rapport and Client Focus subscales were .90 and .77, respectively. Item scale correlations for the subscales ranged from .44 to .77 for Rapport and from .37 to .53 for Client Focus.

Convergent and divergent validities were established using the Supervisory Styles Inventory (SSI; Friedlander \& Ward, 1984) and the Self-Efficacy Inventory (SEI; Friedlander \& Snyder, 1983). More specifically, correlational analyses revealed a significant positive correlation between the Client Focus subscale to the Task-oriented subscale $(r=.52)$, Attractive $(r=.40)$ and Interpersonally Sensitive $(r=.51)$ subscales of the SSI - Trainee Version and to the Task -oriented $(r=.21)$ subscale of the SSI - Supervisor Version. The Rapport subscale was significantly positively related with scores on the Attractive subscale of both the supervisor and trainee version of the SSI and with scores on the Interpersonally Sensitive subscale of the SSI Trainee version. Both the Rapport $(r=.22)$ and Client Focus $(r=.15)$ subscales were significantly, positively related to scores on the Self-Efficacy Inventory. Overall, the findings revealed statistically significant relationships of the SWAI-T and the scales of the SSI and SEI. As mentioned earlier, the SWAI-T was developed to measure the supervisory working alliance from the supervisee perspective. As such, the SWAI-T total scale and the scores on each subscale were used in this study to measure internship trainees' perceptions of their supervisory working alliance. The reason for this is that in order to understand the nature of supervisee use of impression management, it was also important to understand how interns perceive the particular relationship in which they engage such behaviors. 
Impression Management Scale. The Impression Management Scale (IMS) is a measure of impression management behaviors (Bolino \& Turnley, 1999). Bolino and Turnley defined impression management as "the process whereby people seek to influence the image others have of them" (p. 187). To develop a measure based on impression management theory, the authors used Jones and Pittman's (1982) taxonomy of impression management behaviors as the basis for the IMS.

The IMS scale consists of 22 items and comprises five subscales, which reflect Jones and Pittman's theoretical groupings of impression management: self-promotion, ingratiation, exemplification, intimidation, and supplication. Bolino and Turnleys' (1999) definitions of the subscales along with examples of the items reflecting these constructs are as follows:

1) Self-promotion: individuals point out their abilities or accomplishments in order to be seen as competent by observers (e.g., "Make people aware of your accomplishments").

2) Ingratiation: individuals do favors or use flattery to elicit an attribution of likeability from observer (e.g., “Take an interest in your supervisor's personal life”).

3) Exemplification: people self-sacrifice or go above and beyond the call of duty in order to gain the attribution of dedication from observers (e.g., "Arrive at work early in order to look dedicated").

4) Intimidation: people signal their power or potential to punish in order to be seen as dangerous by observers (e.g., "Punish people when they do not behave as you would like"). 
5) Supplication: individuals advertise their weaknesses or shortcomings in order to elicit an attribution of being needy from observers (e.g., "Advertise your incompetence in a particular area or about a particular issue") (Bolino \& Turnley, 1999, p. 190).

Supplication and intimidation subscales are each assessed through five items whereas the remaining subscales each consist of four items. Respondents are asked to rate how frequently they engage in specific behaviors by checking one of five boxes on a Likert-type scale. The measure consists of the following five-point scale anchors: "(1) never behave this way, (2) very rarely behave this way, (3), occasionally behave this way, (4) sometimes behave this way, and (5) often behave this way" (Bolino \& Turnley, p. 192). The subscale scores, which range from 0 to 25 , are the sum of the ratings for each item on the respective subscales.

There appears to be adequate evidence for the construct validity of this measurement. Bolino and Turnley (1999) maintained that "the construct validity of an instrument is supported when confirmatory techniques indicate that the factor structure of the scale is consistent with the constructs that the instrument purports to measure" (p. 195). The Goodness of Fit Index (.97), the Tucker-Lewis Index (1.00), and the Comparative Fit Index (1.00) revealed a good fit between the proposed model and the data. Each item significantly loaded on its appropriate factor (i.e., subscale) $(p<.01)$, suggesting that the items in the respective subscales measure the intended impression management category. To determine whether the combined subscales capture the global impression management factor, the authors conducted a second-order confirmatory factor analysis. These results also revealed a good fit between the five categories and impression management $(\mathrm{GFI}=.91, \mathrm{TLI}=.92, \mathrm{CFI}=.94)$. The following factor loadings from individual impression management tactics to the global impression management factor were all significant $(p<.01)$ : self-promotion (.48), ingratiation (.62), exemplification (.78), intimidation (.46), and 
supplication (.65). Taken together, the results indicated that the subscales measure the intended constructs and offered support for the construct validity of the overall scale.

Convergent and discriminant validities were also established using measures of loyalty, obedience, and functional participation (Organizational Citizenship Behavior Scale; Van Dyne, Graham, \& Dienesch, 1994), conscientiousness (20-item scale of conscientiousness; Goldberg, 1992), perceived organizational support (Survey of Perceived Organizational Support;

Eisenberg, Huntington, Hutchinson, \& Sowa, 1986), self-monitoring (13-item self-monitoring scale; Lennox \& Wolfe, 1984), and careerism (8-item scale of careerism; Feldman \& Weltz, 1991). With respect to convergent validity, self-monitoring and careerism scores were significantly positively correlated with the impression management scale. More specifically, the self-promotion $(r=.30)$, intimidation $(r=.80)$, and supplication $(r=.24)$ subscales were all positively and significantly related to scores on the careerism scale. In other words, individuals who tend to "pursue career advancement through non-performance-based means" are more likely to manage others impressions through tactics associated with self-promotion, intimidation, and supplication (Bolino \& Turnley, 1999, p. 201). The self-monitoring scale was significantly and positively related to self-promotion $(r=.32)$, ingratiation $(r=.28)$, and exemplification $(r=.20)$. Thus, these strategies are likely to be used by individuals who change their behaviors according to the social situation on account of their acute awareness of the impressions they portray and the appropriateness of those impressions.

In regard to discriminant validity, scores on the conscientiousness and perceived organizational support scales failed to demonstrate a significant relationship with any of the impression management tactics. Furthermore, as expected the loyalty subscale on the Organizational Citizenship Behavior Scale was not significantly related to impression 
management. Scores on the obedience subscale were significantly negatively related to supplication and scores on the functional participation subscale were significantly, positively related to ingratiation and exemplification. Thus, individuals are less likely to portray an image of being weak and dependent when they demonstrate greater levels of respect for rules and policies and greater willingness to exert effort on the organization's behalf. On the other hand, individuals who demonstrate greater willingness to perform additional work and to promote their own development are more likely to act in ways that will portray images of likeability and dedication.

Bolino and Turnley's (1999) studies examining reliability of items demonstrated good reliability for the impression management scale. The coefficient alphas for all five impression management subscales were as follows: self-promotion (.78), ingratiation (.83), exemplification (.75), intimidation (.86), and supplication (.88). According to Nunnally (1978), Cronbach coefficient alpha scores that are above .70 are required to meet the criterion for acceptable reliability. In sum, the psychometric properties of this instrument indicate that it is both a valid and reliable measure of impression management strategies.

Although the scale was not developed using a sample of counseling supervisees, it was normed on diverse samples from multiple organizations. These samples differed with respect to gender, age, and hierarchical status. Furthermore, the authors' qualitative analyses during the scale development process suggested that participants engaged in strategies to create favorable impressions with their bosses or supervisors. Given the hierarchical and evaluative nature of the organizations from which these samples were drawn, this scale should be applicable for use across diverse organizational settings, including psychology internship sites. 
There is evidence to suggest, moreover, that this scale is a valid and reliable measure of impression management strategies in counseling supervision. Using a sample of master's level counselor supervisees, Pitariu's (2007) dissertation research revealed findings similar to those of Bolino and Turnley (1999). For instance, an examination of the correlation matrix revealed a pattern of positive relationships among the various impression management strategies and all of the subscales correlated positively with the total IMS. More specifically, positive correlations emerged among the following subscales: self-promotion, ingratiation and exemplification; ingratiation and exemplification; and exemplification and supplication. In addition, all of the subscales proved to be sufficiently internally consistent, with Cronbach's alphas of .70 or higher: self-promotion (.87), ingratiation (.83), exemplification (.77), intimidation (.86), supplication (.89). Taken together, Pitariu's research confirmed that the IMS is a reliable and valid instrument and more importantly, that it is an appropriate measure to use with trainee counselors in supervision.

For purposes of this study, only four subscales were included: self-promotion, ingratiation, exemplification, and supplication. Due to the estimated time of completion, the researcher first attempted to shorten the measure by removing scales with insufficient factor loadings; however, with the exception of one item, the factor loadings for each item were high (.65 and above). Therefore, the elimination of the intimidation scale was based on theoretical rationale. An exploration of the four subscales provided useful information regarding whether interns intentionally manage their supervisors' impressions as well as a more in-depth understanding of the nature of supervisee use of impression management. More specifically, analyses of the subscales offered insight into the types of impressions supervisees seek to portray and the behaviors commonly used to elicit these images. 
Counseling Self-Estimate Inventory. Larson and colleagues (1992) developed the Counseling Self-Estimate Inventory (COSE) to provide a measure of "counselor judgments of their capabilities to counsel successfully in counseling situations or their expectancies for success in counseling situations" (i.e., counseling self-efficacy) (p. 106). The construction of this scale was based on counselor trainees enrolled in graduate level programs. According to Larson and Daniels (1998), the COSE is the most commonly used scale of CSE with adequate measures of validity and reliability.

The COSE consists of 53 items and is structured into a Likert scale format. Respondents are asked to rate how confident they are in their counseling abilities on a scale that ranges from one, strongly disagree, to six, strongly agree. Scores can range from 62 to 222, with higher scores reflecting higher levels of CSE and lower scores suggesting lower CSE levels.

According to the results of a principal-factors extraction (varimax rotation), the COSE comprises five subscales: Microskills, Process, Difficult Client Behaviors, Cultural Competence, and Awareness of Values. Items on each subscale assess how confident respondents are in their abilities to perform the related skills. The Microskills subscale assesses the quality of counseling responses and the ability to track client responses (e.g., "I am certain that the content of my interpretation and confrontation responses will be consistent with and not discrepant from what the client is saying"). This factor consists of 12 items and has factor loadings that range from .41 to .64 .

Process refers to the delivery of counselor responses over time, ongoing client conceptualization in session and the integration of responses and interpretations when working with the client. This subscale is assessed through 10 items and has factor loadings ranging from .43 to .58 . An example of the items that reflect this construct is "I am worried that my 
interpretation and confrontation responses may not over time assist the client to be more specific in defining and clarifying the problem."

The third subscale, Difficult Client Behaviors, measures respondents' confidence levels in their abilities to effectively work with "clients who are unmotivated, suicidal, abused, alcoholic, indecisive, or silent" (e.g., "I do not feel I possess a large enough repertoire of techniques to deal with the different problems my clients may present”) (Larson et al., p. 109). There are seven items on this subscale with factor loadings ranging from .46 to .63. Two items pertain to the perceptions of knowledge and techniques and one item concerns the ability to perform effectively.

The Cultural Competence subscale concerns the perceived ability to behave in a competent way when providing therapeutic services to clients of differing ethnicities, cultural backgrounds, and social classes (e.g., "In working with culturally different clients I may have a difficult time viewing situations from their perspective"). Four items measure respondents' confidence in Cultural Competence. The factor loadings range from .51 to .66. Awareness of Values consists of four items and has factor loadings ranging from .42 to .64. This scale assesses how confident counselor trainees are in their levels of awareness regarding their biases and values (e.g., "I feel confident that I have resolved conflicts in my personal life so that they will not interfere with my counseling abilities").

Larson et al. (1992) used Cronbach's alpha coefficient to provide estimates of internal consistency. Reliability estimates for the total score and for the subscales all exceeded .70: COSE Total (.93), Microskills (.88), Process (.87), Difficult Client Behaviors (.80), Cultural Competence (.78), Awareness of Values (.62). Item total correlations ranged from .32 to .65, with the exception of three items which were $.27, .16$, and .23 . In addition, test-retest reliability 
over a three-week interval for the COSE proved to be adequate: COSE Total $(r=.87)$, Microskills $(r=.68)$, Process $(r=.74)$, Difficult Client Behaviors $(r=.80)$, Cultural Competence $(r=.71)$, and Awareness of Values $(r=.83)$

Convergent and divergent validities were assessed using the Tennessee Self-Concept Scale (TSCS), the State-Trait Anxiety Inventory (STAI), the Problem Solving Inventory (PSI), the Social Desirability Scale (SDS), the Graduate Record Examination (GRE), undergraduate grade point average (GPA), and the Myers-Briggs Type Indicator (MBTI). With respect to convergent validity, scores on the COSE were significantly, moderately related to self-concept scores on the TSCS (.51). As expected, scores on the COSE were significantly negatively related to state (-.42) and trait anxiety (-51) as measured by the STAI. In addition, the findings revealed a significant negative correlation between scores on the COSE and the PSI (-.73). Since lower scores on the PSI are indicative of perceptions of more effective problem-solving skills, this suggests that higher levels of CSE are related to more positive perceptions of problemsolving abilities. With respect to divergent validity, scores on the COSE were minimally related to ratings of defensiveness on the SDS (.27) and to faking on the TSCS (-.18). Likewise, the COSE was minimally related to measures reflecting aptitude (.16, Verbal; .10, Quantitative) and achievement (.25). Personality type as measured by the MBTI was not related to scores on the COSE.

In this study, the COSE was used to determine participants' general CSE levels. Only the combined score of three subscales were included: process, cultural competence and awareness of values. Due to the estimated time of completion, the researcher first attempted to remove scales based on insufficient factor loadings; however, all of the items had relatively high factor loadings. As a result, two scales were cut out of the instrument based on theoretical and 
empirical grounds. Research findings suggest that competency in microskills and dealing with difficult client behaviors are areas that have greater relevance for upcoming psychologists at the beginning stages of their training (Larson et al., 1992). Given that the participants of this study were at an advanced level of their training, the microskills and difficult client behaviors subscales were excluded. An analysis of this scale will provide valuable information on the nature of the relationship between impression management, the supervisory working alliance and CSE.

Although supervisees in their final stages of training have high CSE (Sipps et al., 1988), the curvilinear relationship between graduate training level and CSE necessitates consideration of heteroskedasticity, which occurs when the variance of a variable is not constant. If this occurred, then the researcher corrected for heteroskedasticity by weighting each participant's score on the COSE by the inverse of the standard deviation of the error for that observation. The use of this method allows for unbiased standard errors of coefficients.

\section{Design}

To determine whether counseling self-efficacy and/or the supervisory working alliance predicted the use of impression management strategies, a standard multiple regression analysis was conducted. Since more than one variable was used to predict supervisee use of impression management, this was considered the most appropriate design. This test provided information regarding the relationship of the demographic variables (i.e., experience and training level), the supervisory working alliance, and counseling self-efficacy (predictor variables) to the criterion variable (impression management strategies).

More specifically, this study sought to address the following research questions: 
1) Can we predict, using multiple linear regression, a respondent's Self-Promotion score based on a linear combination of their [SWAI-T score + COSE Total Score + Hours of Experience + Gender + Ethnicity] The predictor variables will be the total score on the SWAI-T, the total score of COSE, experience level and the criterion (dependent) variable will be the Self-Promotion subscale on the IMS.

2) Can we predict, using multiple linear regression, a respondent's Ingratiation score based on a linear combination of their [SWAI-T score + COSE Total Score + Hours of Experience + Gender + Ethnicity] The predictor variables will include the total score on the SWAI-T, the total score on the COSE, experience level, gender, and ethnicity. The Ingratiation subscale on the IMS will be the criterion (dependent) variable.

3) Can we predict, using multiple linear regression, a respondent's Exemplification score based on a linear combination of their [SWAI-T score + COSE Total Score + Hours of Experience + Gender + Ethnicity] The predictor variables will include the total score on the SWAI-T, the total score on the COSE, experience level, gender, and ethnicity. The Exemplification subscale on the IMS will be the criterion (dependent) variable.

4) Can we predict, using multiple linear regression, a respondent's Supplication score based on a linear combination of their [SWAI-T score + COSE Total Score + Hours of Experience + Gender + Ethnicity] The predictor variables will include the total score on the SWAI-T, the total score on the COSE, experience level, gender, and ethnicity. The Supplication subscale on the IMS will be the criterion (dependent) variable.

5) Can we predict, using multiple linear regression, a respondent's Total score on the IMS based on a linear combination of their [SWAI-T score + COSE Total Score + Hours of Experience + Gender + Ethnicity] The predictor variables will include the total score on 
the SWAI-T, the total score on the COSE, experience level, gender, and ethnicity. The total score on the IMS will be the criterion (dependent) variable. 


\section{Chapter 4}

\section{Results}

\section{Descriptive Statistics}

In this study, the total number of participants was 159 doctoral level interns; however, only 157 of these participants' scores were analyzed. The excluded participants' responses for experience level were more than two standard deviations greater than the responses of the sample. Their data were removed since the inclusion of these outliers resulted in a non-normal distribution. Respondents provided demographic information regarding gender, ethnicity, age, doctoral training program, degree of program, internship site, experience level, amount of supervision, time spent with current supervisor, and frequency of supervision. Descriptive analyses were performed on the demographic information to determine the percentages, frequencies, means, and standard deviations.

The average age of interns who participated in this study was 29 years; their ages ranged from 25 to 50 (see Table 1). The sample consisted of $81.5 \%(\mathrm{n}=128)$ female and $16.6 \%(\mathrm{n}=$ 26) male participants. With respect to ethnicity, $79 \%$ of the respondents were White $(n=124)$ and 19\% described themselves as African American $(n=8)$, Asian American $(n=4)$, Hispanic/Latino $(\mathrm{n}=8)$, Native American $(\mathrm{n}=3)$, Middle-Eastern American $(\mathrm{n}=3)$, Canadian $(n=2)$, Biracial $(n=1)$, or Foreign National $(n=1)$. For statistical purposes, these participants were labeled non-White $(\mathrm{n}=30)$. The frequencies for gender and ethnicity are presented in Table 2 .

Most of the interns were enrolled in Psy.D. (50.3\%) and Ph.D. programs (47.8\%). Only one participant reported being enrolled in an Ed.D. program (.63\%). The majority of interns were enrolled in Clinical Psychology (75.8\%) and Counseling Psychology programs (16.6\%). Interns enrolled in different psychology programs $(6.3 \%)$ reported their programs' orientations as 
one of the following: Combined Clinical-Counseling Psychology, Combined Counseling-School Psychology, School Psychology, and Educational Psychology. Most of the respondents' internships included Medical Centers and hospitals (19.1\%), Community Mental Health Centers (17.8\%), Veterans Administration hospitals (16.6\%), and College Counseling Centers (14.6\%). Additional internship sites included Correctional Facilities/Prisons (8.3\%), Outpatient Centers and Practices (6.4\%), Residential Treatment Center (3.8\%), Consortiums (3.2\%), Psychiatric and Inpatient Hospitals (3.2\%), Private Practices (2.5\%), Military Medical Centers (2.5\%) and Military Internships (.6\%). The data are presented in Table 3.

The average experience level of interns was 1337.28 hours with a median of 1000 hours. The least and greatest levels of experience were 50 and 4000 hours, respectively. This variable was positively skewed $(\mathrm{z}=5.75)$ : most respondents reported having less experience. On average, interns reported 53.68 months (4 years, 5.68 months) for total time spent in supervision and 7.06 months for time spent with current supervisor. In terms of frequency of supervision, $60.5 \%$ of the interns received supervision once a week, $24.8 \%$ received supervision twice a week, $12.1 \%$ received supervision more than twice a week, and $1.3 \%$ received supervision every other week. The data are presented in Table 4.

Table 1

Descriptive Data of Participants Age

\begin{tabular}{lrcccc}
\hline & $\mathrm{n}$ & Minimum & Maximum & Mean & Std. Deviation \\
\hline Age & 136 & 25 & 50 & 29.9 & 3.90 \\
Missing Data & 21 & & & & \\
\hline
\end{tabular}


Table 2

Frequencies of Gender and Ethnicity

\begin{tabular}{lcc}
\hline & Frequency & Percent \\
\hline Gender & & \\
Female & 128 & 81.5 \\
Male & 26 & 16.6 \\
Missing Data & 3 & 2.0 \\
Ethnicity & & \\
White & 124 & 79.0 \\
Non-White & 30 & 19.0 \\
Missing Data & 3 & 2.0 \\
\hline
\end{tabular}

Table 3

Frequencies of Degree, Training Program, and Internship Site of Participants

\begin{tabular}{|c|c|c|}
\hline & Frequency & Percent \\
\hline \multicolumn{3}{|l|}{ Degree } \\
\hline Ph.D. & 75 & 47.8 \\
\hline Psy.D. & 79 & 50.3 \\
\hline Ed.D. & 1 & 0.6 \\
\hline Missing Data & 2 & 1.3 \\
\hline \multicolumn{3}{|l|}{ Training Program } \\
\hline Counseling Psychology & 26 & 16.6 \\
\hline Clinical Psychology & 119 & 75.8 \\
\hline Other & 10 & 6.3 \\
\hline Missing Data & 2 & 1.3 \\
\hline \multicolumn{3}{|l|}{ Internship Site } \\
\hline Medical Center/Hospital & 30 & 19.1 \\
\hline Community Mental & 28 & 17.8 \\
\hline \multicolumn{3}{|l|}{ Health } \\
\hline Veteran's & 26 & 16.6 \\
\hline \multicolumn{3}{|l|}{ Administration } \\
\hline College Counseling & 23 & 14.6 \\
\hline \multicolumn{3}{|l|}{ Center } \\
\hline Correctional & 13 & 8.3 \\
\hline \multicolumn{3}{|l|}{ Facility/Prison } \\
\hline Outpatient Center & 10 & 6.4 \\
\hline Residential Treatment & 6 & 3.8 \\
\hline Consortium & 5 & 3.2 \\
\hline Inpatient Hospital & 5 & 3.2 \\
\hline Private Practice & 4 & 2.5 \\
\hline Military Medical Center & 4 & 2.5 \\
\hline Military & 1 & 0.6 \\
\hline Missing Data & 2 & 1.3 \\
\hline
\end{tabular}


Table 4

Descriptive Data of Counseling Experience and Supervision

\begin{tabular}{|c|c|c|c|c|c|}
\hline & $\mathrm{N}$ & Minimum & Maximum & Mean & Std. Deviation \\
\hline Hours of Experience & 137 & 50 & 4000 & 1337.28 & 871.35 \\
\hline Missing Data & 20 & & & & \\
\hline Months of Supervision & 149 & 8 & 108 & 53.68 & 17.68 \\
\hline Missing Data & 8 & & & & \\
\hline $\begin{array}{l}\text { Months with Current Supervisor } \\
\text { Missing Data }\end{array}$ & $\begin{array}{r}151 \\
6\end{array}$ & 1 & 72 & 7.06 & 6.32 \\
\hline Frequency of Supervision & 151 & 1 & 4 & 1.54 & .76 \\
\hline Missing Data & 6 & & & & \\
\hline
\end{tabular}

\section{Inferential Statistics}

Preliminary Analyses. Prior to analysis, hours of experience (Experience), supervisory working alliance (SWAI), and counseling self-efficacy (COSE) were examined for outliers. Two cases with extremely high z scores on Experience were found to be univariate outliers. Case \#128 had a score of 14,000 , which is approximately 14.53 standard deviations above the mean (1337.28) of this variable and case \# 154 had a score of 7,000, which is approximately 6.49 standard deviations above the mean. Both cases are considered to be outliers since they are beyond the $p=.001$ criterion of 3.29 , two tailed, and they are disconnected from the other cases. Similarly, inclusion of the cases rendered the data un-interpretable, as evidenced by Mahalanobis Distance values exceeding the critical Chi Square value of 20.52. Although both cases are considered to be from the intended population and were not found to be recorded in error, when the cases were retained and their scores were assigned a value that was one unit larger than the next most extreme score, the two cases still proved to be outliers. Since the distribution of this variable continued to be non-normal even after the cases were assigned a value of 5,457, the outliers were removed from the dataset, leaving 157 cases for analysis. With the use of $p<.001$ criterion for Mahalanobis distance, no additional outliers among the cases were found. 
Preliminary analyses were also conducted to ensure that the assumptions of normality, linearity, multicollinearity, and homoscedasticity were not violated. Both of the dichotomous independent variables, gender and ethnicity, met the recommended criteria with more than $10 \%$ and less than $90 \%$ of the participants in their respective categories. Gender consisted of $81.5 \%$ females and $16.6 \%$ males. With respect to race, $79 \%$ of the participants were White and $19 \%$ were Non-White. The normality of distributions of all continuous independent variables was analyzed through examination of normality plots, normal probability plots of residuals and scatter diagrams of residuals versus predicted residuals, and skewness and kurtosis statistics. Both the normality plots and the results of skewness and kurtosis indicated that COSE was normally distributed (Skewness, $\mathrm{z}=-1.28$; Kurtosis, $\mathrm{z}=.71$ ). Experience and SWAI were not normally distributed. Experience was positively skewed $(\mathrm{z}=5.75)$ and SWAI was negatively skewed $(\mathrm{z}=-4.48)$. As a result, a square root transformation was taken on the Experience variable. According to Tabachnick and Fidell (2013) when a variable's “distribution differs moderately from normal" and is positively skewed then a square root transformation should be attempted first (p. 87). The variable's skewness was greatly improved by this transformation, resulting in a normal distribution (Skewness, $\mathrm{z}=2.78$; Kurtosis, -.25 ). As suggested by Tabachnick and Fidell, a reflect and logarithmic transformation was taken on the SWAI variable since the normality of its distribution varies moderately and it is negatively skewed. This transformation also improved the skewness of the variable and resulted in a normal distribution (Skewness, $\mathrm{z}=1.01$; Kurtosis, 1.42). After these variables were transformed, no violations of normality, linearity, or homoscedasticity of residuals were detected. Descriptive statistics for the continuous independent variables are provided in Table 5. 
Table 5

Normality Data of Continuous Independent Variables

\begin{tabular}{lrrrrrrr}
\hline & N & Mean & Std. Deviation & \multicolumn{2}{c}{ Skewness } & \multicolumn{2}{c}{ Kurtosis } \\
& & & & Statistic & Std. Error & Statistic & Std. Error \\
\hline COSE & 132 & 80.10 & 12.34 & -.27 & .21 & -.30 & .42 \\
SWAI & 143 & 5.37 & .86 & -.91 & .20 & .64 & .40 \\
Transformed & 143 & .40 & .14 & .20 & .20 & -.57 & .40 \\
Experience & 137 & 1469.12 & 1457.75 & 1.19 & .21 & .64 & .41 \\
Transformed & 137 & 34.80 & 11.28 & .58 & .21 & -.10 & .41 \\
\hline
\end{tabular}

Statistical Analysis of Hypotheses. To determine whether counseling self-efficacy, supervisory working alliance, experience level, gender, and ethnicity predict the use of impression management strategies, the proposed hypotheses were tested using standard multiple regression. More specifically, a forward selection statistical regression was performed between the dependent variable (the subscales and total scale of impression management) and the independent variables (gender, ethnicity, hours of experience, supervisory working alliance, and counseling self-efficacy). Analysis was performed using IBM SPSS Regression.

Hypothesis I. The first research hypothesis was as follows: Self-Promotion scores will be significantly predicted by a linear combination of their responses on the SWAI-T, COSE, hours of experience, gender, and ethnicity.

The researcher expected that SWAI-T, COSE, experience level, gender, and ethnicity would predict their use of Self-Promotion in supervision. Given previous research findings (i.e., Pitariu, 2007), the researcher anticipated that higher scores of counseling self-efficacy would predict lower scores on the Self-Promotion subscale. The hypothesized relationship between counseling self-efficacy and amount of counseling experience led the researcher to anticipate a similar finding regarding participants' reported hours of experience and their use of Self- 
Promotion. Similarly, scores reflecting stronger working alliances were expected to predict fewer endorsements of Self-Promotion. The researcher also anticipated that differences in gender and ethnicity would be predictive of Self-Promotion.

Results. This hypothesis was analyzed using a forward selection statistical regression. The predictor variables were the total score on the SWAI-T, the total score of COSE, experience level, gender, and ethnicity and the criterion (dependent) variable was the Self-Promotion subscale on the IMS. When all five independent variables (gender, ethnicity, experience level, supervisory working alliance, and counseling self-efficacy) were entered into the model the regression analysis revealed that the model did not significantly predict Self-Promotion, F (5, $107)=.36, p=.87$. R Square for the model was .02 and Adjusted R Square was - .03.

The removal of independent variables is consistent with Bendel and Afifi's (1977) suggestion to use "a liberal criterion for entry of predictors in forward regression. Important variables are less likely to be excluded from the model with a more liberal probability level for entry of .15 to .20 rather than .05 " (Tabachnick \& Fidell, 2013, p.140). Therefore, variables that did not make a significantly unique contribution to the model were removed one at a time until all remaining variables had a significance level equal to or less than .10. Since Experience had the least significance $(p=.97)$, it was the first variable to be removed. Regression analyses after removal of this variable revealed that the model did not significantly predict Self-Promotion, F $(4,121)=1.18, p=.32$. R Square for the model was .04 and Adjusted R Square was .01. After the second variable was removed from the model (Ethnicity, $p=.56$ ), regression analyses still revealed that the model failed to significantly predict Self-Promotion, $\mathrm{F}(3,122)=1.46, p=.23$. R Square for the model was .04 and Adjusted R Square was .01. Gender was the third variable removed from the model $(p=.51)$. Regression analyses indicated that the resultant model did 
not significantly predict Self-Promotion, F $(2,123)=1.98, p=.14$. R Square for the model was .03 and Adjusted R Square was .02.

After removal of the fourth variable (COSE, $p=.34$ ) the model did significantly predict Self-Promotion, $\mathrm{F}(1,133)=3.12, p=.08$. R Square for the model was .02 and Adjusted $\mathrm{R}$ Square was .02. Therefore, although SWAI was found to be a significant predictor of SelfPromotion, it only explains $2 \%$ of the variance in the dependent variable $(t=-1.77, p=.08)$. The results of the analyses are presented in Table 6.

Table 6

Results of Multiple Regression Analysis for Self-Promotion Subscale

Model Summary

\begin{tabular}{rccc}
\hline Model & $\mathrm{R}^{2}$ & Adjusted $\mathrm{R}^{2}$ & Std. Error of Estimate \\
1 & .02 & .02 & 3.22 \\
\hline
\end{tabular}

ANOVA

\begin{tabular}{lcrccc}
\hline & Sum of Squares & df & Mean Square & F & Sig. \\
\hline Regression & 32.49 & 1 & 32.49 & 3.12 & .08 \\
\hline Residual & 1382.72 & 133 & 10.40 & & \\
\hline
\end{tabular}

\begin{tabular}{cccccccc}
\hline & B & Std. Error & $\beta$ & $\mathrm{t}$ & Sig. & $95 \%$ CI for B & $\begin{array}{r}\text { Partial } \\
\text { Correlations }\end{array}$ \\
\hline SWAI & -3.59 & 2.03 & -.15 & -1.77 & .08 & $(-7.61, .427)$ & -.15 \\
\hline
\end{tabular}

Hypothesis II. Ingratiation scores will be significantly predicted by a linear combination of their responses on the SWAI-T, COSE, hours of experience, gender, and ethnicity.

The researcher expected that SWAI-T, COSE, experience level, gender, and ethnicity would predict participant use of Ingratiation in supervision. The researcher anticipated that higher scores of counseling self-efficacy and supervisory working alliance would predict lower scores on the Ingratiation subscale. The hypothesized relationship between counseling self- 
efficacy and amount of counseling experience led the researcher to anticipate a similar finding regarding participants' reported hours of experience and their use of Ingratiation. The researcher also anticipated that differences in gender and ethnicity would be predictive of Self-Promotion.

Results. This hypothesis was analyzed using a forward selection statistical regression. The predictor variables included the total score on the SWAI-T, the total score on the COSE, experience level, gender, and ethnicity. The Ingratiation subscale on the IMS was the criterion (dependent) variable. When all five independent variables (gender, ethnicity, hours of experience, supervisory working alliance, and counseling self-efficacy) were entered into the model the regression analyses revealed that the model significantly predicted Ingratiation, $\mathrm{F}$ (5, $107)=6.45, p<.01$. R Square for the model was .23 and Adjusted R Square was .20.

Per Bendel and Afifi's (1977) recommendation, variables that did not make a significantly unique contribution to the model were removed one at a time until all variables that remained in the model had a significance level equal to or less than .10 (Tabachnick \& Fidell, 2013). Since SWAI had the least significance $(p=.32)$, it was the first variable to be removed. Regression analyses after removal of this variable revealed that the model significantly predicted Ingratiation, $\mathrm{F}(4,113)=7.72, p<.01$. R Square for the model was .21 and Adjusted R Square was .19. The final four variables, Gender $(p=.05)$, Ethnicity $(p=.07)$, Experience $(p=.01)$ and Counseling Self-Efficacy $(p<.01)$, were retained. Table 7 displays the unstandardized regression coefficients (B), intercept, and standardized regression coefficients $(\beta)$ for each variable.

In terms of individual relationship between the independent variables and Ingratiation, Gender $(t=1.94, p=.05)$, Ethnicity $(t=-1.85, p=.07)$, Experience $(t=-2.62, p=.01)$, and $\operatorname{COSE}(t=-4.36, p<.01)$ significantly predicted the dependent variable (see Table 7). 
Together, the three variables contributed $19 \%$ in shared variability. The independent variables that made the greatest contributions to the model included $\operatorname{COSE}(\beta=-.36, p<.01)$, which explained $13.2 \%$ of the variance, and Experience $(\beta=-.23, p=.01)$, which explained $5.2 \%$ of the variance. Gender contributed 2.6\% $(\beta=.16, p=.05)$ and Ethnicity contributed $2.6 \%(\beta=-$ $.16, p=.07)$ of the variability in the dependent variable.

Table 7

Results of Multiple Regression Analysis for Ingratiation Subscale

Model Summary

\begin{tabular}{rlcc}
\hline Model & $\mathrm{R}^{2}$ & Adjusted $\mathrm{R}^{2}$ & Std. Error of Estimate \\
1 & .21 & .19 & 3.54 \\
\hline
\end{tabular}

ANOVA

\begin{tabular}{lcrccc}
\hline & Sum of Squares & df & Mean Square & F & Sig. \\
\hline Regression & 386.65 & 4 & 96.66 & 7.72 & .00 \\
\hline Residual & 1414.20 & 113 & 12.51 & & \\
\hline
\end{tabular}

\section{Coefficients}

\begin{tabular}{lrcccccc}
\hline & B & Std. Error & $\beta$ & $\mathrm{t}$ & Sig. & 95\% CI for B & $\begin{array}{r}\text { Partial } \\
\text { Correlations }\end{array}$ \\
\hline Gender & 1.74 & .90 & .16 & 1.94 & .05 & $(-.03,3.52)$ & .18 \\
Ethnicity & -1.52 & .82 & -.16 & -1.85 & .07 & $(-3.15, .11)$ & -.17 \\
Experience & -.08 & .03 & -.23 & -2.62 & .01 & $(-.14,-.02)$ & -.24 \\
COSE & -.11 & .03 & -.36 & -4.36 & .00 & $(-.17,-.06)$ & -.38 \\
\hline
\end{tabular}

Hypothesis III. Exemplification scores will be significantly predicted by a linear combination of their responses on the SWAI-T, COSE, hours of experience, gender, and ethnicity.

The researcher expected that SWAI-T, COSE, experience level, gender, and ethnicity would predict participant use of Exemplification in supervision. The researcher anticipated that higher scores of counseling self-efficacy and supervisory working alliance would predict lower 
scores on the Exemplification subscale. Higher levels of counseling experience were expected to predict lower use of Exemplification. Similarly, differences in gender and ethnicity were expected to predict endorsement of Exemplification items.

Results. This hypothesis was analyzed using a forward selection statistical regression. The predictor variables included the total score on the SWAI-T, the total score on the COSE, experience level, gender, and ethnicity. The Exemplification subscale on the IMS was the criterion (dependent) variable. When all five independent variables (gender, ethnicity, experience, supervisory working alliance, and counseling self-efficacy) were entered into the model the regression analyses revealed that the model significantly predicted Exemplification, $\mathrm{F}$ $(5,106)=5.60, p<.01 . \mathrm{R}$ Square for the model was .21 and Adjusted R Square was .17.

Per Bendel and Afifi's (1977) recommendation, variables that did not make a significantly unique contribution to the model were removed one at a time until all variables that remained in the model had a significance level equal to or less than .10 (Tabachnick \& Fidell, 2013). Experience, the variable with the least significance $(p=.76)$ was removed first. Regression analyses after removal of this variable revealed that the model still significantly predicted Exemplification, $\mathrm{F}(4,120)=6.23, p<.01$. R Square for the model was .17 and Adjusted R Square was .14. Gender was the second variable to be removed from the model ( $p=$ .62). Regression analyses indicated that the resultant model significantly predicted Exemplification, $\mathrm{F}(3,121)=8.27, p<.01$. R Square for the model was .17 and Adjusted $\mathrm{R}$ Square was .15. The final three variables, Ethnicity $(p=.02)$, SWAI $(p=.08)$, and Counseling Self-Efficacy $(p<.01)$, were retained. Table 8 displays the unstandardized regression coefficients (B), intercept, and standardized regression coefficients $(\beta)$ for each variable. 
In terms of the relationship between the independent variables and Exemplification,

Ethnicity $(t=-2.35, p=.02), \operatorname{SWAI}(t=1.78, p=.08)$, and $\operatorname{COSE}(t=-3.70, p<.01)$

significantly predicted the dependent variable (see Table 8). Together, the three variables contributed $15 \%$ in shared variability. Ethnicity explained $3.8 \%(\beta=-.19, p=.02)$, SWAI explained $2.3 \%(\beta=-.15, p=.08)$, and COSE explained $9.7 \%(\beta=-.31, p<.01)$ of the shared variability in the dependent variable.

Table 8

Results of Multiple Regression Analysis for Exemplification Subscale

Model Summary

\begin{tabular}{rccc}
\hline Model & $\mathrm{R}^{2}$ & Adjusted $\mathrm{R}^{2}$ & Std. Error of Estimate \\
1 & .17 & .15 & 3.52 \\
\hline
\end{tabular}

ANOVA

\begin{tabular}{lcrccc}
\hline & Sum of Squares & df & Mean Square & F & Sig. \\
\hline Regression & 308.34 & 3 & 102.78 & 8.27 & .00 \\
\hline Residual & 1503.15 & 121 & 12.42 & & \\
\hline
\end{tabular}

\section{Coefficients}

\begin{tabular}{lrrrrrrr}
\hline & B & Std. Error & $\beta$ & $\mathrm{t}$ & Sig. & 95\% CI for B & $\begin{array}{r}\text { Partial } \\
\text { Correlations }\end{array}$ \\
\hline Ethnicity & -1.88 & .80 & -.19 & -2.35 & .02 & $(-3.47,-.30)$ & -.21 \\
SWAI & 4.24 & 2.38 & .15 & 1.78 & .08 & $(-.47,8.94)$ & .16 \\
COSE & -.10 & .03 & -.31 & -3.69 & .00 & $(-.15,-.05)$ & -.31 \\
\hline
\end{tabular}

Hypothesis IV. Supplication scores will be significantly predicted by a linear combination of their responses on the SWAI-T, COSE, hours of experience, gender, and ethnicity.

The researcher expected that SWAI-T, COSE, experience level, gender, and ethnicity would predict participant use of Supplication in supervision. Higher scores on measures of counseling self-efficacy and supervisory working alliance were expected to predict lower scores 
on the Supplication subscale. The researcher expected a similar finding regarding participants' reported hours of experience and their use of Supplication. Similarly, scores reflecting stronger working alliances were expected to predict fewer endorsements of Supplication. The researcher also anticipated that differences in gender and ethnicity would be predictive of Supplication.

Results. This hypothesis was analyzed using a forward selection statistical regression. The predictor variables included the total score on the SWAI-T, the total score on the COSE, experience level, gender, and ethnicity. The Supplication subscale on the IMS was the criterion (dependent) variable. When all five independent variables (gender, ethnicity, experience level, supervisory working alliance, and counseling self-efficacy) were entered into the model the regression analyses revealed that the model did not significantly predict Supplication, F (5, 113) $=1.54, p=.18$. R Square for the model was .07 and Adjusted $\mathrm{R}$ Square was .02 .

Per Bendel and Afifi's (1977) recommendation, variables not making a significantly unique contribution to the model were removed one at a time until all remaining variables a significance level equal to or less than .10 (Tabachnick \& Fidell, 2013). Ethnicity, the variable with the least significance $(p=.60)$ was removed first. Regression analyses after removal of this variable revealed that the model still did not significantly predict Supplication, F $(4,109)=1.86$, $p=.12$. R Square for the model was .06 and Adjusted R Square was .03. Experience was the second variable removed from the model $(p=.69)$. Regression analyses indicated that the resultant model did not significantly predict Supplication, $\mathrm{F}(3,123)=1.79, p=.15$. R Square for the model was .04 and Adjusted R Square was .02. After removal of the third variable with the least significance, Gender $(p=.53)$, regression analyses revealed that the model did significantly predict Supplication, F $(2,124)=2.50, p=.09$. R Square for the model was .04 and Adjusted R Square was .02. SWAI $(p=.40)$ was the final variable removed from the model, 
which resulted in a significant prediction of Supplication, $\mathrm{F}(1,130)=7.01, p=.01$. $\mathrm{R}$ Square for the model was .05 and Adjusted R Square was .04.

Counseling Self-Efficacy (COSE) $(t=-2.65, p=.01)$ was the only variable found to significantly predict Supplication. Table 9 displays the unstandardized regression coefficients (B), intercept, and standardized regression coefficients $(\beta)$ for this variable. Despite its significance, COSE only contributed $5.1 \%(\beta=-.23, p=.01)$ of the variance in the dependent variable (see Table 9).

Table 9

Results of Multiple Regression Analysis for Supplication Subscale

Model Summary

\begin{tabular}{rccc}
\hline Model & $\mathrm{R}^{2}$ & Adjusted $\mathrm{R}^{2}$ & Std. Error of Estimate \\
1 & .05 & .04 & 2.64 \\
\hline
\end{tabular}

ANOVA

\begin{tabular}{lcrccc}
\hline & Sum of Squares & df & Mean Square & F & Sig. \\
\hline Regression & 48.86 & 1 & 48.86 & 7.01 & .01 \\
\hline Residual & 906.02 & 130 & 6.97 & & \\
\hline
\end{tabular}

Coefficients

\begin{tabular}{lccccccc}
\hline & B & Std. Error & $\beta$ & $\mathrm{t}$ & Sig. & $95 \%$ CI for B & $\begin{array}{c}\text { Partial } \\
\text { Correlations }\end{array}$ \\
\hline COSE & -.05 & .02 & -.23 & -2.65 & .01 & $(-.09,-.01)$ & -.23 \\
\hline
\end{tabular}

Hypothesis $\boldsymbol{V}$. Total Scores on the IMS will be significantly predicted by a linear combination of their responses on the SWAI-T, COSE, hours of experience, gender, and ethnicity.

The researcher expected that SWAI-T, COSE, experience level, gender, and ethnicity would predict participant use of Impression Management strategies in supervision. Higher scores on the counseling self-efficacy and supervisory working alliance measures were expected to predict lower scores on the Impression Management Scale. Similarly, greater levels of 
experience level were expected to predict fewer endorsements of Impression Management. The researcher anticipated that differences in gender and ethnicity would also be predictive of Impression Management.

Results. This hypothesis was analyzed using a forward selection statistical regression. The predictor variables included the total score on the SWAI-T, the total score on the COSE, experience level, gender, and ethnicity. The total score on the IMS was the criterion (dependent) variable. When all five independent variables (gender, ethnicity, hours of experience, supervisory working alliance, and counseling self-efficacy) were entered into the model the regression analyses revealed that the model significantly predicted Impression Management, F $(5,104)=4.07, p<.01 . \mathrm{R}$ Square for the model was .19 and Adjusted R Square was .15 .

Per Bendel and Afifi's (1977) recommendation, variables not making a significantly unique contribution to the model were removed one at a time until all remaining variables a significance level equal to or less than .10 (Tabachnick \& Fidell, 2013). Gender, the variable with the least significance $(p=.52$ ), was removed first. Regression analyses after removal of this variable revealed that the model still significantly predicted Impression Management, F (4, $105)=6.19, p<.01$. R Square for the model was .19 and Adjusted R Square was .16. Experience was the second variable removed from the model $(p=.32)$. Regression analyses indicated that the resultant model significantly predicted Impression Management, F $(3,119)=$ 6.77, $p<.01$. R Square for the model was .15 and Adjusted R Square was .12. The final variable to removed was SWAI $(p=.44)$.

The remaining two variables, Ethnicity $(p=.13)$ and $\operatorname{COSE}(p<.01)$, were retained: this model significantly predicted Impression Management, $\mathrm{F}(2,124)=10.05, p<.01$. R Square for the model was .14 and Adjusted R Square was .13. In terms of individual relationship between 
the independent variables and Impression Management, both Ethnicity $(t=-1.88, p=.13)$ and $\operatorname{COSE}(t=-4.31, p<.01)$ significantly predicted the dependent variable (see Table 10$)$.

Together, the two variables contributed $13 \%$ in shared variability. Ethnicity explained $1.5 \%(\beta=$ $-.13, p=.13)$ and COSE explained $12.4 \%(\beta=-.35, p<.01)$ of the shared variability in the dependent variable.

Table 10

Results of Multiple Regression Analysis for Impression Management Scale

Model Summary

\begin{tabular}{rccc}
\hline Model & $\mathrm{R}^{2}$ & Adjusted $\mathrm{R}^{2}$ & Std. Error of Estimate \\
1 & .14 & .13 & 8.77 \\
\hline
\end{tabular}

ANOVA

\begin{tabular}{llllll}
\hline & Sum of Squares & df & Mean Square & F & Sig. \\
\hline Regression & 1544.95 & 2 & 772.47 & 10.05 & .00 \\
\hline Residual & 9534.64 & 124 & 76.89 & & \\
\hline
\end{tabular}

\section{Coefficients}

\begin{tabular}{lllccccc}
\hline & B & Std. Error & $\beta$ & $\mathrm{t}$ & Sig. & $95 \%$ CI for B & $\begin{array}{l}\text { Partial } \\
\text { Correlations }\end{array}$ \\
\hline Ethnicity & -2.99 & 1.99 & -.13 & -1.51 & .13 & $(-6.93, .93)$ & -.13 \\
COSE & -.27 & .06 & -.35 & -4.23 & .00 & $(-.40,-.15)$ & -.35 \\
\hline
\end{tabular}




\section{Chapter 5}

\section{Discussion}

Neither the extent nor the implications of upcoming doctoral level psychologists' uses of impression management in supervision has been explored. Yet it is clear that supervisees do manage the impressions of their supervisors, and in clinical supervision these behaviors have important consequences. They can deter professional development and fail to ensure client welfare. For that reason, the fact that impression management-related behaviors are frequently referenced is noteworthy (Callis, 1997; Gulla, 2008; Hess, 2008; Ladany, Hill, Corbett, \& Nutt, 1996; Pitariu, 2007; Walsh, Gillespie, Greer, \& Eanes, 2002; Ward, Friedlander, Schoen, \& Klein, 1985; Webb \& Wheeler, 1998). When the emphasis in training is on supervisees forming desired impressions, the central purposes of supervision, which are to serve a gatekeeping function and to provide a supportive and educational experience, are sidestepped (Bernard \& Goodyear, 2009). In order to foster trainees' professional development and ensure client welfare, it is necessary for supervisors to be aware that these behaviors occur and to consider relevant factors that drive interns to manage impressions. To examine these factors, this study explored the use of impression management among pre-doctoral psychology interns and in particular its role in Counseling Self-Efficacy (CSE), the supervisory working alliance, counseling experience, gender, and ethnicity.

The present study collected data from 157 pre-doctoral level interns in psychology programs. The interns provided basic demographic data and information about their doctoral programs, internship sites, and extent of experience in counseling and supervision. Interns who participated in this study reported an average age of 30.1; however, their ages ranged from 25 to 50 years. These participants were primarily White $(n=126,80.2 \%)$ and female $(n=128$, $81.5 \%)$ and were enrolled in either Psy.D. $(n=79,50.3 \%)$ or Ph.D. $(n=75,47.8 \%)$ programs 
with Clinical ( $n=119,75.8 \%)$ or Counseling Psychology $(n=26,16.6 \%)$ orientations. Only one intern was enrolled in an Ed.D. program. A small percentage of interns indicated that they were enrolled in programs with combined Clinical-Counseling Psychology, combined Counseling-School Psychology, School Psychology, and Educational Psychology orientations. In sum, the majority of the interns who participated in this study were White females with a mean age of 30.1 enrolled in Clinical Psychology doctoral programs. This finding is expected and considered to be representative of the population from which the sample was drawn. According to the Association of Psychology Postdoctoral and Internship Centers' (2011) most recent survey of internship applicants, doctoral students at internship sites in 2011 - 2012 were primarily White (80\%) females (79\%) enrolled in Clinical Psychology doctoral programs (79\%). In regard to internship sites, the participants reported a diverse range. The majority of students were interning at medical centers and hospitals, community mental health centers, Veterans Administration hospitals, and college counseling centers. The remaining internship sites included correctional facilities/prisons, outpatient centers and practices, residential treatment centers, consortiums, psychiatric and inpatient hospitals, private practices, military medical centers and military internships.

Extent of experience was measured through direct contact hours. The total number of direct contact hours ranged from 50 to 4,000, with an average of 74 hours. Most of the interns reported experience levels at the lower end of this range. Interns were under supervision for an average of four years and five months. A large percentage of the sample $(60.5 \%)$ received supervision once a week and nearly a quarter (24.8\%) attended supervision twice a week. Some interns received supervision more than twice a week (12.1\%) and only a few met with their 
supervisors every other week (1.3\%). The internship students who participated in this study attended supervision on a routine basis for approximately four and a half years.

Given the exploratory nature of this study, only one empirical study (Pitariu, 2007) could be used as a direct comparison. Although Pitariu's research directly investigated variables related to supervisee use of impression management, it did not address the impact of the supervisory working alliance on impression management. Accordingly, comparisons to related studies, such as those that address supervisee nondisclosures, the supervisory working alliance, and doctoral level internship supervisees, were also examined.

\section{Discussion of Findings}

Hypothesis I. The first hypothesis proposed that intern uses of self-promotion strategies would be predicted by their perceptions of the supervisory working alliance (SWAI-T), their beliefs about their capabilities to be an effective counselor (COSE), their levels of experience, their gender, and their ethnicity. A multiple regression analysis offered partial support for this hypothesis: a negative correlation emerged between supervisory working alliance, the predictor variable, and self-promotion, which is the dependent, or criterion variable. Intern supervisees who perceived stronger working alliances with their supervisors indicated that they were less likely to use impression management strategies to promote themselves.

This finding can be used in clinical supervision research to establish an empirical link between specific supervisee impression management behaviors and the working alliance.

Neither of the investigations that directly examined the use of impression management in clinical supervision (Pitariu, 2007; Ward et al., 1985) included the effect of the supervisory working alliance on these behaviors even though the researchers conjectured that strong supervisory relationships could be used to address the negative effects of these behaviors. Although related 
research suggested supervisee nondisclosures may be related to the working alliance, the connection between supervisee non-disclosures and impression management could only be inferred. Nonetheless, given that supervisee nondisclosures are sometimes driven by attempts to manage impressions, and that nondisclosures are known to relate to the quality of supervisory relationships (e.g., Callis, 1997; Gulla, 2008; Hess, 2008; Ladany, 1996), the negative relation between supervisee self-promotion and the working alliance was expected. Taken together, the present study's finding offers empirical evidence that substantiates both the theoretical assertions and inferences of related research about the relationship between impression management and the supervisory relationship. The significant predictor of self-promotion is the supervisory working alliance.

Hypothesis II. The second hypothesis predicted that interns would use ingratiation strategies based on their perceptions of the supervisory working alliance (SWAI-T), beliefs about their capabilities to be an effective counselor (COSE), levels of experience, gender, and ethnicity. A multiple regression analysis once again offered partial support for this hypothesis: ingratiating behavior was negatively related to CSE and experience level, and positively related to gender and ethnicity. Counseling Self-Efficacy was the greatest predictor of ingratiation.

Put another way, intern gender, ethnicity, level of counseling experience, and personal judgments of their capabilities to effectively counsel (Larson et al., 1992) significantly predict their use of favors or flattery to elicit an attribution of likeability (i.e., ingratiation) from their supervisors (Bolino \& Turnley, 1999). Interns are more likely to use ingratiation strategies in supervision when they have lower CSE levels and less counseling experience. With respect to gender and ethnicity, interns who are female and White are more likely to employ ingratiation strategies with their supervisors compared to those who are male and non-White. Given that 
gender and ethnicity provide minimal contributions to the model $(2.6 \%)$, this finding should be interpreted with caution.

The findings of this hypothesis have not been previously described. Pitariu (2007) was unable to demonstrate a relationship among Ingratiation and CSE, gender, ethnicity, or experience. The contradictory results are likely a product of the differences between the two studies' samples. Pitariu based her study on master's-level students while data for this study were collected from pre-doctoral level interns. Supervisees may approach supervision in fundamentally different ways depending on their level of training. Furthermore, the stakes are much higher for a doctoral level intern than a master's-level practicum student. Internship is usually the final step before entry into the profession and much rests on the evaluation from supervisors at this level whereas master's-level students enrolled in practicums are often at the beginning stages of their training. Also, with greater levels of training, students have more opportunities to reflect on their counseling skills and abilities. The additional experience, skill acquisition, and knowledge may be reflected in how trainees at differing levels evaluate their capabilities.

Ingratiation is the only impression management strategy that is predictive of experience level. This result reflects the inconsistencies regarding training levels within the CSE literature. On one hand, if the relationship between training level and CSE is linear (e.g., Johnson, Baker, Kopala, Kiselica, \& Thompson, 1989; Tang et al., 2004) or curvilinear (Sipps, Sugden, \& Favier, 1988) then one would expect that most supervisees in their final stages of training would report high levels of CSE. Since higher levels of CSE are predictive of low impression management use, it should follow that experience level would demonstrate similar findings. Counseling selfefficacy and experience level predicted ingratiation strategies but experience level failed to 
predict all other behaviors where CSE succeeded. On the other hand, if the two are not related (e.g., O’Brien, Heppner, Flores, \& Bikos, 1997), then the independent variables could produce similar or dissimilar findings. This could explain why experience level was not related to other impression management behaviors predicted by CSE.

Although the relationship between Ingratiation and CSE revealed in this study differs from other dissertation research on impression management (Pitariu, 2007), it is consistent with and extends earlier non-disclosure studies. The negative relationship corroborates previous findings that described weak supervisee perceptions of competence as a reason to withhold information in an effort to impress supervisors (Gulla, 2008; Hess, 2008; Ladany et al., 1996). Negative feelings were associated with negative self-perceptions as well as the need to protect oneself or to survive, especially when supervisees reported negative perceptions of their supervisory relationships (Gulla; Hess).

Hypothesis III. The third hypothesis proposed that intern uses of exemplification strategies would be predicted by their perceptions of the supervisory working alliance (SWAI-T), their beliefs about their capabilities to be an effective counselor (COSE), their levels of experience, their gender, and their ethnicity. A multiple regression analysis offered partial support for this hypothesis: exemplification use was negatively related to CSE, the supervisory working alliance, and ethnicity.

Expressed differently, respondents' ethnicity, evaluations of personal counseling capabilities (Larson et al., 1992), and perceptions of their counseling supervision relationships (Efstation et al., 1990), predicted their use of self-sacrificing behaviors so as to appear dedicated to their supervisors. Participants who reported perceptions of stronger working alliances and higher CSE were less likely to attempt to appear dedicated through impression management 
behaviors (i.e., exemplification) than those with perceptions of weaker supervisory working alliances and lower CSE levels. Intern supervisees who were White were significantly more likely to engage in exemplification behaviors than interns who identified with diverse racial backgrounds.

This result differs from Pitariu's (2007) research on supervisee impression management which failed to find a significant relationship between CSE and exemplification. This discrepancy may be explained by a number of factors, such as differences in sample demographics, time spent in supervision, and reports of CSE levels among participants. Research on the nature of CSE suggests that counseling experience and training level may be related to CSE levels. Depending on which study is referred to, these variables either have a curvilinear (e.g., Sipps, Sugden, \& Favier, 1988) or a linear relationship (e.g., Johnson, Baker, Kopala, Kiselica, \& Thompson, 1989; O’Brien et al., 1997). Over half of Pitariu's participants (59.23\%) had no counseling experience, had an average of 27 client contact hours, and were at the beginning stages of their training (master's level), which contrasts with the present study, where pre-doctoral level interns reported an average of 1337.28 hours of counseling experience. In addition, trainees who receive supervision tend to have higher efficacy levels than those who have had little to no supervision (Cashwell \& Dooley, 2001; Larson et al., 1992). Pitariu did not report the average amount of supervision. However, since supervision accompanies counseling experience, the minimal counseling experience reported by her participants and their low stages of training (master's level) suggests a discrepancy between the two samples concerning supervision experience and therefore efficacy levels as well. Therefore, given the proposed links between CSE and experience level and supervision, it is probable that the diverse experience levels between Pitariu's and the present study's samples explain the different findings. 
An equally important finding from this analysis is the negative correlation between supervisory working alliance and exemplification. Although this relationship has not been researched prior to the present study, previous researchers have described a relationship between nondisclosures and the supervisory working alliance. Evidence suggests that supervisees are more likely to withhold information when they report perceptions of poor supervisory relationships (Callis, 1997; Gulla, 2008; Hess, 2008; Ladany et al., 1996; Walsh, Gillespie, Greer, \& Eanes, 2002; Webb \& Wheeler, 1998), and to add to that, nondisclosures within this context are more likely to have negative repercussions (Gulla; Hess). It was expected, therefore, that interns who provided low ratings of the supervisory working alliance would endorse greater use of exemplification behaviors.

Hypothesis IV. The fourth hypothesis predicted that interns would use supplication strategies based on their perceptions of the supervisory working alliance (SWAI-T), beliefs about their capabilities to be an effective counselor (COSE), level of experience, gender, and ethnicity. A multiple regression analysis offered partial support for this hypothesis by demonstrating that CSE is negatively related to supplication. Intern supervisees who have greater confidence in their counseling capabilities are less likely to advertise their weaknesses or shortcomings in order to portray an impression of neediness to their supervisors than those having less confidence.

This result is consistent with Pitariu's (2007) study which showed that a negative relationship existed between supplication and supervisees' confidence in their levels of awareness of biases and values and their ability to navigate how these manifest in the counseling relationship (i.e., values subscale of IMS). However, in contrast to Pitariu's findings, supervisee uses of supplication demonstrated a negative relationship to CSE as measured by the total scale of IMS. The most likely explanation for this difference is the varying levels of experience 
between the two samples. Having a reference point for assessing one's ability to be effective as a counselor, such as knowing how personal biases and values impact the counseling relationship, likely impacts the responses given. Participants who are able to use multiple past experiences, as both a counselor and a supervisee, will likely respond differently than those who have minimal experience or none at all on questions regarding competence levels and behaviors in supervision. Greater experience leads to more reference points that can be used as a means for self-reflection.

Hypothesis V. The fifth hypothesis proposed that interns' general use of impression management strategies (Total Score on IMS) would be predicted by their perceptions of the supervisory working alliance (SWAI-T), beliefs about their capabilities to be an effective counselor (COSE), level of experience, gender, and ethnicity. A multiple regression analysis offered partial support for this hypothesis by demonstrating that general impression management use is negatively related to CSE and ethnicity. Interns who have low efficacy beliefs about their personal counseling capabilities and who are White are significantly more likely to manage their supervisors' impressions of them.

This result accords with earlier observations, which showed that CSE is related to behaviors related to impression management: non-disclosures. Qualitative investigations consistently demonstrated that supervisees who reported withholding important information from their supervisors for impression management reasons also reported self-doubt, low confidence regarding competence levels, and negative feelings such as shame, related to self-perceptions of abilities (e.g., Gulla, 2008; Hess, 2008; Ladany et al., 1996). The findings from Pitariu's (2007) dissertation research corroborated this relationship by showing that trainees' self-efficacy levels for different counseling areas (i.e., subscales of COSE) were related to specific impression management strategies. Her study did not provide any information on the relationship between 
CSE and general impression management use (i.e., total score of IMS). This study's test of this hypothesis not only confirms Pitariu's prior research but goes one step further by demonstrating that general impression management use is negatively related to CSE (i.e., total scale of COSE).

The relationship between ethnicity and impression management use does conflict, however, with Pitariu's failure to find any relationship between the two variables. Further examination sheds light on one possible reason for why this relationship is easy to overlook. In the present study, ethnicity made a minimal contribution to the prediction (i.e., 1.5\%) of the model. That means this variable could only account for $1.5 \%$ of the reason for participants' endorsement of impression management behaviors. It is also possible that the homogeneity of research samples with respect to ethnicity contributed to these results.

Summary of Findings. To summarize, the analyses revealed several significant findings. Turning to the supervisory working alliance, this variable was a significant predictor of self-promotion and exemplification, with stronger alliances marked by lower use of both impression management strategies. Of great interest in the current investigation was the importance of counseling self-efficacy in predicting multiple impression management strategies. Counseling self-efficacy was a significant predictor of ingratiation, exemplification, supplication, and general impression management use. That is to say, interns with low CSE levels managed their supervisors' impressions of them through self-promotion, ingratiation, exemplification, and supplication strategies as well as general impression management use.

Another noteworthy finding revealed that supervisee use of specific impression management strategies is impacted by their gender, ethnicity, and counseling experience. Ethnicity significantly predicted ingratiation, exemplification, and general impression management use. Interestingly, both gender and experience level significantly predicted only 
one impression management behavior: ingratiation. Interns with less experience reported greater use of ingratiation strategies.

These findings confirm and expand upon both supervision and impression management theory and research by suggesting that counseling self-efficacy and the supervisory working alliance have primary importance for understanding intern use of impression management in supervision. Furthermore, these results are different from previous research, suggesting that the ethnicity of supervisees does indeed impact supervisee behaviors and therefore, warrants further research. Likewise, the current study furthers prior research by documenting that gender and experience level were related to one type of impression management use.

Unexpected Findings. The testing of the hypotheses led to several surprising findings. This researcher anticipated that CSE would be inversely related to all impression management strategies, but the results indicate no such relationship appears between CSE and self-promotion. This is in direct contrast to Pitariu's (2007) research which revealed a negative relationship. It is possible that the conflicting findings regarding CSE and self-promotion may involve the use of the COSE. In the present study, only the total score of the COSE was used as a predictor whereas Pitariu used each of the COSE subscales as individual predictors. Only one of the subscales on the COSE (i.e., microskills) significantly predicted Self-Promotion behaviors in Pitariu's study. In addition, no information regarding the relationship between the COSE total scale and this impression management strategy was provided. Therefore, the present study might have produced a similar finding if the relationship between each of the COSE subscales and selfpromotion was examined.

The vast amount of supervision literature emphasizes the importance of the supervisory working alliance on trainee outcomes. Qualitative research studies on supervisee nondisclosures 
have alluded to the role of this alliance in facilitating a safe context for supervisees to lower their defenses and facilitate genuine open discussions about their experiences. Given the similarities between nondisclosures and impression management, it was surprising to find that the supervisory relationship bears no relationship to ingratiation, supplication, and general impression management use.

Contrary to expectations, the multiple regression analyses did not reveal a relationship between the supervisory working alliance and impression management. While it is likely that interns' perceptions of the working alliance truly have no relationship with their efforts to elicit desired impressions from their supervisors, there are other likely explanations for these findings. For example, it is possible that the design of the study prevented participants from providing an accurate depiction of their experiences.

Previous studies of supervisee nondisclosures, behaviors related to impression management, were either qualitative or were a combination of quantitative and qualitative methods. The results of these studies suggested that nondisclosures are negatively related to the supervisory relationship (Callis, 1997; Gulla, 2008; Hess, 2008; Ladany et al., 1996; Walsh et al., 2002; Webb \& Wheeler, 1998). Participants in the majority of these studies elaborated on their responses, which provided them the opportunity to explain their negative and positive ratings of the supervisory relationships. The present study was quantitative and therefore did not acquire additional information that may have explained participant ratings.

Studies have demonstrated that experience level influences trainee competence, confidence levels, and experiences. It is surprising, therefore, that experience level is not related to self-promotion, exemplification, supplication, or general impression management use. It is likely that this finding is accurate: that counseling experience and self-promotion have no 
relationship. On the other hand, the researcher's method for quantifying experience level by hours could also have produced differing responses based on participants' interpretation of what was meant by hours of experience.

From the findings, it also appears that sex is not related to self-promotional, exemplification, supplication, or general impression management tactics among supervisees. Although this is consistent with past research on supervisee impression management use (i.e., Pitariu, 2007), this researcher expected that these variables would be significant predictors for doctoral level intern supervisees. Given what is understood about sex differences in impression management, specifically that men and women have different impression management goals and employ differing strategies consistent with gender role expectations, this researcher anticipated that sex would predict self-promotion (e.g., Bolino \& Turnley, 2003; Guadagno, \& Cialdini, 2007; Rudman, 1998).

In addition, impression management goals and tactics are motivated by personal experiences and values. Since cultural, ethnic, and racial identities produce different experiences of the world, including interactions with others and expectations of social interchanges, this researcher expected to find differences among diverse individuals that would result in significant predictions. The results of multiple regression analyses did not support this expectation for interns' use of self-promotion or supplication tactics.

With respect to gender and ethnicity, there may truly be no difference between women and men or among individuals with diverse ethnic backgrounds in their use of impression management strategies. It is just as likely, however, that the high percentage of White women and low percentage of males and non-White participants in this study precluded a significant finding. Although the proportions of gender and ethnicity in the study sample accurately 
depicted the population of psychology pre-doctoral interns, the results may not be representative of group differences since the population is limited.

\section{Strengths and Limitations}

There are a number of limitations to this study that need to be addressed. The first limitation relates to the instruments used to assess impression management and the supervisory working alliance. The development of the IMS (Bolino \& Turnley, 1999) was normed primarily on professionals working in large organizations, not pre-doctoral interns required to receive supervision. However, no other impression management measure exists and the IMS was found to be a valid and reliable assessment of impression management in Pitariu's (2007) study of counseling trainees in clinical supervision. The findings of the present study and those of Pitariu's suggest that this instrument is applicable to supervisees in the field of psychology. Nonetheless, the findings must be interpreted with this limitation in mind.

With respect to the SWAI (Efstation et al., 1990), it is possible that this measure does not accurately reflect interns' definitions of strong and weak supervisory alliances. This measure assesses supervisee perceptions of the supervisory relationship based on Bordin's (1983) definition of the working alliance; however, there is evidence to suggest that trainees' definitions of what constitutes a working alliance differ from this. Trainees associate strong supervisory relationships with feelings of safety, valued supervisory styles, open discussions about the supervisory relationship, collaboration, mutuality, and perceptions of supervisors as supportive, challenging and committed to the supervisory relationship (Gulla, 2008; Hess, 2008; Walsh et al., 2002; Yourman \& Farber, 1996). On the other hand, weak relationships are associated with distrust, feelings of discomfort, inappropriate developmental approaches, failure to discuss the supervisory relationship, and perceptions of supervisors as interpersonally insensitive, critical, 
evaluative, and not invested in the relationship (Gulla, 2008; Hess, 2008; Ladany et al., 1996; Walsh et al., 2002; Yourman \& Farber, 1996). The SWAI-T assesses supervisee perceptions of supervisor behaviors that facilitate rapport and trainee understanding of clients (Efstation et al., 1990); however, interns may place more importance on these other unassessed aspects of the supervisory relationship when evaluating the strength of their alliances. This potential difference in definitions may account for why the current study showed that trainees attribute nondisclosures and impression management concerns to poor working alliances (Gulla; Hess; Ladany et al., 1996; Walsh et al.; Yourman \& Farber), whereas previous research did not. This limitation may also explain why the supervisory working alliance is not predictive of all impression management strategies.

An additional issue involves the scope of the study. Both impression management and the supervisory working alliance are constructs that are best understood in terms of the social context. That is, a comprehensive understanding of how these two variables play out requires ratings from the perspectives of both persons involved in this social exchange, the supervisee and the supervisor.

Another weakness concerns this study's reliance on self-report instruments. It is possible that participants' perceptions of their impression management use, supervisory working alliances, and CSE were less than accurate. Since there was no control for social desirability, the participants may have responded in a manner that would portray a favorable impression. Even though participants were informed that all responses were confidential and anonymous, failure to control for this means that they may have rated themselves in a socially desirable way. Since the researcher made no attempt to assess supervisors' perceptions or to conduct a controlled, 
experimental design that allowed for the observation of such behaviors, the results may not be accurate depictions of actual impression management use among interns.

Another limitation is related to the design of the study. The correlational nature of this study precludes causal inferences of the relationships between the independent and dependent variables. The results of this study suggest instead that a significant relationship between these variables exists. With that said, it is likely that other, unknown variables may have influenced interns' responses on the measures. Some findings were unexpected. For example, some significant predictions of impression management only minimally explained why interns endorsed certain behaviors on some independent variables. The supervisory working alliance, for example, accounted for $2 \%$ of the variation in self-promotion behaviors. This leaves $98 \%$ of self-promotion variance left unexplained. Furthermore, ethnicity (3.8\%) and supervisory working alliance $(2.3 \%)$ made a minimal contribution to the prediction of intern exemplification behaviors. Likewise, CSE could only explain $5.1 \%$ of the reason why interns employ supplication behaviors. The contributions of each predictor variable, therefore, should be taken into consideration when interpreting the significant findings in this study.

Finally, the generalizability of the findings of this study may be limited. The results cannot be generalized to doctoral trainees who are not on internship or to master's counselor trainees. On the other hand, it is also important to note that the study sample consisted primarily of White females from Clinical Psychology programs, and that this is representative of the general population, according to the Association of Psychology Postdoctoral and Internship Centers' survey of internship applicants who matched in 2011.

Despite the noted limitations, the current investigation contributes to the supervision literature in a number of ways. First, this study furthers the understanding of intern experiences 
and how these factors influence their behaviors in supervision. Employing a multiple regression analysis to examine impression management allowed for the examination of several independent variables, including ethnicity, gender, counseling experience, the supervisory working alliance, and counseling self-efficacy beliefs. This study also provided further support for Larson's (1998) Social Cognitive Model of Counselor Training theory which described how counselors' willingness to examine and work on counseling skills is a function of the perceived environment, or perceptions of the quality of the supervisory relationship. In addition, the present study extended prior research that linked CSE with impression management among supervisees (Pitariu, 2007).

This study is important because little is known about supervisee behaviors, other than non-disclosures, that occur in supervision at advanced levels of training. Prior to the present investigation, only one study examined the prevalence of this phenomenon, but the sample was limited to supervisees at the master's level of training (Pitariu, 2007). It is now evident that doctoral trainees at their final stages of training also engage in protective behaviors in supervision, suggesting a need to consider this as an important matter to address across all developmental levels. Yet another unique contribution of the present research was attention to the relationship between the supervisory working alliance and impression management. The findings provide empirical support for a negative association, similar to research on supervisee nondisclosures. Likewise, interns' perceptions of competence proved to be especially important to understanding impression management use. In contrast to research suggesting that trainees at the advanced levels of training have higher CSE, interns in the present study reported low efficacy beliefs and this was related to a greater tendency to manage supervisor impressions. This speaks to the influence of counseling self-efficacy on advanced trainees' behaviors and 
more importantly, offers insight into factors that can be addressed in supervision to help trainees overcome obstacles to professional development.

Use of the separate IMS subscales produced detailed information regarding differential use of impression management strategies among men and women and individuals of diverse backgrounds, as well as the differing tactics employed when negative beliefs of competence and the supervisory alliance are present. As mentioned earlier, the influences of gender, ethnic, and cultural group norms, values, and expectations on individual behaviors likely explain why sex and ethnicity predicted differing tactics. To gain a complete understanding of factors related to impression management, the researcher of this study acknowledged the importance of individual differences by determining which types of impression management strategies are used by whom. That is, an examination of general impression management use among a diverse group of participants without consideration of differential use of strategies would have only revealed whether differing participants engaged in such behaviors, and would have neglected to acknowledge the significant role of societal and cultural influences on individual behaviors.

Likewise, that only certain strategies were predicted by measures of CSE and the working alliance further demonstrates the utility of the IMS subscales. Without information regarding the differences in strategies, the researcher could have wrongly assumed that only CSE predicted impression management. This would have failed to take into account how trainees may engage in specific defensive behaviors when they had a less than ideal supervisory alliance, or for that matter, how trainees don't use self-promotional strategies to compensate for their low beliefs of competence. Therefore, another strength of this study is its inclusion of the IMS subscales, in addition to its total scale, and is therefore recommended for future researchers using the IMS. 
Overall, this research was the first to study the relationships among supervisory working alliance, counseling self-efficacy, and impression management behaviors among supervisees at the advanced training level of internship. Future research is needed to better understand the nuances of these relationships in supervision and this study provides a necessary baseline for additional studies. Empirical studies, such as the present one, are the means for understanding factors that influence supervisee behaviors that ultimately contradict their own professional goals, which is evident in the amount of effort put forth to reach internship as a psychology trainee. Incorporating findings from this study and conducting future studies on supervisee experiences will ensure that time spent in supervision is effective in reducing intern defenses. This, in turn, will better enable supervisors to fulfill their roles as gatekeepers for the profession, monitors of quality of supervisee work, enhancers of professional functioning, teachers, counselors, consultants, and advocates for client welfare (Bernard \& Goodyear, 2009).

\section{Future Research Directions}

The limitations of the present study lay the groundwork for subsequent research. The instruments used in this study give rise to a number of avenues. Given that the IMS, SWAI-T, and the COSE were not normed on doctoral level interns, the validity and reliability of these instruments need to be established for this target population. The IMS and SWAI-T, in particular, would benefit from further refinement of their psychometric properties. In addition, there appears to be inconsistencies among definitions of the supervisory working alliance. It is possible that the context and training level impact perceptions of what constitutes a strong and weak supervisory alliance. This question may best be addressed through a qualitative study designed to examine differences in perceptions among supervisees at different levels of training. 
An instrument that assesses this construct specifically among doctoral level interns would further ensure that interns' perceptions of the supervisory working alliance are accurately assessed.

As mentioned earlier, the IMS was normed on employees of large organizations and then established as a reliable and valid measure of impression management for trainee counselors. However, it is possible that the scale was too limited to cover impression management behaviors specific to intern supervisees. To illustrate, doctoral level trainees on internship are evaluated at all times and are required to participate in individual supervision for at least two hours per week. In addition, supervision of upcoming psychologists entails more than demonstration of skill sets. It may also call for examination of more delicate matters, such as screening for personal biases with respect to clients. The complex circumstances and experiences of supervision are uniquely different from experiences of trainees in professions outside of psychology and of trainees who are at lower, less intense levels of training. Taken together, future research on impression management use among doctoral level trainees may also benefit from a mixed method study involving qualitative and quantitative measures to determine whether impression management concerns manifest differently for psychology interns. Such a determination may then prove to be useful in establishing an impression management measure that accurately depicts the experiences of interns.

The limitation of the present study in controlling potentially moderating variables suggests that there may be other, unknown variables contributing to impression management use. A qualitative study designed to explore interns' underlying motivations and reasons for impression management use would help identify such variables. The findings of such a study could prove useful in removing barriers to upcoming psychologists' professional development. 
An investigation involving both supervisor and supervisee perceptions can help to provide a more comprehensive understanding of how supervisee impression management impacts supervision. Given the complex nature of relationships, it is likely that a qualitative study will offer a more thorough depiction of how impression management influences the supervisory process. With this information it would then be possible to research how supervisors can effectively reduce impression management concerns and ensure the advantages of supervision.

\section{Implications for Counseling and Clinical Psychologists}

These findings offer valuable information for clinical and counseling psychologists and clinical supervisors alike. To begin, the prevalence of impression management use among interns suggests that it is important for supervisors to attend to supervisee behaviors in supervision. Interns who negatively evaluate their competence levels and/or have weak supervisory alliances may minimize the hierarchical and evaluative components of supervision through impression management. When a supervisor fails to build rapport, encourage supervisee understanding of client conceptualizations, or empower the supervisee to work collaboratively towards shared tasks and goals, interns may resort to strategies of self-promotion or exemplification. Individuals engage in self-promotion to appear competent whereas exemplifiers seek to be perceived as dedicated, hardworking moral supervisees with high levels of integrity (Jones \& Pittman, 1982). Therefore, supervisee emphasis on these attributes serves as a sign that supervisors need to attend to the quality of the supervisory alliance. Both rapport and mutual agreement on tasks and goals, specifically regarding client understanding, may need further attention. 
There are also behavioral indicators that warrant a need for supervisors to direct their attention to supervisee self-efficacy beliefs. These include ingratiation, exemplification, supplication, and impression management use in general. By definition, ingratiatory behaviors make supervisees appear more likeable and are intended to generate favorable outcomes, such as feedback, evaluations, and recommendation letters. This behavior can take the form of opinion conformity, rendering favors, and flattery (Turnley \& Bolino, 2001). In line with Bandura's (1986) theory of self-efficacy, perceptions of incompetence will likely persist because these behaviors can prevent opportunities for growth. In turn, supervisees may believe that feedback and evaluations are based on attributions of likeability rather than actual abilities and skills, thereby preventing increases in self-efficacy. As previously mentioned, supervisees portray themselves as hardworking and dedicated when the supervisory relationship is weak; however, interns also exemplify themselves when they have little confidence in their counseling abilities. Low CSE also lends to supervisee attempts to appear needy or elicit sympathy by emphasizing personal limitations (Jones \& Pittman, 1982).

Intended effects of supplication attempts can include, but are not limited to, additional help from supervisors and postponement of discomfort associated with avoided discussions (e.g., nondisclosures of important, relevant information). The relationship between general impression management and CSE suggests that supervisees who have low self-confidence may use more than one of the above strategies in supervision.

An important distinction concerns the difference between the present study's findings regarding supervisee experiences and supervisee goals. The underlying goals of supervisees were not assessed but what this study has demonstrated is that there are intrinsic (CSE) and extrinsic (supervisory relationship) factors that influence supervisee use of impression 
management strategies. These factors need to be attended to for the intended benefits of supervision to take place.

In the context of impression management theory and research, interns engage in impression management because they believe that the impressions they make will have positive implications for them in terms of the outcomes of supervision (rewards versus negative consequences) (Leary, 1996; Leary \& Kowalski, 1990; Schlenker, 1980; Schlenker \& Britt, 1999; Schlenker \& Pontari, 2000; Schlenker \& Weigold, 1992; Silver \& Schlenker, 1981). Power differentials in relationships heighten motivations for supervisees because they create a sense of dependency on the supervisor to attain desired goals (e.g., entry into the profession) (Leary \& Kowalski; Schlenker; Schlenker \& Weigold). As this study confirms, supervisee perceptions of supervisory alliances do influence impression management use. Also, the value of desired goals and the discrepancy between a desired impression and an actual self-view can motivate one to manage impressions (Leary \& Kowalski; Schlenker \& Weigold). As such, interns' motivations are heightened because their goals, with respect to supervision, have great importance for their future. In addition, their low-efficacy beliefs conflict with their desired professional identity, thereby motivating them to resolve this discrepancy, sometimes through self-defeating means.

The fact that all supervisees used impression management strategies confirms the pervasiveness of impression management in training. Models of training that fail to take this into account might also misjudge the motives, and therefore the intent, of trainees seeking to become psychologists. That is to say, impression management is a ubiquitous feature of interpersonal exchanges. It is at times consciously and at other times unconsciously driven, it includes both 
genuine and disingenuous portrayals, and it can be guided by intentions ranging from altruism to selfishness.

That all interns reported managing supervisor impressions simply suggests they all had a conscious awareness of what behaviors were needed to manage impressions. This increased awareness heightens impression management motivations. Interns' conscious management of their supervisor's impressions could reflect a range of possible motivations. It could reflect attempts to accurately portray themselves according to self-views (Leary, 1996; Schlenker, 1980), efforts to help supervisors 'save-face' (e.g., confirm supervisor perceptions of self as reliable, caring, and competent) (Goffman, 1959; Leary; Schlenker; Schlenker \& Britt, 1999; Schlenker \& Pontari, 2000; Schlenker \& Weigold, 1992), or desires to gain self-confidence through successful portrayals of their ideal selves to supervisors (Leary, Schlenker).

Furthermore, attempts to manage supervisor impressions are not necessarily detrimental to intern professional development. For example, supervisees who successfully portray themselves as competent to their supervisors are likely to develop positive efficacy beliefs. In line with impression management theory and research, public behaviors alter private selfconceptions. One explanation for this phenomenon suggests that the accessibility of behaviors and beliefs consistent with successful self-portrayals in recent memory leads individuals to believe they possess such qualities. Another explanation proposes that others' perceptions impact self-views, meaning that when others appear to believe the intended impression portrayed, individuals begin to believe that they truly possess the desired qualities.

Although interns engage in impression management techniques to improve supervisors’ appraisals of them, these behaviors may come at an unanticipated cost. Interns may find themselves in a dilemma in that their efforts to appear competent or dedicated actually precludes 
opportunities for increased self-awareness and raised competence levels, which are contingent upon genuine depictions of counseling experiences and authentic self-representations.

The strength of the present study is that it offers additional evidence of an empirical link between CSE and impression management. It indicates that this relationship deserves further attention. Additionally, the relation of the supervisory alliance to specific impression management strategies produces preliminary evidence for some important theoretical assertions. These include the claim that stronger supervisory relationships lower trainee defenses and encourage more genuine self-portrayals. Any understanding of how these findings translate to supervision of upcoming counseling and clinical psychologists requires consideration of the potential obstacles associated with supervisee impression management as it relates to CSE and the supervisory alliance.

Some issues related to intern impression management are evident in research on supervisee nondisclosures and self-efficacy. In 2008, Hess found that pre-doctoral interns with weak supervisory working alliances were more likely to withhold important information and that this decreased both confidence and perceived competence levels. Reports of lowered selfefficacy levels are associated with increases in nondisclosures and lowered investment in supervision (Gulla, 2008; Hess, 2008). To add to that, negative efficacy expectations lead to decreased willingness to attempt tasks, perseverance, and effort expenditure (Bandura, 1986). Therefore, in line with Bandura's self-efficacy theory, interns with low self-efficacy are likely to engage in avoidance behaviors that prevent them from challenging perceptions of incompetence, from gaining sufficient knowledge, and from being exposed to experiences of success. In this case, the avoidant behaviors used among interns with low self-efficacy would include impression management; that is, withholding important information as a way of managing impressions. 
Therefore, the negative effects of nondisclosures and avoidant behaviors suggest that supervisee impression management behaviors hinder the development of intern professional development, supervisory relationships, and positive efficacy beliefs about counseling capabilities.

The present study's findings suggest that weak supervisory relationships combined with low efficacy beliefs, if left unaddressed, could undermine efforts to foster intern professional development. Supervisors contribute to trainee CSE through modeling, social influence, and supervisory feedback when the relationship is perceived to be a trusting one (Larson, 1998). However, research suggests that supervisee nondisclosures conceal evaluation concerns, clinical mistakes, perceived counselor inadequacies, and negative reactions when the temptation to manage impressions is heightened (e.g., Ladany et al., 1996). Gains in CSE are unlikely if supervisors remain unaware of what clinical areas need to be addressed through modeling, feedback, and persuasion. Supervisee unwillingness to examine and work on counseling skills hinders supervisor attempts to "increase the chance of counseling success" (Larson 1990, p. 240). If trainees avoid addressing areas of concerns in supervision, supervisors' attentions may be directed elsewhere.

Considering the context of intern impression management behaviors should encourage supervisors to adopt an understanding stance and promote a collaborative working alliance. Supervisors who directly address intern impression management and empathize with the underlying insecurities driving these behaviors are likely to prevent overuse of impression management. Given that supervisees are likely to disclose information if their supervisors inquire about relevant incidences or disclose personal counseling experiences (Hess, 2008), supervisors should not only normalize intern experiences but also ask direct questions about supervisee efficacy beliefs, evaluative concerns, and perceptions of the working alliance. In this 
way, supervisors are more likely to foster a safe environment in which interns are less likely to focus on the potentially threatening perceptions their supervisors may form and, in turn, expend more energy on furthering their professional development. Open acknowledgement of what takes place in supervision, such as supervisory dynamics and supervisee concerns, provides a starting place for supervisors to successfully fulfill their roles as gatekeepers and supportive mentors.

Since interns who have little confidence in their counseling abilities report greater efforts towards ensuring that supervisors have positive impressions of them, it is also important that supervisors do not base their ongoing assessments solely on supervisee reports of therapeutic process, cultural competence, and awareness of values. Reliance on additional sources, such as videos or observations of counseling sessions, would benefit both the supervisor and the supervisee. Efficacy beliefs are not indicative of actual abilities and skills; instead, they mediate the impact of skill proficiency and ability level on performance (Bandura, 1986). Therefore, supervisors' perceptions of supervisees are more likely to be accurate when information is gleaned from multiple sources.

When considering interactions among more than two individuals, the complex nature of impression management requires psychologists to attend to what implications impression management has for group supervision. When an audience is larger, there is the possibility that individuals are more likely to manage impressions. The format of group sessions leaves open the possibility that group members may be concerned with managing multiple impressions. As the present research indicates, working alliance and group members' CSE motivate the use of impression management strategies. Therefore, supervisors need to attend to the supervisory 
working alliance in addition to the cohesiveness and safety (rapport) of the group and the focus of the group sessions (client focus).

The relationship of CSE to different types of impression management strategies suggests that group members with low efficacy beliefs may attempt to manage impressions differently. When individuals are motivated to perform well but have low efficacy beliefs, they are more likely to "perceive a threat to identity" and their sense of threat is only heightened in the presence of a larger audience (Schlenker \& Weigold, 1992, p. 154). Yet group supervision has many benefits including opportunities for an increased sense of support, the sharing of common experiences, peer-based learning, and feedback (providing and receiving) (Bernard \& Goodyear, 2009). Supervisors should facilitate the sharing of similar experiences among peers to normalize interns' experiences as well as model openness and appropriate disclosures, and respectful feedback to encourage modeling, feedback, and social persuasion (Larson et al., 1992).

The approach taken by supervisors plays an integral role in the degree to which the supervisory alliance lessens supervisee perceptions that they need to protect themselves rather than risk revealing perceived weaknesses (Hess, 2008). For this reason, Counseling Psychology's emphasis on a developmental, strength-based approach is recommended. In supervision, it is not enough simply to focus on interns' perceived inadequacies and offer feedback. Rather, it is important for supervisors to adjust their approach in order to meet the individual needs of the supervisee, taking into consideration their respective developmental levels. Supervisors who adapt their supervision style to meet the individual needs of supervisees are likely to promote a greater sense of CSE among interns (Fernando \& Hulse-Kilacky, 2005). Furthermore, careful consideration of interns' individual strengths and weaknesses is essential in using supervisees' professional and personal strengths to improve areas of weakness while 
simultaneously empowering them. Using this knowledge to discuss interns' perceived inadequacies in a supportive manner offers greater insight into the validity of efficacy beliefs which in turn can be effectively addressed through constructive feedback, social influence, or modeling. Additionally, supervisors would be more capable of teaching interns how to identify and address potentially inaccurate efficacy beliefs, thereby helping supervisees to conduct realistic self-evaluations, which is an essential skill for continued professional development.

The implications of the present research are compatible with the assumptions and approaches that underlie developmental models of supervision. Both the accurate assessment of trainee efficacy beliefs and the correspondence of the supervisory environment to developmental levels echo a fundamental premise of existing supervision models. That premise holds that supervisory effectiveness depends on a supervisor's ability to recognize trainee developmental levels and to match supervisory interventions accordingly (e.g., Stoltenberg, McNeil, \& Delworth, 1998). Likewise, developmental supervision models hold that the nature of the supervisory relationship is related to supervisee progression through developmental stages (Worthington, 1987). This underscores the importance of supervisor attentiveness to the supervisory working alliance as instrumental in lowering trainee defenses and enhancing professional growth.

Regardless of the developmental level of supervisees, enhancing supervisee selfawareness is essential to increased confidence, competency, and non-defensiveness (Loganbill, Hardy, \& Delworth, 1982; Stoltenberg et al.). Taken together, supervisors who have a grasp on supervisee strengths and weaknesses, efficacy beliefs, and the value of a strong working alliance have the knowledge base to accurately assess developmental levels and to use developmentally appropriate interventions to facilitate progression to more advanced professional levels. 
In conclusion, impression management is inherently dyadic. Sustained use of these behaviors within ongoing relationships is only possible if the others' actions, or inactions for that matter, convey an implicit approval and consent to accept these portrayals. According to Goffman (1959), impression management is possible because individuals can trust that the roles they assume through impression management behaviors will be supported and upheld within relationships. Placed in the context of clinical supervision, impression management behaviors are likely to persist when supervisors overlook these behaviors and fail to facilitate discussions about interns' sense of self-efficacy, the working alliance, or the interpersonal process in the supervisory relationship. Past research indicates, however, that supervisors rarely have discussions with their supervisees about the supervisory relationship in supervision (Smothers, 2010). It is likely that these discussions are needed to foster a safe context for interns to have honest dialogues about their low efficacy beliefs and their levels of professional development, and the present study provides a focus for such discussions. 


\section{References}

Abernethy, C., \& Cook, K. (2011). Resistance or disconnection? A relational-cultural approach to supervisee anxiety and nondisclosure. Journal of Creativity in Mental Health, 6(1), 2-14. doi:10.1080/15401383.2011.560067

Association of Psychology Postdoctoral and Internship Centers (APPIC) (2011, May 30). 2011 APPIC match: Survey of internship applicants. Retrieved from http://www.appic.org/Match/MatchStatistics/ApplicantSurvey2011Part1.aspx

Bandura, A. (1977a). Social learning theory. Englewood Cliffs, NJ: Prentice-Hall

Bandura, A. (1977b). Self-efficacy: Toward a unifying theory of behavioral change. Psychological Review, 84(2), 191-215. doi:10.1037/0033-295X.84.2.191

Bandura, A. (1982). Self-efficacy mechanism in human agency, American Psychologist, 37(2), $122-147$.

Bandura, A. (1986). Social foundations of thought \& action: A social cognitive theory. Upper Saddle River, NJ: Prentice-Hall

Bandura, A. (1991). Social cognitive theory of self-regulation. Organizational Behavior and Human Decision Processes, 50,122 - 147.

Baumeister, R. F. (1982). A self-presentational view of social phenomena. Psychological Bulletin, 91(1), 3-26. doi:10.1037/0033-2909.91.1.3

Baumeister, R.F., Tice, D.M., \& Hutton, D.G. (1989). Self-presentational motivations and personality differences in self-esteem. Journal of Personality, 57(3), 547 - 579.

Behnke, S. (2005). The supervisor as gatekeeper: Reflections on ethical standards 7.02, 7.04, 7.05, 7.06, and 10.01. Monitor on Psychology, 36(5), 90. Retrieved from www.apa.org./monitor/may05/ethics.html 
Bernard, J.M. \& Goodyear, R.K. (1998). Fundamentals of Clinical Supervision (2nd ed.). Needham Heights, MA: Allyn \& Bacon.

Bernard, J.M. \& Goodyear, R.K. (2009). Fundamentals of Clinical Supervision (4th ed.). Upper Saddle River, NJ: Merrill

Bolino, M. C., \& Turnley, W. H. (1999). Measuring impression management in organizations: A scale development based on the Jones and Pittman Taxonomy. Organizational Research Methods, 2(2), 187-206. doi:10.1177/109442819922005

Bolino, M. C., \& Turnley, W. H. (2001). Gender and the use of supplication and intimidation in organizations. Academy of Management Proceedings \& Membership Directory, A1-A6. doi:10.5465/APBPP.2001.6132955

Bordin, E. S. (1979). The generalizability of the psychoanalytic concept of the working alliance. Psychotherapy: Theory, Research \& Practice, 16(3), 252-260. doi:10.1037/h0085885

Bordin, E. S. (1983). Supervision in counseling II: Contemporary models of supervision: A working alliance based model of supervision. The Counseling Psychologist, 11(1), 35-42. doi:10.1177/0011000083111007

Branaman, A. (1997).Goffman's social theory by ann branaman. In C.Lemert \& A. Branaman, (Eds.) The Goffman Reader, p. xlv - xliii. Blackwell Publishing: Malden, MA.

Britt, T.W., Doherty, K., \& Schlenker, B.R. (1997). Self-evaluation as a function of self-esteem, performance feedback, and self-presentational role. Journal of Social and Clinical Psychology, 16(4), $463-483$.

Buss, A. H., \& Briggs, S. R. (1984). Drama and the self in social interaction. Journal of Personality and Social Psychology, 47(6), 1310-1324. doi:10.1037/0022-3514.47.6.1310 
Callis, M. I. (1997). Frequency of trainees' nondisclosures to their supervisors as affected by relationship quality and trainee reactance. (Doctoral dissertation). Retrieved from ProQuest Dissertations and Theses.

Cashwell, T. H., \& Dooley, K. (2001). The impact of supervision on counselor self-efficacy. Clinical Supervisor, 20(1), 39.

Cohen, J. (1992). A power primer. Psychological Bulletin, 112(1), 155 - 159.

Cooley, C.H. (1902). Human nature and the social order. New York: Charles Scribner's Sons

Daniels, J. A. \& Larson, L. M. (2001). The impact of performance feedback on counseling selfefficacy and counselor anxiety. Counselor Education and Supervision, 41(2), 120-130. doi:10.1002/j.1556-6978.2001.tb01276.x

Delano, F., \& Shah, J. C. (2011). Games played in the supervisory relationship: The modern version. Relational Child \& Youth Care Practice, 24(1/2), 177-185.

Efstation, J. F., Patton, M. J., \& Kardash, C. M. (1990). Measuring the working alliance in counselor supervision. Journal of Counseling Psychology, 37(3), 322-329. doi:10.1037/0022-0167.37.3.322

Faul, F., Erdfelder, E. Buchner, A., \& Lang, A. (2009). Statistical power analyses using G*Power 3.1: Tests for correlation and regression analyses. Behavior Research Methods, 41, 1149 - 1160. doi: 10.3758/BRM.41.4.1149

Faul, F., Erdfelder, E., Lang A., \& Buchner, A. (2007). G*Power3: A flexible statistical power analysis program for the social, behavioral, and biomedical sciences. Behavior Research Methods, 39(2), 175 -5 191. 
Fernando, D. M., \& Hulse-Killacky, D. (2005). The relationship of supervisory styles to satisfaction with supervision and the perceived self-efficacy of a master's-level counseling students. Counselor Education and Supervision, 44(4), 293-304.

Friedlander, M. L., \& Ward, L. G. (1984). Development and validation of the supervisory styles inventory. Journal of Counseling Psychology, 31(4), 541-57.

Gnilka, P. B., Chang, C. V., \& Dew, B. J. (2012). The relationship between supervisee stress, coping resources, the working alliance, and the supervisory working alliance. Journal of Counseling \& Development, 90(1), 63-70.

Goffman, E. (1959). The Presentation of Self in Everyday Life. New York: Doubleday, Anchor Books.

Goffman, E. (1961a). Asylums: Essays on the Social Situation of Mental Patients and Other Inmates. Garden City, NY: Anchor Books

Goffman, E. (1961b). Encounters: Two Studies in the Sociology of Interaction. Oxford, England: Bobbs-Merrill

Goffman, E. (1967). Interaction Ritual: Essays on Face-To-Face Behavior. New York: Doubleday, Anchor Books

Goffman, E. (1971). Relations in Public: Microstudies of the Public Order. New York: Basic Books

Goffman, E. (1974). Frame Analysis: An Essay on the Organization of Experience. New York: Harper and Row.

Guadagno, R. E., \& Cialdini, R. B. (2007). Gender Differences in Impression Management in Organizations: A Qualitative Review. Sex Roles, 56(7/8), 483-494. doi:10.1007/s11199007-9187-3 
Gulla, J. P. W. (2008). Disclosure and withholding in older predoctoral intern supervisees: A retrospective study. (Doctoral dissertation). Retrieved from ProQuest Dissertations and Theses.

Hahn, W. K. (2001). The experience of shame in psychotherapy supervision. Psychotherapy: Theory, Research, Practice, Training, 38(3), 272-282. doi:10.1037/0033-3204.38.3.272

Heppner, P. P., \& Roehlke, H. J. (1984). Differences among supervisees at different levels of training: implications for a developmental model of supervision. Journal of Counseling Psychology, 31(1), 76-90.

Hess, S. A., Knox, S., Schultz, J. M., Hill, C. E., Sloan, L., Brandt, S., Kelley, F., \& Hoffman, M. (2008). Predoctoral interns' nondisclosure in supervision. Psychotherapy Research, 18(4), 400-411. doi:10.1080/10503300701697505

Hill, C. E., Thompson, B. J., \& Corbett, M. M. (1992). The impact of therapist ability to perceive displayed and hidden client reactions on immediate outcome in first sessions of brief therapy. Psychotherapy Research, 2(2), 143-155. doi:10.1080/10503309212331332914

Holloway, E. L. (1987). Developmental models of supervision: Is it development? Professional Psychology: Research and Practice, 18(3), 209-216. doi:10.1037/0735-7028.18.3.209

Holloway, E. L., \& Wolleat, P. L. (1981). Style differences of beginning supervisors: an interactional analysis. Journal of Counseling Psychology, 28(4), 373-376.

Hsu, S. (2007). Why things left unsaid by supervisees? Chinese Annual Report of Guidance and Counseling, 21,167-200.

Humeidan, M. A. (2002). Counseling self-efficacy, supervisory working alliance, and social influence in supervision. (Doctoral dissertation). Retrieved from ProQuest Dissertations and Theses. 
Johnson, E., Baker, S. B., Kopala, M., \& Kiselica, M. S. (1989). Counseling self-efficacy and counseling competence in prepracticum training. Counselor Education and Supervision, 28(3), 205-218. doi:10.1002/j.1556-6978.1989.tb01109.x

Jones, E. E., Gergen, K. J., \& Jones, R. G. (1963). Tactics of ingratiation among leaders and subordinates in a status hierarchy. Psychological Monographs: General and Applied, 77(3), 1-20. doi:10.1037/h0093832

Jones, E.E. (1964). Ingratiation. New York: NY, Meredith Publishing Company.

Jones, E. E., \& Pittman, T. S. (1982). Toward a general theory of strategic self-presentation. In J. Suls (Ed.), Psychological Perspectives on the Self(Vol. 1, pp. 231 - 260). Hillsdale, NJ: Lawrence Erlbaum Associates.

Kadushin, A. (1968). Games People Play in Supervision. Social Work, 13(3), 23-32.

Kadushin, A. A. (1992). What's wrong, what's right with social work supervision? The Clinical Supervisor, 10(1), 3-19.

Kocarek, C. E. (2001). Understanding the relationships among counseling self-efficacy, anxiety, developmental level, coursework, experience, and counselor performance. (Doctoral dissertation). Retrieved from ProQuest Dissertations and Theses.

Kozina, K., Grabovari, N., Stefano, J., \& Drapeau, M. (2010). Measuring changes in counselor self-efficacy: Further validation and implications for training and supervision. Clinical Supervisor, 29(2), 117. doi:10.1080/07325223.2010.517483

Ladany, N. (1992). The supervisory working alliance: Its relation to trainee self-efficacy and satisfaction with supervision. (Doctoral dissertation). Retrieved from ProQuest Dissertations and Theses. 
Ladany, N., Ellis, M.V., Friedlander, M.L. (1999). The supervisory working alliance, trainee self-efficacy, and satisfaction. Journal of Counseling Psychology, 77, 447 - 455.

Ladany, N., Hill, C. E., Corbett, M. M., \& Nutt, E. A. (1996). Nature, extent, and importance of what psychotherapy trainees do not disclose to their supervisors. Journal of Counseling Psychology, 43(1), 10-24. doi:10.1037/0022-0167.43.1.10

Larson, L. M. (1998). The social cognitive model of counselor training. Counseling Psychologist, 26(2), 219.

Larson, L. M., \& Daniels, J. A. (1998). Review of the counseling self-efficacy literature. Counseling Psychologist, 26(2), 179-218.

Larson, L. M., Suzuki, L. A., Gillespie, K. N., Potenza, M. T., Bechtel, M. A., \& Toulouse, A. L. (1992). Development and validation of the counseling self-estimate inventory. Journal of Counseling Psychology, 39(1), 105-120. doi:10.1037/0022-0167.39.1.105

Leach, M. D. \& Stoltenberg, C. D. (1997). Self-efficacy and counselor development: Testing the integrated developmental model. Counselor Education \& Supervision, 37(2), 115.

Leary, M.R. (1996). Self-presentation: Impression management and interpersonal behavior. Boulder, CO: Westview Press

Leary, M. R., \& Kowalski, R. M. (1990). Impression management: A literature review and twocomponent model. Psychological Bulletin, 107(1), 34-47. doi:10.1037/00332909.107.1.34

March, D. F. (2005). The relationship between self-disclosure, self-efficacy, and the supervisory working alliance of counselor education practicum and internship students. (Doctoral dissertation). Retrieved from ProQuest Dissertations and Theses.

Mead, G. H. (1934). Mind, Self, and Society. Chicago: University of Chicago Press 
Mehr, K. E., Ladany, N., \& Caskie, G. L. (2010). Trainee nondisclosure in supervision: What are they not telling you? Counseling \& Psychotherapy Research, 10(2), 103-113. doi:10.1080/14733141003712301

Melchert, T. P., Hays, V.L., Wiljanen, L.M., \& Kolocek, A.K. (1996). Testing models of counselor development with a measure of counseling self-efficacy. Journal of Counseling \& Development, 74(6), 640.

Mirgon, T. L. (2007). The relationship of supervisory working alliance and counselor selfefficacy to supervisee development: An exploratory study. (Doctoral dissertation). Retrieved from ProQuest Dissertations and Theses.

O'Brien, K. M., Heppner, M. J., Flores, L. Y., \& Bikos, L. (1997). The career counseling selfefficiency scale: Instrument development and training applications. Journal of Counseling Psychology, 44(1), 20-31. doi:10.1037/0022-0167.44.1.20

Pitariu, G. V. (2007). Prediction of impression management in clinical supervision among practicum students. (Doctoral dissertation). Retrieved from ProQuest Dissertations and Theses.

Rudman, L. A. (1998). Self-promotion as a risk factor for women: The costs and benefits of counterstereotypical impression management. Journal of Personality and Social Psychology, 74(3), 629-645. doi:10.1037/0022-3514.74.3.629

Schlenker, B.R. (1980). Impression management: The self-concept, social identity, and interpersonal relations. Belmont, CA: Brooks/Cole

Schlenker, B. R. (2003). Self-presentation. In M. R. Leary \& J. Tangney (Eds.), Handbook of self and identity (pp. 492-518). New York, NY: Guilford Press 
Schlenker, B. R., \& Britt, T. W. (1999). Beneficial impression management: Strategically controlling information to help friends. Journal of Personality and Social Psychology, 76(4), 559-573. doi:10.1037/0022-3514.76.4.559

Schlenker, B. R., \& Leary, M. R. (1982). Social anxiety and self-presentation: A conceptualization model. Psychological Bulletin, 92(3), 641-669. doi:10.1037/00332909.92.3.641

Schlenker, B.R. \& Pontari, B.A. (2000). The strategic control of information: Impression management and self-presentation in daily life. In A. Tesser, R.B. Felson, \& J. M. Suls (Eds.) Psychological Perspectives on Self and Identity. Washington, DC: American Psychological Association

Schlenker, B.R. \& Weigold, M.F. (1992). Interpersonal process involving impression regulation and management. Annual Review of Psychology, 43, 133 - 168.

Schwartz, W. (2008). Presentations of self and the status dynamics of psychotherapy and supervision. American Journal of Psychotherapy, 62(1), 51-65.

Silver, S.E. \& Schlenker, B.R. (1981). Self-presentational reactions to interpersonal evaluations. Paper presented at the Annual Convention of the American Psychological Association (89th, Los Angeles, CA, August 24-26, 1981).

Sipps, G. J., Sugden, G. J., \& Faiver, C. M. (1988). Counselor training level and verbal response type: Their relationship to efficacy and outcome expectations. Journal of Counseling Psychology, 35(4), 397-401. doi:10.1037/0022-0167.35.4.397

Snyder, M. (1983, May). The self in action. Paper presented at the Annual Meeting of the Midwestern Psychological Association, Chicago, IL. 
Smothers, M. K. (2010). Counseling self-efficacy: The contributions of early attachment and the supervisory relationship. (Doctoral dissertation). Retrieved from ProQuest Dissertations and Theses.

Sterner, W. R. (2009). Influence of the supervisory working alliance on supervisee work satisfaction and work-related stress. Journal of Mental Health Counseling, 31(3), 249263.

Stoltenberg, C. D., \& Delworth, U. (1987). Supervising Counselors and Therapists: A Developmental Approach. San Francisco: Jossey-Bass

Strauss, D. M. (1994). The relationship between supervisory factors and counseling self-efficacy factors. (Doctoral dissertation). Retrieved from ProQuest Dissertations and Theses.

Tang, M., Addison, K. D., LaSure-Bryant, D., Norman, R., O'Connell, W., \& Stewart-Sicking, J. A. (2004). Factors that Influence Self-Efficacy of Counseling Students: An Exploratory Study. Counselor Education and Supervision, 44(1), 70-80.

Ting, H. C. (2009). Satisfaction with supervision as a function of the supervisory working alliance and self-efficacy among taiwanese master-level counseling internship students. (Doctoral dissertation). Retrieved from ProQuest Dissertations and Theses

Tyler, J.M. (2009). Compensatory self-presentation in upward comparison situations. Human Communication Research, 35, 511 - 533. doi:10.1111/j.1468-2958.2009.01361.x

Walsh, B. B., Gillespie, C., Greer, J. M., \& Eanes, B. E. (2002). Influence of Dyadic Mutuality on Counselor Trainee Willingness to Self-Disclose Clinical Mistakes to Supervisors. The Clinical Supervisor, 21(2), 83-98. doi:10.1300/J001v21n02_06 
Ward, L. G., Friedlander, M. L., Schoen, L. G., \& Klein, J. G. (1985). Strategic self-presentation in supervision. Journal of Counseling Psychology, 32(1), 111-118. doi:10.1037/00220167.32.1.111

Webb, A., \& Wheeler, S. (1998). How honest do counsellors dare to be in the supervisory relationship? An exploratory study. British Journal of Guidance \& Counselling, 26(4), 509-524. doi:10.1080/03069889800760431

Yourman, D. B. (2003). Trainee disclosure in psychotherapy supervision: The impact of shame. Journal of Clinical Psychology, 59(5), 601-609.

Yourman, D. B., \& Farber, B. A. (1996). Nondisclosure and distortion in psychotherapy supervision. Psychotherapy: Theory, Research, Practice, Training, 33(4), 567-575. doi:10.1037/0033-3204.33.4.567 


\section{Appendix A}

\section{Demographic Form}

Thank you for your participation in this research project. All information that you provide will be kept confidential. Your responses on the following items will provide demographic information about yourself. Please complete the following items.

1. Age:

2. Gender:

Female
Male
Other

3. Ethnicity:
African American
Asian American
Caucasian American
Hispanic/Latino American
Native American
Middle-Eastern American
Other (please specify)

4. Degree of program currently enrolled:

Ph.D. Ed.D. Psy.D. Other: Please specify

5. What type of training program are you currently enrolled?

Counseling Psychology

Clinical Psychology

Other: Please specify

6. How many hours of counseling experience do you have?

7. Please indicate the type of internship site in which you are currently working (e.g., college counseling center, VA, etc.).

8. How many years and months of counseling supervision have you received thus far?

9. Please choose one current supervisor you have for individual supervision who you would like to focus on for purposes of this study. Please indicate the number of months that you have received supervision from this supervisor.

10. How frequently do you meet?

Once a week

Every other week
Twice a Week Once a month
More than twice a week Other 


\section{Appendix B}

\section{Recruitment Letter to Program Directors}

\section{Dear Program Director,}

I am a doctoral candidate in the Counseling Psychology Ph.D. program at West Virginia University. For my dissertation, I am examining the relationship among supervisee use of impression management strategies, the supervisory working alliance and counseling selfefficacy. Impression management refers to attempts to control information about the self in order to portray oneself in a particular light, that is, the manner in which individuals manage the impressions they would like to make. To my knowledge, this is the first empirical study on the relationship among these three variables in the context of supervision at the doctoral internship level. I am contacting all directors of APPIC listed internship sites and requesting their assistance with my study. I would greatly appreciate it if you would forward the attached email to your internship trainees.

Participation from your trainees would involve completing an online survey about their demographic information, their experience with a current supervisor, their sense of confidence in their counseling abilities, and their attempts to manage their supervisors' impressions. Survey completion is expected to last approximately 5 to 10 minutes. No identifying information will be requested regarding their training programs, internship sites, or supervisors. The study poses no greater than minimal risk to participants. While it is possible that participants may experience minor discomfort in reflecting on the supervision alliance, their sense of self-efficacy, and their attempts to manage supervisor impressions, it is anticipated that the potential insight into supervision and possibly into the self will outweigh this discomfort.

If you have questions or comments, please do not hesitate to contact me by phone at 843-2712907 or at my email address jhaist@ mix.wvu.edu. The principal investigator, Dr. Jeffrey Daniels, can also be contacted by phone at 304-293-2235 or by email at Jeffrey.Daniels@mail.wvu.edu. If you have any questions or concerns about your rights as a participant in this research study, you may contact the Institutional Review Board (IRB) which oversees the protection of human research participants at (304) 293-7073. West Virginia University's IRB has acknowledgment of this study on file.

Thank you for your support with this study.

Sincerely,

Jenni Haist, M.Ed., LPC

Doctoral Candidate, Counseling Psychology

West Virginia University 


\title{
Appendix C
}

\author{
Recruitment Letter to Participants
}

\section{Dear Internship Trainee,}

I am a doctoral student in the Ph.D. Counseling Psychology program at West Virginia University. For my dissertation, I am examining the relationship among supervisee impression management, the supervisory working alliance and counseling self-efficacy. Impression management refers to the manner in which you manage the impressions you would like to make on your supervisors. Possible benefits from participating in this research may include reflecting on and gaining greater understanding of your supervisory relationship and of yourself. In addition, increased knowledge about the relationship between impression management, counseling self-efficacy and the supervisory relationship may contribute to a greater understanding of the needs of supervisees at the doctoral internship level.

I am recruiting assistance with my study from doctoral students enrolled in APPIC listed internship sites. However, if you are not currently receiving ongoing individual supervision, then this study is not intended for you and you can delete this email at this point.

I would greatly appreciate your help in completing an online survey about your experience with your current supervisor, your attempts to manage supervisor impressions, your sense of confidence as an upcoming psychologist, and your demographic information. No identifying information will be requested on you or your training programs, internship sites, or supervisors. Survey completion time is expected to take approximately 5 to 10 minutes. There is no compensation for participation in this study other than knowing that your participation will contribute to current understandings of clinical and counseling supervision. Please note that participation is voluntary. By completing the surveys you are acknowledging that you have been informed about the study and are giving your consent to participate. The surveys are on the Qualtrics website. A link to the web address of the surveys can be found at the end of this letter.

If you have questions or comments, please do not hesitate to contact me by phone at 843-2712907 or at my email address jhaist@mix.wvu.edu. The principal investigator, Dr. Jeffrey Daniels, can also be contacted by phone at 304-293-2235 or by email at Jeffrey.Daniels@mail.wvu.edu. If you have any questions or concerns about your rights as a participant in this research study, you may contact the Institutional Review Board (IRB) which oversees the protection of human research participants at (304) 293-7073. West Virginia University's IRB has acknowledgment of this study on file. Thank you for your support with this study.

Sincerely,

Jenni Haist, M.Ed., LPC

Doctoral Candidate, Counseling Psychology

West Virginia University

Survey Link: https://wvuhre.qualtrics.com/SE/?SID=SV_0VW7G2JC92IgvXf 
Appendix E: Supervisory Working Alliance Inventory - Trainee (SWAI-T)

Supervisory Working Alliance Inventory - Trainee Form

\section{Instructions}

Please indicate the frequency with which the behavior described in each of the following items seems characteristic of your supervisor. Beside each item, circle the number corresponding to the appropriate point on the following seven-point scale.

\begin{tabular}{|c|c|c|c|c|c|c|c|}
\hline \multirow{2}{*}{$\begin{array}{l}\text { Item } \\
\text { 1. I feel comfortable with my supervisor. }\end{array}$} & \multicolumn{5}{|c|}{$\begin{array}{l}\text { Almost } \\
\text { Never }\end{array}$} & \multicolumn{2}{|c|}{$\begin{array}{l}\text { Almost } \\
\text { Always }\end{array}$} \\
\hline & 1 & 2 & 3 & 4 & 5 & 6 & 7 \\
\hline $\begin{array}{l}\text { 2. My supervisor welcomes my explanations about } \\
\text { the client's behavior. }\end{array}$ & 1 & 2 & 3 & 4 & 5 & 6 & 7 \\
\hline $\begin{array}{l}\text { 3. My supervisor makes the effort to understand } \\
\text { me. }\end{array}$ & 1 & 2 & 3 & 4 & 5 & 6 & 7 \\
\hline $\begin{array}{l}\text { 4. My supervisor encourages me to talk about my } \\
\text { work with clients in ways that are comfortable } \\
\text { for me. }\end{array}$ & 1 & 2 & 3 & 4 & 5 & 6 & 7 \\
\hline $\begin{array}{l}\text { 5. My supervisor is tactful when commenting about } \\
\text { my performance. }\end{array}$ & 1 & 2 & 3 & 4 & 5 & 6 & 7 \\
\hline $\begin{array}{l}\text { 6. My supervisor encourages me to formulate my } \\
\text { own interventions with the client. }\end{array}$ & 1 & 2 & 3 & 4 & 5 & 6 & 7 \\
\hline $\begin{array}{l}\text { 7. My supervisor helps me talk freely in our } \\
\text { sessions. }\end{array}$ & 1 & 2 & 3 & 4 & 5 & 6 & 7 \\
\hline $\begin{array}{l}\text { 8. My supervisor stays in tune with me during } \\
\text { supervision. }\end{array}$ & 1 & 2 & 3 & 4 & 5 & 6 & 7 \\
\hline $\begin{array}{l}\text { 9. I understand client behavior and treatment } \\
\text { technique similar to the way my supervisor does. }\end{array}$ & 1 & 2 & 3 & 4 & 5 & 6 & 7 \\
\hline $\begin{array}{l}\text { 10. I feel free to mention to my supervisor any } \\
\text { troublesome feelings I might have about him/her. }\end{array}$ & 1 & 2 & 3 & 4 & 5 & 6 & 7 \\
\hline $\begin{array}{l}\text { 11. My supervisor treats me like a colleague in our } \\
\text { supervisory sessions. }\end{array}$ & 1 & 2 & 3 & 4 & 5 & 6 & 7 \\
\hline $\begin{array}{l}\text { 12. In supervision, I am more curious than anxious } \\
\text { when discussing my difficulties with clients. }\end{array}$ & 1 & 2 & 3 & 4 & 5 & 6 & 7 \\
\hline $\begin{array}{l}\text { 13. In supervision, my supervisor places a high } \\
\text { priority on our understanding the client's } \\
\text { perspective. }\end{array}$ & 1 & 2 & 3 & 4 & 5 & 6 & 7 \\
\hline $\begin{array}{l}\text { 14. My supervisor encourages me to take time to } \\
\text { understand what the client is saying and doing. }\end{array}$ & 1 & 2 & 3 & 4 & 5 & 6 & 7 \\
\hline $\begin{array}{l}\text { 15. My supervisor's style is to carefully and } \\
\text { systematically consider the material I bring to } \\
\text { supervision. }\end{array}$ & 1 & 2 & 3 & 4 & 5 & 6 & 7 \\
\hline
\end{tabular}




\begin{tabular}{|c|c|c|c|c|c|c|c|}
\hline \multirow{2}{*}{$\begin{array}{l}\text { Item } \\
\text { 16. When correcting my errors with a client, my } \\
\text { supervisor offers alternative ways of intervening } \\
\text { with that client. }\end{array}$} & \multicolumn{5}{|c|}{$\begin{array}{l}\text { Almost } \\
\text { Never }\end{array}$} & \multicolumn{2}{|c|}{$\begin{array}{l}\text { Almost } \\
\text { Always }\end{array}$} \\
\hline & 1 & 2 & 3 & 4 & 5 & 6 & 7 \\
\hline $\begin{array}{l}\text { 17. My supervisor helps me work within a specific } \\
\text { treatment plan with my clients. }\end{array}$ & 1 & 2 & 3 & 4 & 5 & 6 & 7 \\
\hline $\begin{array}{l}\text { 18. My supervisor helps me stay on track during our } \\
\text { meetings. }\end{array}$ & 1 & 2 & 3 & 4 & 5 & 6 & 7 \\
\hline $\begin{array}{l}\text { 19. I work with my supervisor on specific goals in } \\
\text { the supervisory session. }\end{array}$ & 1 & 2 & 3 & 4 & 5 & 6 & 7 \\
\hline
\end{tabular}


Appendix F: Impression Management Scale (IMS)

Impression Management Scale

DIRECTIONS: How often do you use each of the behaviors described below while in supervision and at your internship site? Please check just ONE of the five boxes for each statement.

\begin{tabular}{|c|c|c|c|c|c|}
\hline & $\begin{array}{l}\text { Never } \\
\text { behave } \\
\text { this } \\
\text { way }\end{array}$ & $\begin{array}{l}\text { Very } \\
\text { rarely } \\
\text { behave } \\
\text { this way }\end{array}$ & $\begin{array}{l}\text { Occasionally } \\
\text { behave this } \\
\text { way }\end{array}$ & $\begin{array}{l}\text { Sometimes } \\
\text { behave } \\
\text { this way }\end{array}$ & $\begin{array}{l}\text { Often } \\
\text { behave } \\
\text { this way }\end{array}$ \\
\hline $\begin{array}{l}\text { 1. Talk proudly about your } \\
\text { experience or education }\end{array}$ & & & & & \\
\hline $\begin{array}{l}\text { 2. Make people aware of your } \\
\text { talents or qualifications. }\end{array}$ & & & & & \\
\hline $\begin{array}{l}\text { 3. Let others know that you are } \\
\text { valuable to the organization. }\end{array}$ & & & & & \\
\hline $\begin{array}{l}\text { 4. Make people aware of your } \\
\text { accomplishments. }\end{array}$ & & & & & \\
\hline $\begin{array}{l}\text { 5. Compliment your colleagues } \\
\text { so they will see you as } \\
\text { likeable. }\end{array}$ & & & & & \\
\hline $\begin{array}{l}\text { 6. Take an interest in your } \\
\text { colleagues' personal lives to } \\
\text { show them that you are } \\
\text { friendly. }\end{array}$ & & & & & \\
\hline $\begin{array}{l}\text { 7. Praise your colleagues for } \\
\text { their accomplishments so they } \\
\text { will consider you a nice } \\
\text { person. }\end{array}$ & & & & & \\
\hline $\begin{array}{l}\text { 8. Do personal favors for your } \\
\text { colleagues to show them that } \\
\text { you are friendly. }\end{array}$ & & & & & \\
\hline $\begin{array}{l}\text { 9. Stay at work late so people } \\
\text { will know you are hard } \\
\text { working. }\end{array}$ & & & & & \\
\hline $\begin{array}{l}\text { 10. Try to appear busy, even at } \\
\text { times when things are slower. }\end{array}$ & & & & & \\
\hline $\begin{array}{l}\text { 11. Arrive at work early in order } \\
\text { to look dedicated. }\end{array}$ & & & & & \\
\hline $\begin{array}{l}\text { 12. Come to the office at night or } \\
\text { on weekends to show that you } \\
\text { are dedicated. }\end{array}$ & & & & & \\
\hline
\end{tabular}




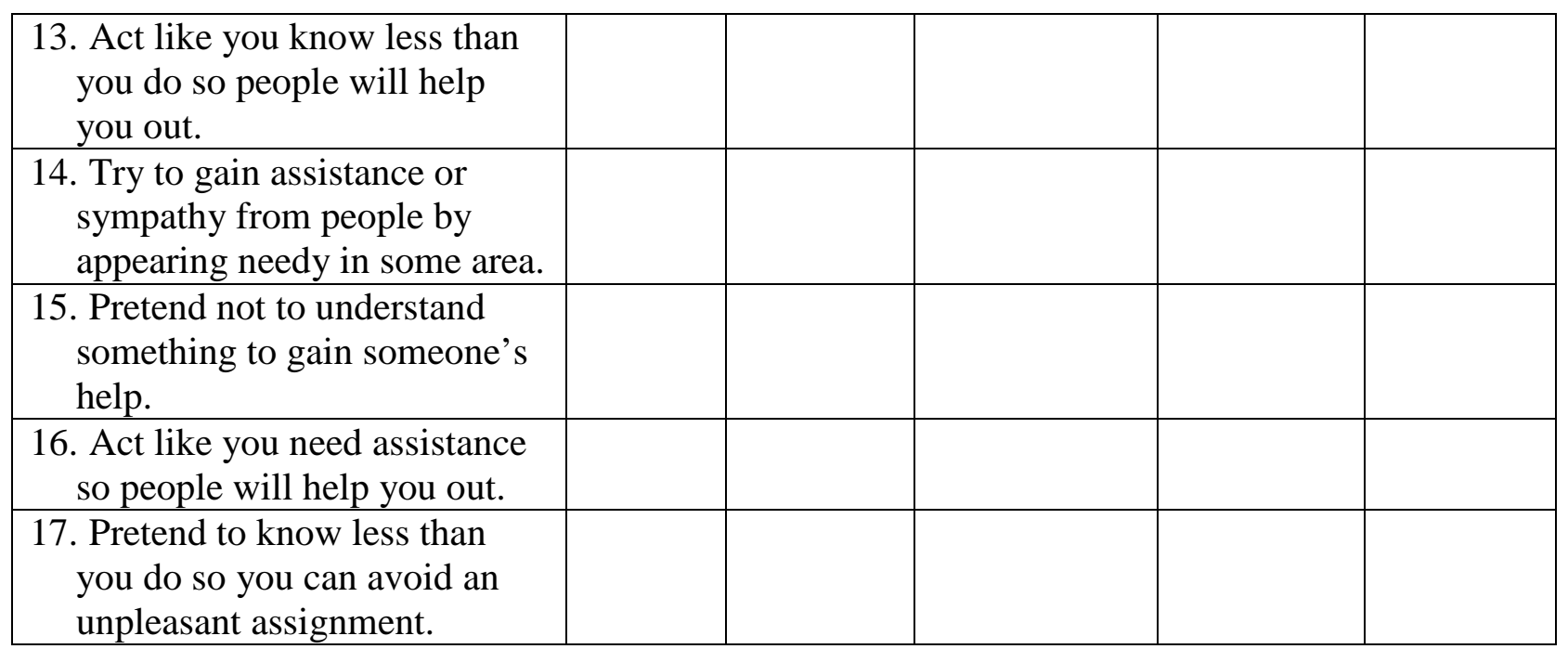


Appendix G: Sample Items from the Counseling Self-Estimate Inventory (COSE)

\section{Counseling Self-Estimate Inventory}

This is not a test. There are no right or wrong answers. Rather - it is an inventory that attempts to measure how you feel you will behave as a counselor or in a counseling situation. Please respond to the items as honestly as you can so as to most accurately portray how you think you will behave as a counselor. Do not respond with how you wish you could perform each item rather answer in a way that reflects your actual estimate of how you will perform as a counselor at the present time.

Below is a list of 18 statements. Read each statement, and then indicate the extent to which you agree or disagree with that statement, using the following alternatives:

$$
\begin{aligned}
& 1=\text { Strongly Disagree } \\
& 2=\text { Moderately Disagree } \\
& 3=\text { Slightly Disagree } \\
& 4=\text { Slightly Agree } \\
& 5=\text { Moderately Agree } \\
& 6=\text { Strongly Agree }
\end{aligned}
$$

PLEASE - Put your responses for this inventory to the right of each statement.

1. I am worried that my interpretation and confrontation responses may not over time assist the client to be more specific in defining and clarifying the problem.

3. I feel I will respond to the client in an appropriate length of time (neither interrupting the client or waiting too long to respond).

9. I am confident that my interpretation and confrontation responses will be effective in that they will be validated by the client's immediate response.

12. In working with culturally different clients I may have a difficult time viewing situations from their perspective.

17. I feel that I will not be able to respond to the client in a non-judgmental way with respect to client's values, beliefs, etc. 